\title{
Measurements and Dynamics of Multiple Scale Bedforms in Tidally Energetic Environments
}

by

Katie Renae Jones

B.S., Swarthmore College (2014)

Submitted to the Joint Program in Applied Ocean Science \& Engineering in partial fulfillment of the requirements for the degree of

Master of Science in Oceanographic Engineering

at the

MASSACHUSETTS INSTITUTE OF TECHNOLOGY

and the

WOODS HOLE OCEANOGRAPHIC INSTITUTION

June 2018

(C) 2018 Katie R. Jones.

All rights reserved.

The author hereby grants to MIT and WHOI permission to reproduce and to distribute publicly paper and electronic copies of this thesis document in whole or in part in any medium now known or hereafter created.

Author

Joint Program in Applied Ocean Science \& Engineering Massachusetts Institute of Technology \& Woods Hole Oceanographic Institution

May 3, 2018

Certified by

Peter Traykovski Associate Scientist in Applied Ocean Physics and Engineering Woods Hole Oceanographic Institution Thesis Supervisor

Accepted by

Rohan Abeyaratne

Chair, Committee on Graduate Students Massachusetts Institute of Technology

Accepted by

Henrik Schmidt

Chair, Joint Committee for Applied Ocean Science \& Engineering Massachusetts Institute of Technology Woods Hole Oceanographic Institution 


\title{
Measurements and Dynamics of Multiple Scale Bedforms in Tidally Energetic Environments
}

\author{
by \\ Katie Renae Jones \\ Submitted to the Joint Program in Applied Ocean Science \& Engineering
Massachusetts Institute of Technology
\& Woods Hole Oceanographic Institution
on May 3, 2018, in partial fulfillment of the
requirements for the degree of
Master of Science in Oceanographic Engineering
}

\begin{abstract}
The presence of superimposed bedforms, where smaller bedforms exist on larger bedforms, is ubiquitous to energetic tidal environments. Due to their wide range in scale, it is difficult to simultaneously observe these features over tidal timescales. This thesis examines the morphological response of superimposed bedforms to a tidally reversing flow using novel instrumentation and platform systems. A method is outlined in chapter 2 to expand the functionality of low-mounted sidescan sonars by utilizing sonar shadows to estimate bedform height and asymmetry. Empirical models are generated to account for realistic variability in the seabed and the method is validated with bathymetric observations of wave-orbital ripples and tidally reversing megaripples. Given the high temporal and spatial resolution of seafloor frame mounted rotary sidescan sonars, the dynamics and evolution of the bedforms over an approximately $40 \mathrm{~m} \times 40 \mathrm{~m}$ area can be resolved. In chapter 3 the method is applied to data of superimposed bedforms at Wasque Shoals, an ebb delta off the southeast corner of Martha's Vineyard, MA. These data reveal the small, superimposed bedforms reversing their asymmetry with the flow while the larger bedforms on which they reside remain oriented in the direction of the dominant flow. Similar bedform dynamics are observed at Nauset Inlet, a dynamic inlet system, on Cape Cod, MA using an autonomous jet-powered kayak, the Jetyak, equipped with a bathymetric swath sonar. The time needed for bedform asymmetry to reverse in the presence of a tidal flow was estimated with a geometric bedform model that incorporates an empirical sediment transport rate. The morphological lag time from the observations agree well with the geometric model with larger bedforms and slower flows resulting in a longer lag time. Finally, the migration of these superimposed bedforms is considered in chapter 4. Data from the rotary sidescan sonar at Wasque Shoals capture the interaction of smaller bedforms, or megaripples, with a dune. The net convergence of megaripples on the tidally dominate lee face of the dune suggests that the smaller bedforms serve as an intermediate step between grain-scale transport processes and larger scale dune migration.
\end{abstract}

Thesis Supervisor: Peter Traykovski

Title: Associate Scientist in Applied Ocean Physics and Engineering

Woods Hole Oceanographic Institution 


\section{Acknowledgments}

This thesis could not have been possible without the support of many.

First, I would like to thank my advisor, Peter Traykovski, for his constant help, guidance, and advice. I am grateful for Peter's willingness to discuss research and for having his office door always open for me to walk in with any questions or problems I was currently facing. It's been a lot of fun working with Peter in the field and I will always remember running laps along the beach in life-suits to warm up while the Jetyak was surveying alongside us. Finally, I am grateful of Peter's support for my career and life goals.

I would also like to thank Heidi Nepf, Steve Elgar, John Trowbridge, Eric Adams, Henrik Schmidt, Rocky Geyer, Chris Sherwood, and Britt Raubenheimer for their willingness to discuss my research and provide guidance. A number of students, post-docs, and individuals have also provided ideas, support, and encouragement including Anna, Erika, Shawn, Charlie, Jenny, Bryce, Suzi, Rachael, and Kevin.

Thank you to the Academic Programs Office and MIT department staff for representing and supporting me and answering all of my questions regarding the logistics of navigating graduate school.

I am also very grateful for the love and support of my husband, Ben. He has been there for me through it all and I am so blessed to have him in my life. I would also like to thank my mom, dad, and sisters, Emily and Ashley, for their continual encouragement and willingness to listen to both my frustrations and joys throughout graduate school. I am grateful for the Jones family for providing me with free meals, a place to stay when needed, dog-sitting, and treating me like their own daughter/sister. Finally, I would like to thank my dog, Sandy, whose squeals when I walked in the door made me happy regardless of my day.

Financial support was provided by the National Science Foundation through a Graduate Research Fellowship (NSF GRFP), the Massachusetts Institute of Technology Energy Initiative Fellowship, the National Science Foundation under grants OCE-1634481 and OCE1635151, the Office of Naval Research under grants N00014-06-10329 and N00014-131-0364, and the Strategic Environmental Research and Development Program (SERDP) through project \#W912HQ17C0012. 


\section{Contents}

1 Introduction $\quad 21$

2 A method to quantify bedform height and asymmetry from a low-mounted sidescan sonar $\quad 25$

2.1 Introduction . . . . . . . . . . . . . . 26

2.2 Geometric model . . . . . . . . . . . . . . . . . . . 28

2.2 .1 System geometry . . . . . . . . . . . . . . 28

2.2.2 Single triangular bedform . . . . . . . . . . . . . . 29

2.2.3 Multiple triangular bedforms . . . . . . . . . . . . . . . . 29

2.3 Error correction and sensitivity analysis . . . . . . . . . . . 33

2.3.1 Crest sharpness . . . . . . . . . . . . . . . . . 33

2.3 .2 Scoured seabed . . . . . . . . . . . . . . . . 38

2.3.3 Estimation of horizontal range . . . . . . . . . . . . . . . . 39

2.3.4 All seabed configurations considered . . . . . . . . . . . . . . . . 42

2.3.5 Bedform parameter distributions . . . . . . . . . . . . . . . 43

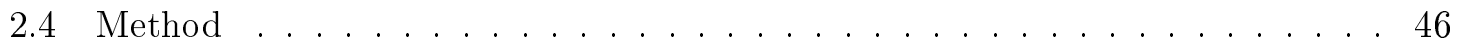

2.4 .1 Instrument configuration . . . . . . . . . . . . . . . . . 46

2.4.2 Data analysis steps . . . . . . . . . . . . . . . . 47

2.5 Validation from field data . . . . . . . . . . . . . . . . . . 48

2.5.1 Wave-orbital ripples . . . . . . . . . . . . . . 48

2.5.2 Tidally-reversing megaripples . . . . . . . . . . . . . . 51

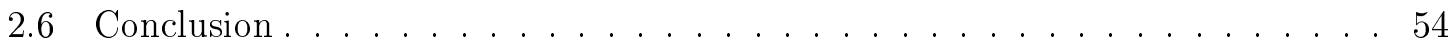


3 Timescales for morphological response of multi-scale bedforms to a tidally $\begin{array}{ll}\text { reversing flow } & 57\end{array}$

3.1 Introduction . . . . . . . . . . . . . . . . . 57

3.2 Methods . . . . . . . . . . . . . . . . . . . . 60

3.2.1 Instrumentation and platforms . . . . . . . . . 60

3.2 .2 Study sites . . . . . . . . . . . . . . . . 63

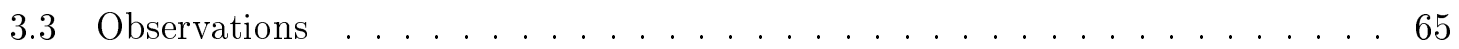

3.3 .1 Wasque Shoals ...................... 65

3.3 .2 Nauset Inlet . . . . . . . . . . . . . . . . . . 67

3.4 Morphological lag time theory . . . . . . . . . . . . . . . . 71

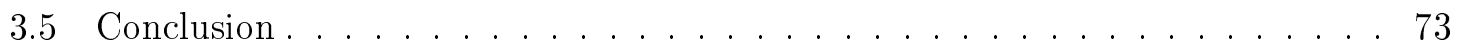

4 Interaction of superimposed megaripples and dunes in a tidally energetic $\begin{array}{ll}\text { environment } & 77\end{array}$

4.1 Introduction . . . . . . . . . . . . . . . . 77

4.2 Observations . . . . . . . . . . . . . . . . . . 79

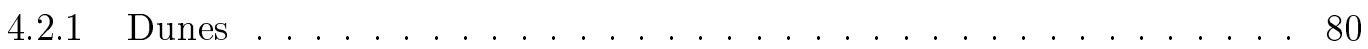

4.2 .2 Megaripples . . . . . . . . . . . . . . . 80

4.3 Principles of bedform migration . . . . . . . . . . . . . 85

4.4 Megaripple and dune interaction conceptual model . . . . . . . . . . . . 87

4.4.1 Change in seabed elevation . . . . . . . . . . . . . . 89

4.4 .2 Dune migration . . . . . . . . . . . . . . . . . . 92

4.5 Conclusion . . . . . . . . . . . . . . . . . . 93

5 Concluding Remarks $\quad 95$ 


\section{List of Figures}

1-1 Schematic of different bedform types. a) Ripples are small bed features compared to the water depth and tend to scale with grain size. b) Dunes are large sand features that scale with water depth and influence the free surface. c) Megaripples are larger than typical ripples but smaller than dunes and do not scale with water depth. d) Superimposed bedforms are bedforms with smaller ripples or megaripples on top of larger dunes. . . . . . . . . . . . . . 22

2-1 System geometry and backscattered intensity of a flat seabed with a single bedform present. The difference between horizontal and slant range is depicted in the system geometry as well as the echo-return strength. The horizontal range, or horizontal distance from the sonar to an arbitrary location, is denoted as $X$ while the slant range to this same location is represented by $R$ and is a function of $X$, the height of the sonar, $H_{i}$, and the height of the seabed at the location of interest, $z(x)$. The difference in backscatter intensity of slant and horizontal range is depicted in the plots of range versus returned echo strength. In these plots, $S$ is the length of the shadow caused from the bedform intercepting the acoustic wave and $L$ is the distance from the sonar to the start of the shadow. The subscripts indicate whether these distances were obtained using the horizontal (subscript $H$ ) or slant (subscript

S) range. . . . . . . . . . . . . . . . . . 30 
2-2 Geometry to determine bedform height $(h)$ and asymmetry $(\alpha)$ when multiple triangular bedforms are present. The same notation is used as in Fig. 2-1 with additional parameters being defined as the wavelength $(\lambda)$, the distance between bedform trough and crest facing the sonar $(c)$, and the height on the adjacent ripple where the shadow intersects $(y)$. The length of $c$ facing the sonar varies depending on the side of the sonar considered where $c_{r}$ is the length of the base facing the sonar on the right side of the sonar and $c_{l}$ is the length of the base facing the left side of the sonar. . . . . . . . . . . 31

2-3 a) System geometry for the right side of the sonar, where bedforms are the composite of two sine waves. In this example, the sonar is $1 \mathrm{~m}$ above the seabed, and bedforms have a wavelength of $2 \mathrm{~m}$, height of $0.2 \mathrm{~m}$, and asymmetry of 0.6. Ray traces from the sonar to the bedform crests are shown where the solid gray lines are rays where $m>m_{\text {crit }}$ and the dashed gray lines are rays where $m<m_{\text {crit }}$. The solid black ray is the critical ray, where asymmetry and height are accurately estimated. The annotations underneath the subplot are for reference when computing the recommended sonar height in Section 2.4.1. b) Estimated asymmetry for the left and right sides as a function of distance from the sonar. The asymmetry equals the true asymmetry of 0.6 at the critical length indicated by the vertical dashed lines. c) Estimated height assuming triangular bedforms for each side of the sonar. For distances shorter than the critical length the height is overestimated while distances larger than the critical length the height is underestimated. . . . . . . . . 35

2-4 Scatter plots of error from theoretical bedforms. Contours are the empirically fitted models. The top row is the error in asymmetry while the bottom row is the error in height. a-b) Error introduced from assuming sinusoidal bedforms are triangular. c-d) Error from having a constant-sloped, scoured seabed. e-f) Error from approximating the horizontal range as the depth independent range. 41 
2-5 a) Estimated asymmetry versus true asymmetry for theoretical bedforms when sinusoidal bedforms on a slanted seabed with depth independent estimated horizontal range are considered together. The blue data are from assuming triangular bedforms on a flat seabed with horizontal range while the red data are empirically corrected. The black line demonstrates a perfect fit. b) Probability of the error in asymmetry for both estimated and empirically corrected asymmetry. c) Estimated $h / \lambda$ versus true $h / \lambda$ when all variations are considered. d) Probability of the error in height. . . . . . . . . 44

2-6 a) Rotary sidescan sonar (grayscale) and pencil beam sonar (overlaid color) data of wave-orbital ripples taken on October 5, 2007 at 17:00:00 off the southern coast of Martha's Vineyard. The red line is an arbitrary transect taken perpendicular to the ripple crests. b) Backscatter intensity of sidescan sonar data taken along the transect. The dashed line indicates the threshold used to distinguish shadow and bright regions in the method. c) Bed elevation from a transect along the pencil beam sonar data. The bed elevation is relative to the lowest elevation in the survey area. . . . . . . . . . . . . . . . . . . 49

2-7 Computed wave-orbital ripple parameters from the pencil beam sonar (red) and rotary sidescan sonar (blue) over a 24 day period for bedforms located at MVCO. The shaded regions represent the $95 \%$ confidence intervals of the parameters. The green is the estimation of the bedform parameters directly below the sonar obtained from extrapolating the data from the rotary sidescan sonar. a) Representative wave orbital velocity from an Acoustic Doppler Velocimeter (ADV) located on a nearby quadpod. b) Computed Shields parameter. The dashed line at 0.05 indicates the critical Shields parameter. c) Estimated bedform asymmetry. d) Bedform aspect ratio $(h / \lambda)$ has good agreement between the estimates from the rotary sidescan sonar and pencil beam sonar. e) Bedform height which show an increase in height during large wave events. f) Bedform wavelength. The overestimation of wavelength from the rotary sidescan sonar could be due to the influence of the quadpod on the surrounding flows and seabed. . . . . . . . . . . . . . . . 52 
2-8 a) Rotary sidescan sonar data of megaripples taken on May 10, 2013 at 17:43:18 at the mouth of the Columbia River. The red line is an arbitrary transect taken perpendicular to the bedform crests. The white dashed lines indicate the start of a shadow region closest to the sonar. b) Multibeam data taken at the same time as the rotary sidescan sonar. The white dashed lines are superimposed at the same location on the multibeam data to show agreement in bedform detection from both instruments. c) Backscatter intensity of sidescan sonar data taken along the transect. The horizontal dashed line indicates the threshold used to distinguish shadow and bright regions in the method while the vertical dashed lines indicate the location of the crests in the multibeam data. d) Bed elevation from a transect along the multibeam sonar data. The bed elevation is relative to the lowest elevation in the survey

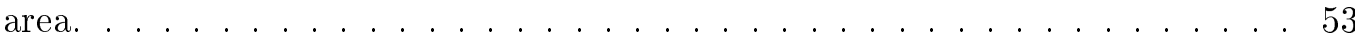

2-9 Computed megaripple parameters from the multibeam sonar (red) and rotary sidescan sonar (blue) over a 2.5 day period for bedforms located at the mouth of the Columbia River. The green is the estimation of the bedform parameters directly below the quadpod. The shaded regions represent the 95\% confidence intervals of the parameters. a) The depth averaged flow obtained from the same quadpod as the rotary sidescan sonar. b) Computed Shields parameter with the critical Shields parameter indicated by the dashed black line. c) Estimated bedform asymmetry. d) Bedform aspect ratio $(h / \lambda)$ which is overestimated for the rotary sidescan sonar given the underestimation of wavelength, however, when only bedform wavelength directly below the quadpod is considered there is good agreement. e) Bedform height which is in good agreement between the two instruments. f) Bedform wavelength in which the bedforms closest to the sonar have a larger wavelength than those farther from the sonar. . . . . . . . . . . . . . . . 55 
3-1 Autonomous jet-powered kayak, Jetyak, equipped with a bathymetric sidescan sonar, dual PPK GNSS antennas, and a Nortek Signature 1000 ADCP. The Jetyak is jet-driven and powered by an air-breathing gas engine. In addition to the autonomous capabilities of the Jetyak, a remote controller can be used to drive the Jetyak, communicating via radio control. . . . . . . . . . 61

3-2 Seafloor frame, or quadpod, placed on the seabed off of the southeast corner of Martha's Vineyard. The quadpod is equipped with multiple acoustic and pressure sensors to measure the seabed and local hydrodynamics. The top of the quadpod is approximately $1.25 \mathrm{~m}$ from the seabed. . . . . . . . . . . . 63

3-3 a) Digital elevation map of the east coast of Massachusetts obtained from NOAA Coastal Relief. b) Wasque Shoals is located off the southeast corner of Martha's Vineyard, indicated by the red triangle. During flood, water is funneled into the inlet between Martha's Vineyard and Nantucket. During ebb, the water leaves Nantucket Sound as a jet. This creates a flood dominated flow at Wasque Shoals. c) GoogleEarth image of Nauset Inlet. The approximate tidal flow is indicated with the arrows where the flow enters the inlet during flood, weaving its way south around the sandbars. During ebb, the flow is directed north and is weaker in velocity magnitude compared to

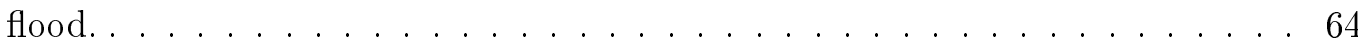

3-4 a) Greyscale image is a Landsat 8 satellite image of the corner of Martha's Vineyard taken on August 23, 2016. The colored overlay is bathymetry obtained at Wasque Shoals from the bathymetric sidescan sonar equipped on the Jetyak. b) Zoom-in of the Jetyak bathymetric survey conducted in September, 2016 referenced to the NAVD88 vertical datum. c) Transect across two dunes where the $\mathrm{x}$-axis is horizontal distance along the transect and the $\mathrm{y}$ axis is depth. The transect shows flood-dominant asymmetric dunes with a wavelength of approximately $80 \mathrm{~m}$ with smaller megaripples superimposed on the dunes. . . . . . . . . . . . . . . . . . . 66 66 
3-5 a) Depth averaged velocity from an Aquadopp mounted on the top of the quadpod over a tidal cycle. A positive flow velocity is in the direction of flood, or to the north-northeast. The black line is the ensemble averaged tidal velocity between November 28, 2013 and December 1, 2014 while the gray line is the standard deviation. b) Megaripple asymmetry estimated from the shadow pattern of the rotary sidescan sonar. An asymmetry of 0.5 represents a symmetric bedform. The vertical black dashed line is the zero-crossing in velocity. .......................... 67

3-6 a) Google-Earth image of Nauset Inlet with a digital elevation map taken from the quadcopter and Jetyak on November 2, 2017 superimposed in color. The elevation is with respect to the NAVD88 datum. b) Zoom-in of the channel where a tripod, indicated by a red triangle, was located which was equipped with an ADV. The yellow line indicates a transect considered near the tripod. 68

3-7 Bathymetry from the Jetyak of a transect near the tripod. The different colors are the times the Jetyak was near the tripod with the red-colors taken from a survey on October 17, 2017 where the flow went from flood to ebb, the yellow-colors taken on November 2, 2017 during ebb and the blue-colors taken on November 9, 2017 where the flow went from ebb to flood. The depth is taken with respect to the NAVD88 datum. . . . . . . . . . . . . . . 69

3-8 a) Flow velocity at the tripod in Fig. 3-6b. Positive values are during flood where the flow is going towards the south, and negative values are during ebb as the flow goes to the north. The colored lines are the times the Jetyak was near the tripod. b) Bathymetry obtained from the Jetyak relative to NAVD88 for October 17, 2017 survey where the flow transitioned from flood to ebb. c) Bathymetry of megaripples from November 2, 2017 during ebb. d) Bathymetry from November 9, 2017 survey as the flow went from ebb to flood. 70 
3-9 a) Average flow velocity over 34 tidal cycles at the tripod taken between November 1, 2017 and November 18, 2017. Positive values are during flood where the flow is going towards the south, and negative values are during ebb as the flow goes to the north. b) Megaripple asymmetry given multiple transects of megaripples near the tripod. The symbols represent the average asymmetry while the vertical lines are the standard deviation. The vertical black dashed line represents slack tide between ebb and flood. . . . . . . . . . 71

3-10 Geometric representation of sediment transport needed to change bedform asymmetry which is used in computing the morphological lag time. $A$ is the area of sediment that must be moved, $\delta$ is the change is asymmetry, $h$ is the bedform height, and $\lambda$ is the bedform wavelength. . . . . . . . . . . . 72

3-11 Morphological lag time versus bedform wavelength for a change in bedform asymmetry of $\delta=0.1$ from $\alpha=0.45$ to $\alpha=0.55$. The solid line with shading is the estimated morphological lag time from a simple geometric model, Eq. 3.6, using the Meyer-Peter and Müeller empirical formula for bedload transport rate. The shaded regions represents a velocity range from 0.5 to $0.7 \mathrm{~m} / \mathrm{s}$ with the solid line the morphological lag time given a flow velocity of $0.6 \mathrm{~m} / \mathrm{s}$. The blue line is the estimated morphological lag time for a bedform aspect ratio of 0.1 , the aspect ratio observed at Wasque Shoals, while the red line is the estimated lag time for a bedform aspect ratio of 0.04 , the megaripple aspect ratio at Nauset Inlet. The morphological lag time was directly computed from the asymmetry data for flood, indicated by a triangle, and ebb, indicated by a square, at both Wasque Shoals and Nauset Inlet for a change in asymmetry between 0.45 and $0.55 \ldots \ldots$. . . . . . . . 73 
4-1 a) The gray-scale image is a Pléiades satellite image taken on July 22, 2014 of the corner of Martha's Vineyard and Wasque Shoals and obtained from Airbus Defence and Space (www.intelligence-airbusds.com/pleiades/). The color is bathymetry from a Jetyak survey with a single-beam echosounder taken on July 18, 2014. b) Bathymetry from three Jetyak surveys over a nine month period. The bedform bathymetry was contoured to a maximum depth of $5.5 \mathrm{~m}$ from the mean tidal elevation. The surface below $5.5 \mathrm{~m}$, not shown, is relatively flat with a maximum depth around $6.5 \mathrm{~m}$. The dunes are primarily migrating northeast at a rate of $50 \mathrm{~cm} /$ day and also rotating slightly in response to flood tide dominated currents and waves from the southwest. The triangle depicts the location of the quadpod that was buried by the 'Y' shaped dune on January 10, 2014. Up is north. c) Transect of flow throughout the water column obtained from the ADCP on the Jetyak during flood. The flow is going from left to right and a wake is present behind the dominant lee face of the dune. . . . . . . . . . . . . . . . . . 81

4-2 a) Rotary sidescan sonar imagery during peak flood on December 3, 2013 at 10:01. b) Sonar imagery during peak ebb on December 5, 2013 at 05:41. c) Time-stack of the intensity along a transect perpendicular to the megaripple crests and relative to distance from the quadpod. The blue tracked megaripples depict the divergence of megaripples while the green tracked megaripple converges into the dune front which is tracked in yellow. . . . . . . . . . . 82

4-3 a) Depth averaged velocity from the Aquadopp mounted on the seafloor frame. The black vertical dashed lines represent the upward zero crossing used to define a tidal cycle. Positive numbers indicate flood where the flow is going towards the north-northeast. b) Megaripple migration rate with respect to distance from the dune front averaged over seven transects perpendicular to the bedform crests and binned at $1 \mathrm{~m}$. Positive values indicate megaripple migrating in the direction of flood. c) Megaripple convergence with respect to distance from the dune front for a 16 day period. . . . . . . . . . . . . 84 
4-4 a) Megaripple cumulative excursion over a 16 day period at four locations, $-4 \mathrm{~m}, 0 \mathrm{~m}, 8 \mathrm{~m}$, and $25 \mathrm{~m}$, from the dune front. Positive excursion indicates megaripple migration in the direction of flood, or towards the north-northeast, whereas negative excursion indicates migration in the direction of ebb. b) Total megaripple excursion after 16 days. c) Megaripple cumulative convergence for the same four locations as in (a). d) Total megaripple convergence. . . . . 85

$4-5$ a) Net tidally averaged megaripple velocity over a 16 day period in a coordinate system relative to distance from the dune front. The gray shaded region is the standard error of the number of bins included in the average from both different tidal periods and different transects. b) Tidally averaged convergence obtained from differentiating the megaripple migration rate. c-e) Schematic of the superposition of megaripples on the dune and their migration and asymmetry during flood (c) and ebb (d) tides. The faded region on the left was not directly observed due to the limited field of view of the rotary sonar system. . . . . . . . . . . . . . . . . 88

4-6 a) Depth averaged flow velocity from the Aquadopp current profiler located at the quadpod. b) RMS wave height computed from ADVs on the quadpod.

c) Depth of the seabed measured from the ABS with a linear fit during 16 days where there were no large wave events. d) The distance of the dune front from the quadpod where the ABS was located with a linear fit over 16 days with no large wave events. . . . . . . . . . . . . . . . . 90 


\section{List of Tables}

2.1 Table of symbols . . . . . . . . . . . . . . . . . . 28

2.2 Range of parameters used in theoretical system geometries to obtain empirical models of the error in estimated height and asymmetry. . . . . . . . . . . 34

2.3 Empirical model coefficients for quantifying the error in asymmetry given sinusoidal bedforms. . . . . . . . . . . . . . . . 38

2.4 Coefficients of error function in estimated height for bedforms that are sinusoidal yet assumed triangular. . . . . . . . . . . . . . . . 38

2.5 Coefficients corresponding to the empirical model of error in estimated asymmetry where scour at the location of the sonar causes a sloped seabed. . . . . 39

2.6 Empirical model coefficients for error in estimated height when a scoured seabed is considered. . . . . . . . . . . . . . . . . . 39

2.7 Coefficients for error in estimated asymmetry by approximating the horizontal range as depth independent. . . . . . . . . . . . . . . . . . . 42

2.8 Empirical coefficients of the error in estimated height assuming seafloor purtubations are significantly smaller than the height of the sonar when estimating the horizontal range. . . . . . . . . . . . . . . . . . . . . . . 42

2.9 Analytical coefficients for recommended sonar height from the seabed. . . . . 46

2.10 Operating parameters of sonars used in field validation of the method . . . . . 48

4.1 Estimate of the change in seabed elevation with time obtained from directly from the ABS and indirectly from megaripple convergence. . . . . . . . . . . 92

4.2 Estimate of the change in seabed elevation with time obtained from directly from the ABS and indirectly from megaripple convergence. . . . . . . . . . 93 


\section{Chapter 1}

\section{Introduction}

Sub-aqueous bedforms are the accumulation of sediment in ridges and troughs that are formed by the interaction of waves and currents with an erodible seabed (Fredsøe and Deigaard, 1992; Nielsen, 1992). They range in scale from small ripples with wavelengths on the order of centimeters to ridges and dunes which can have wavelengths extending from meters to kilometers (Ashley, 1990; Soulsby, 1997; Dalrymple and Rhodes, 1995). The ability of bedforms to steer flow, influence seabed friction, and effect the transport of sediment makes observing bedforms crucial to understanding coastal systems (Ashley, 1990; Nielsen, 1992; Johnson, 1916).

The interaction of bedforms with their surroundings is inherently a multi-scale process and has been studied at a range of scales, from individual sediment grains to fields of bedforms (Siau, 1841; la Beche, 1851; Johnson, 1916). At the grain-scale, sediment is transported when the shear stress imparted by the flow on the seabed exceeds the stabilizing forces (Engelund and Fredsøe, 1982; Shields, 1936). The seabed is rarely flat and through the transport of sediment, bedforms are initiated by either a defect in the seabed, common in slower flows, or by the instantaneous formation of a bedform pattern which is prevalent in stronger flows (Venditti and Church, 2005). Once established, bedforms grow exponentially until reaching an equilibrium height and length (Venditti and Church, 2005; Engelund and Fredsøe, 1982). In unidirectional flows, grain-scale processes can result in bedforms migrating downstream as sediment moves up the downstream face of a bedform before reaching the crest, avalanching, and depositing into the trough (Simons et al., 1965).

Past studies have also been conducted at the scale of individual bedforms when consid- 
a)

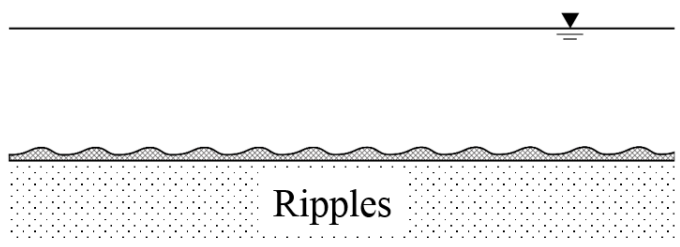

c)

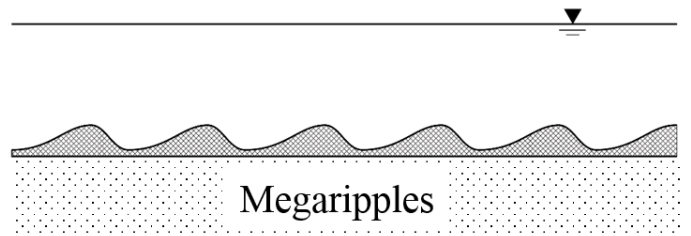

b)

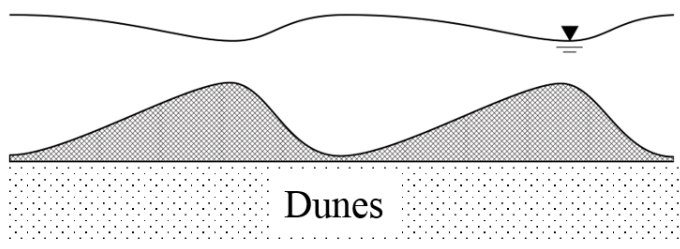

d)

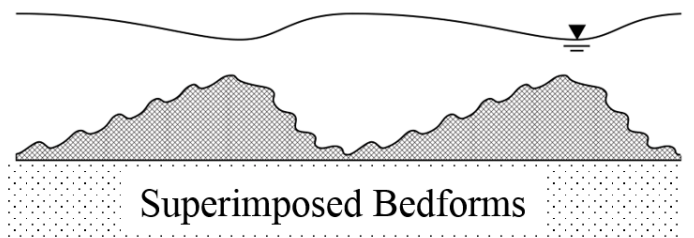

Figure 1-1: Schematic of different bedform types. a) Ripples are small bed features compared to the water depth and tend to scale with grain size. b) Dunes are large sand features that scale with water depth and influence the free surface. c) Megaripples are larger than typical ripples but smaller than dunes and do not scale with water depth. d) Superimposed bedforms are bedforms with smaller ripples or megaripples on top of larger dunes.

ering their effect on the surrounding flow. Bedforms cause an increase in the friction, or roughness, the flow experiences by increasing the form drag through flow separation (Fredsøe and Deigaard, 1992). The increase in seabed roughness can dampen wave energy, slow currents, and influence near-bed turbulence, all of which also controls sediment transport (Hume et al., 2000; Fredsøe and Deigaard, 1992). When bedforms become large relative to the water depth they can redirect currents, refract and shoal waves, and accelerate flow over the crests. Understanding the geometry and dynamics of bedforms is therefore important for maintaining navigable channels and understanding sediment supply to coastlines, the stability of pipelines, and the surrounding topographic evolution such as the formation of shore-face connected sand ridges (Falques et al., 1998).

Bedforms are classified based on their size, shape, and the flow condition in which they are found (Dalrymple and Rhodes, 1995; Ashley, 1990). Historically, bedforms have been characterized as either ripples, dunes, or antidunes (Kennedy, 1969; Fredsøe and Deigaard, 1992), but various other names have been used as well due to the complex shape and size of bedforms found in nature (Ashley, 1990; Venditti et al., 2005). Specifically, in tidally energetic environments the interaction of the unsteady, reversing currents, changes in wa- 
ter depth, and waves produce bedforms of multiple superimposed scales. For consistency throughout this thesis, the term "dune" will be used to refer to the large, $10 \mathrm{~m}$ to $100 \mathrm{~m}$ wavelength features whose size is primarily dependent on water depth (Engelund and Fredsøe, 1982). The term "megaripple" will be used to describe the approximately $1 \mathrm{~m}$ to $5 \mathrm{~m}$ wavelength bedforms that are superimposed on the dunes. Megaripples represent an intermediate scale of bedforms as they are larger than typical ripples but do not scale with water depth like dunes (Fig. 1-1) (Nielsen, 1992; Soulsby, 1997; Amos and King, 1984; Boothroyd and Hubbard, 1975; Berne et al., 1993).

Since as early as the 1950s, the superposition of bedforms has been observed from serial echo soundings (Pretious and Blench, 1951). Since then, these bedforms have been mapped through ship-based echo soundings, sidescan sonars, and, more recently, multibeam sonars (Allen and Collinson, 1974; Bokuniewicz et al., 1976; Langhorne, 1973; Knaapen et al., 2005). These observations have shown that the larger dunes remain oriented towards and slowly migrate in the direction of the dominant tidal flow, whereas surveys taken during maximum ebb and flood reveal smaller bedforms reverse asymmetry with the tides (Bokuniewicz et al., 1976; Winter et al., 2008; Kwoll et al., 2014). Although these studies provide accurate maps of the bedforms and information of their asymmetry and long timescale migration, they lack detail on bedform dynamics throughout the tidal cycle.

The advancement of battery and data storage have enabled instruments to be mounted underwater on a sea-floor frame, providing high temporal resolution over both long and short timescales, and improving our ability to observe bedform dynamics (Irish et al., 1998). Using a ripple profiler mounted on a frame, Hoekstra et al. (2004) observed ripples reversing their asymmetry with the flow. Given the short $3.5 \mathrm{~m}$ length and 1D profile from the ripple profiler, this study was not able to capture bedforms larger than approximately $3 \mathrm{~m}$ and errors exist when the bedforms were not oriented perpendicular to the profile (Hoekstra et al., 2004). Rotary sidescan sonars have provided 2D images of the backscatter intensity of the seabed, but past studies have been limited to only a $4 \mathrm{~m}$ radius image of the seabed which has restricted observations to only small scale features (Irish et al., 1998; Rubin et al., 1983). Additionally, sidescan sonars provide an image of the seabed based on backscatter intensity but do not have any bathymetry or depth information associated with the image. Therefore, while frame mounted instruments can resolve tidal processes, they are limited in spatial extent for both ripple profilers and rotary sidescan sonars with sidescan sonars also 
lacking depth information.

With new observational techniques, we have been able to capture both the dynamics of multiple scales of bedforms and the surrounding flow on tidal timescales. Using a frame mounted rotary sidescan sonar that can image the seabed over a $20 \mathrm{~m}$ radius, an area that is larger than has previously been possible, we have been able to simultaneously observe the interaction of different scales of bedforms. The utility of a rotary sidescan sonar is broadened in chapter 2 where a method to estimate bedform height and asymmetry from the shadow pattern on both sides of the sonar is developed. This method accounts for the periodic structure of bedform fields and the projection of the shadows on adjacent bedforms. We validate the method with bathymetric observations of wave-orbital ripples, with wavelengths ranging from $0.3 \mathrm{~m}$ to $0.8 \mathrm{~m}$, and tidally reversing megaripples, with wavelengths from $5 \mathrm{~m}$ to $8 \mathrm{~m}$. In both cases, bathymetric measuring sonars were deployed in addition to a rotary sidescan sonar to provide a ground truth.

Chapter 3 applies the method outlined in chapter 2 to a dataset at Wasque Shoals, a tidally energetic environment with superimposed bedforms off of the southeast corner of Martha's Vineyard, MA. The time needed for bedform asymmetry to equilibrate with the reversing tidal flow is examined and compared to a geometric model. In addition to the sea-floor frame, the use of autonomous vehicles as survey platforms have paved the way for novel datasets of multiple scales of bedforms, including autonomous surface vehicles (ASV) and small unmanned aerial vehicles (sUAV). The lag time of superimposed bedforms is also observed with data collected with an ASV and sUAV at Nauset Inlet, located on Outer Cape Cod, MA. Finally, in chapter 4, megaripple and dune migration at Wasque Shoals is analyzed where the differential migration of the megaripples along the dune give rise to a theory of the interaction of superimposed bedforms. Overall, the principle contribution of this thesis is increased understanding of the morphological response of superimposed bedforms to a tidally reversing flow using advances in observational techniques. 


\section{Chapter 2}

\section{A method to quantify bedform height and asymmetry from a low-mounted sidescan sonar}

This chapter was previously published as Jones and Traykovski (2018) and is governed by the below copyright policy.

(C)Copyright 2018 American Meteorological Society (AMS). Permission to use figures, tables, and brief excerpts from this work in scientific and educational works is hereby granted provided that the source is acknowledged. Any use of material in this work that is determined to be "fair use" under Section 107 of the U.S. Copyright Act or that satisfies the conditions specified in Section 108 of the U.S. Copyright Act (17 USC §108) does not require the AMS's permission. Republication, systematic reproduction, posting in electronic form, such as on a website or in a searchable database, or other uses of this material, except as exempted by the above statement, requires written permission or a license from the AMS. All AMS journals and monograph publications are registered with the Copyright Clearance Center (http://www.copyright.com). Questions about permission to use materials for which AMS holds the copyright can also be directed to the AMS Permissions Officer at permissions@ametsoc.org. Additional details are provided in the AMS Copyright Policy statement, available on the AMS website (http://www.ametsoc.org/CopyrightInformation). 


\section{$2.1 \quad$ Introduction}

Bedforms have been observed from a variety of platforms (ship-based and underwater frames) and instruments (optical and acoustical). In order to document bedform dynamics and evolution, both high temporal and spatial resolution data are required. Ship-based measurements with modern multibeam sonars can provide spatial resolution of approximately $10 \mathrm{~cm}$ when taken in shallow waters $(\sim 10 \mathrm{~m})$. This is sufficient to measure bedforms on the order of $1 \mathrm{~m}$ or larger, however, it is difficult to capture smaller bedforms. Ship-based measurements are also limited temporally as repeated surveys are difficult and expensive especially on short, tidal timescales or during storm events. To address these limitations, sidescan sonars have been mounted on underwater frames and rotated 360 degrees to obtain a circular image of the backscattered intensity of the seafloor (such instruments are referred to as rotary sidescan sonars (Irish et al., 1998; Hay and Wilson, 1994; Rubin et al., 1983)). Unlike the $10 \mathrm{~cm}$ resolution of multibeam sonars, rotary sidescan sonars can have $2 \mathrm{~cm}$ resolution over a $40 \mathrm{~m}$ x $40 \mathrm{~m}$ area and at very high temporal (minutes to hourly) resolution. Due to their ability to consistently survey the same area over long periods of time, studies with rotary sidescan sonars are able to resolve temporal bedform dynamics.

Although sidescan sonars provide an image of the seafloor, they are unable to obtain direct measurements of seafloor elevation. Recent developments in image processing have enabled backscatter intensity to be inverted to obtain seabed elevation maps using an image model based on surface roughness scattering strength (Coiras et al., 2007; Tang et al., 2009; Nishimura, 1997). In near-shore environments where the water is shallow and bedforms are ubiquitous due to ample sediment supply, waves, and currents, sensors are often mounted close to the bed. Given these shallow depths and low grazing angles, shadows form away from the sonar as bedforms block the acoustic waves from reaching the seafloor behind them (Blondel, 2009; Reed et al., 2003). Except for a very limited area below the sonar that does not contain shadows, the backscatter intensity inversion methods become ineffective as it is based on an assumption of full insonification of the seabed. This is especially problematic with larger bedforms $(\lambda>1 \mathrm{~m})$ as only one or two bedforms may be present in the nonshadowed area leading to poor statistical estimates. 
Previous efforts have revealed methods to estimate object heights, such as mines, from sidescan sonar shadows, however, these methods typically assume a flat seabed with uninterrupted shadows (Reed et al., 2003; Doherty et al., 1989; Chew et al., 2007). This flat seabed assumption is not applicable to estimating bedform height as bedforms typically occur in sets where the shadow cast from one bedform is truncated by the subsequent bedform. This shortening of the shadow length reduces the apparent bedform height. Previous work has been conducted on estimating bedform heights from sidescan shadows, however, most of this work provides limited details and assumptions on how these estimates were obtained (Bouma et al., 1980; Green, 1986). In Lonsdale et al. (1972) a cross-profile of the bedforms suggest a triangular geometry was used in estimating dune height from shadows where the lee slope was additionally estimated from the maximum slope of the shadowed ray. Depending on the horizontal location of the bedform relative to the sonar, the lee slope may be underestimated when using the maximum shadowed ray slope as the lee slope.

This method contributes to this body of knowledge by utilizing sidescan acoustic shadows to explicitly and directly estimate bedform height and asymmetry, validating this method against independently measured bedform parameters, and providing sensitivity analyses on the assumptions made. First, we describe the geometric model used to derive the method assuming triangular bedforms on a flat seabed and known horizontal range. We then discuss the effects of realistic variability, including crest sharpness, a sloping seabed due to scour, and approximating the horizontal range given the assumption that the sonar is mounted significantly higher than the seabed perturbations. Theoretical bedform fields are generated that incorporate this variability and the error computed when assuming the simplified idealized bedform configuration. Empirical models are fit to the error and used to correct for the variability. Sensitivity analyses are also performed on the assumption of uniform parameters. The method is then validated with field data in which both sidescan sonar images and bathymetry are obtained. This validation took place in locations with wave-orbital ripples and tidally reversing bedforms, features that do not scale with water depth like dunes, but are larger than typical ripples, to demonstrate the performance of the method on different types of bedforms. 
Table 2.1: Table of symbols

\begin{tabular}{cl}
\hline$B$ & length of bright return \\
$c$ & horizontal distance from crest to trough of a bedform \\
$d_{50}$ & median grain diameter \\
$h$ & bedform height \\
$H_{i}$ & sonar height \\
$l$ & reference to geometry to the left of the sonar \\
$L$ & distance from sonar to start of shadow \\
$m$ & ray slope \\
$r$ & reference to geometry to the right of the sonar \\
$R$ & slant distance from sonar \\
$S$ & length of shadow \\
$x_{c r i t}$ & critical distance from sonar for sinusoidal bedforms \\
$x_{s o n a r}$ & maximum range of the sonar \\
$X$ & horizontal distance from sonar \\
$X_{L}$ & non-dimensional critical distance for sinusoidal bedforms \\
$y$ & height shadow intercepts subsequent bedform \\
$z$ & seabed elevation \\
$\alpha$ & bedform asymmetry \\
$\beta$ & coefficients for empirical models of error \\
$\gamma$ & coefficient for recommended sonar height from seabed \\
$\lambda$ & bedform wavelength \\
$\theta$ & angle of seabed for scour pit \\
\hline
\end{tabular}

\subsection{Geometric model}

\subsubsection{System geometry}

Rotary sidescan sonars transmit a fan of acoustic waves and record the intensity of the reflected, or backscattered, returns (Klein, 2002). The location of this intensity is recorded in units of "range" distance, based on the time it takes an echo to leave the transducer, hit a target, and return to the sonar. The distance from the transducer to the target is the "slant" range, $R$ (Fig. 2-1). Therefore, objects at the same range but different elevations will be recorded at the same location. If the seabed bathymetry, $z(x)$, is known, the horizontal range, $X$, can be computed from the slant range given the height of the sonar from the seabed, $H_{i}$ :

$$
X=\sqrt{R^{2}-\left(H_{i}-z(x)\right)^{2}}
$$


However, because rotary sidescan sonars are imaging sonars which only provide backscatter intensity not depth, the seabed elevation, $z(x)$ is usually unknown. By assuming the sonar is mounted significantly higher than the elevation of seabed perturbations $\left(H_{i}>>z(x)\right)$, or that the range is much larger than the sonar height $\left(R>>H_{i}\right)$, Eq. 2.1 can be simplified to the following:

$$
X=\sqrt{R^{2}-H_{i}^{2}}
$$

in which the horizontal range, $X$, is no longer a function of $z(x)$, and will therefore be referred to as the "depth independent range". This approximation is valid for most instrument deployments, and will be used to compute the horizontal range needed in the method described below. The sensitivity of the method to this assumption is discussed in Section 2.3.3.

\subsubsection{Single triangular bedform}

As demonstrated in existing literature, Reed et al. (2003); Doherty et al. (1989); Chew et al. (2007), the height of a single object on a flat seabed can be explicitly determined from the geometry of the system. Although the height can be computed when there is one bedform present on a flat seabed, the bedform asymmetry cannot be determined. Given the height of the sonar, $H_{i}$, the distance of the object from the sonar, $L$, and the length of the shadow, $S$, the height can be explicitly determined (Fig. 2-1):

$$
\frac{H_{i}}{L+S}=\frac{h}{S}
$$

This holds true for both the horizontal range measurements $\left(L_{H}\right.$ and $\left.S_{H}\right)$, and the slant range measurements $\left(L_{S}\right.$ and $\left.S_{S}\right)$ as depicted in Fig. 2-1.

\subsubsection{Multiple triangular bedforms}

It is unlikely for a single bedform to exist on a flat seabed given feedbacks between bottom perturbations, the movable seabed, and the overlying flow. Due to its influence on the flow, a single bedform will decrease the bed shear stress downstream of the bedform, resulting in the downstream deposition of sediment, and the generation of a secondary bedform (Bagnold, 1946; Dalrymple and Rhodes, 1995). As this process repeats itself, a field 


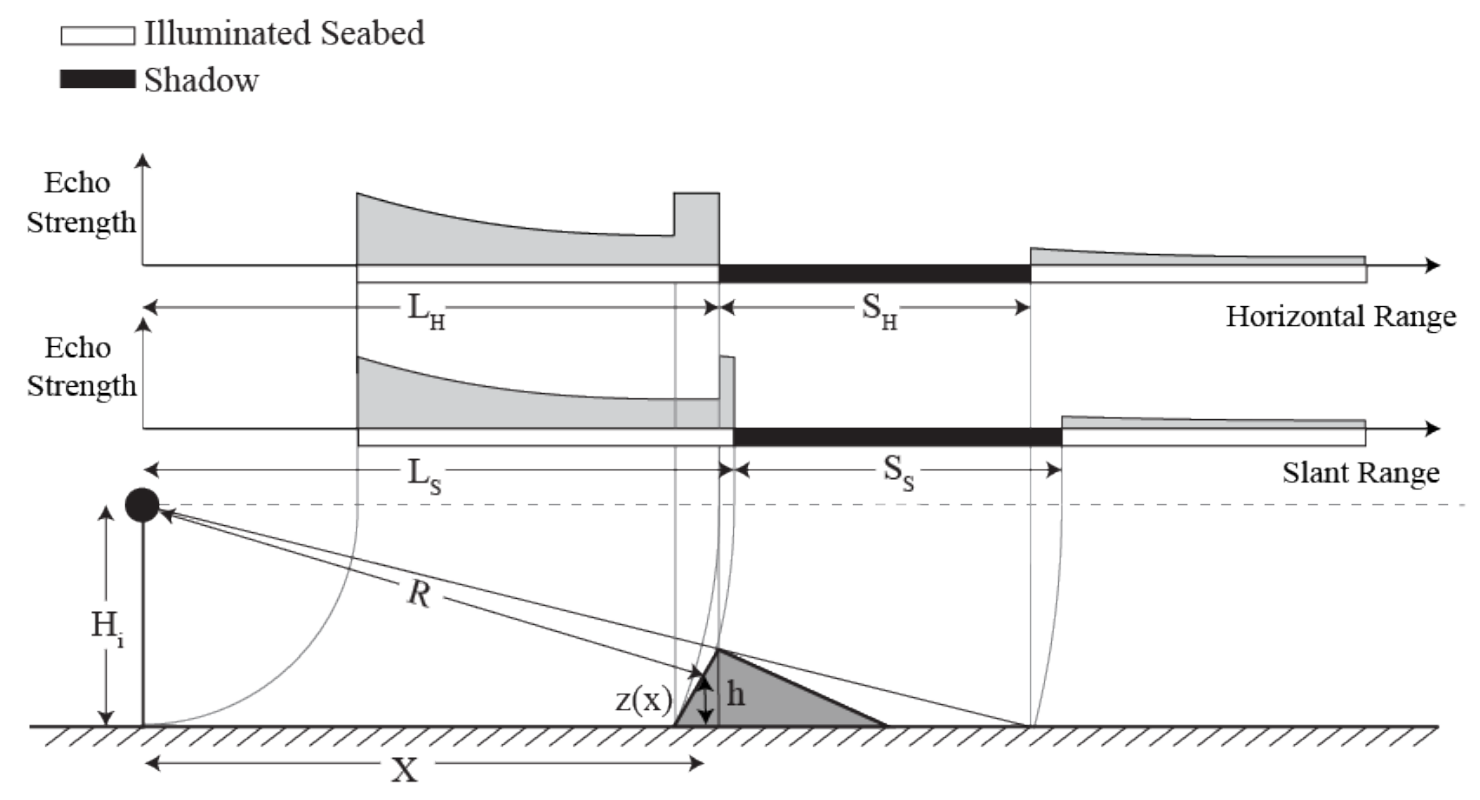

Figure 2-1: System geometry and backscattered intensity of a flat seabed with a single bedform present. The difference between horizontal and slant range is depicted in the system geometry as well as the echo-return strength. The horizontal range, or horizontal distance from the sonar to an arbitrary location, is denoted as $X$ while the slant range to this same location is represented by $R$ and is a function of $X$, the height of the sonar, $H_{i}$, and the height of the seabed at the location of interest, $z(x)$. The difference in backscatter intensity of slant and horizontal range is depicted in the plots of range versus returned echo strength. In these plots, $S$ is the length of the shadow caused from the bedform intercepting the acoustic wave and $L$ is the distance from the sonar to the start of the shadow. The subscripts indicate whether these distances were obtained using the horizontal (subscript $H$ ) or slant (subscript $S$ ) range.

of bedforms form, and the lengths of bedform shadows become intercepted and shortened by subsequent bedforms (Fig. 2-2) invalidating Eq. 2.3. By assuming a field of uniform, triangular bedforms on a flat seabed, individual bedform heights as well as asymmetries can be determined. Similar to the single bedform case, the geometry of the system is used to obtain a relationship between bedform shape and the shadow pattern:

$$
\frac{H_{i}-y}{L+S}=\frac{h-y}{S}
$$

where $y=h(c-B) \cdot c^{-1}$ is the height at which the shadow intercepts the subsequent bedform, $B=\lambda-S$ is the length of brightness or strong return, and $c$ is the horizontal distance from the bedform crest to the trough, closest to the sonar (Fig. 2-2). Because $\lambda$ and $c$ are defined based on horizontal distances, the quantities $L, S$, and $B$ are computed using 


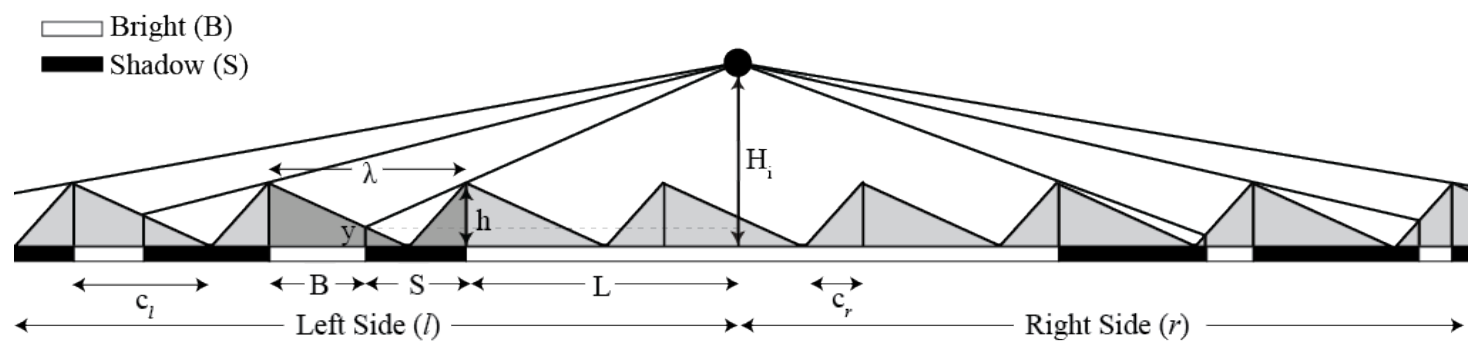

Figure 2-2: Geometry to determine bedform height $(h)$ and asymmetry $(\alpha)$ when multiple triangular bedforms are present. The same notation is used as in Fig. 2-1 with additional parameters being defined as the wavelength $(\lambda)$, the distance between bedform trough and crest facing the sonar $(c)$, and the height on the adjacent ripple where the shadow intersects $(y)$. The length of $c$ facing the sonar varies depending on the side of the sonar considered where $c_{r}$ is the length of the base facing the sonar on the right side of the sonar and $c_{l}$ is the length of the base facing the left side of the sonar.

the horizontal depth independent range in Eq. 2.2 as opposed to the slant range. Also, while $S$ and $B$ are directly related to one another given a uniform wavelength, both measurements are maintained in this method as the assumption of a uniform wavelength is not always true, especially for field data. It is therefore recommended that users compute $B$ directly from the length of the bright return of the sonar. Simplifying Eq. 2.4 and substituting the expression for $y$, we relate the shadow pattern directly to the bedform height and $c$, which is a measure of bedform asymmetry:

$$
\frac{h}{\left(H_{i}-h\right) c}=\frac{S}{B L}
$$

When there are multiple bedforms, Eq. 2.5 becomes a system of equations with two unknowns for each bedform: $h$ and $c$. If at least two bedforms are present such that there are two measurements of $S, B$, and $L$, the height and $c$ can be directly computed given the two equations and two unknowns, however, variability in field data results in poor estimates with only two bedforms.

The estimates can be improved for asymmetric bedforms if the shadow pattern is obtained on each side of the sonar as one face of the bedform is illuminated on one side of the sonar while the other face of the bedform is illuminated on the other side of the sonar. This results in a different shadow pattern on each side. On the right $(r)$ side of the sonar Eq. 2.5 becomes $h /\left(\left(H_{i}-h\right) c_{r}\right)=S_{r} /\left(B_{r} L_{r}\right)$, and on the left $(l)$ side of the sonar it becomes $h /\left(\left(H_{i}-h\right) c_{l}\right)=S_{l} /\left(B_{l} L_{l}\right)$. Defining the geometry based on each side of the sonar as op- 
posed to flow direction is necessary to quantify bedform reversal in tidal flows where the lee and stoss side change as the definition of downstream changes.

By assuming that all bedforms have the same height and asymmetry, Eq. 2.5 for each side can be combined into a single equation relating the lengths of the two bedform bases to the shadow pattern:

$$
\frac{c_{r}}{c_{l}}=\frac{B_{r} L_{r}}{S_{r}} \frac{S_{l}}{B_{l} L_{l}}
$$

Because $c_{r}+c_{l}=\lambda$, Eq. 2.6 can be simplified further, and written in terms of an asymmetry parameter, $\alpha=c_{r} / \lambda$, that ranges from 0 to 1 with symmetric bedforms having an $\alpha=0.5$. This parameter is similar to the asymmetry parameter defined by Clifton and Dingler (1984),Lefebvre et al. (2016), and Haque and Mahmood (1985), however, instead of defining the asymmetry as $\beta / \lambda$ (here $\beta$ is the downstream distance from crest to trough), $\alpha$ is defined based on a prescribed direction to permit the quantification of bedform orientation reversals:

$$
\alpha=\frac{c_{r}}{\lambda}=\frac{\lambda-c_{l}}{\lambda}=\frac{\frac{B_{r} L_{r}}{S_{r}}}{\frac{B_{r} L_{r}}{S_{r}}+\frac{B_{l} L_{l}}{S_{l}}}
$$

The bedform shadow length, $S$, brightness length, $B$, and distance from sonar, $L$, are obtained for each bedform from the rotary sidescan sonar imagery as discussed in Section 2.4.2. By assuming that all bedforms have the same height and shape, the ratio $S /(B L)$ is the same for the bedforms on each side of the sonar (Eq. 2.5). Therefore, for a field of uniform triangular bedforms on a flat bed, bedform asymmetry can be estimated if at least one bedform exists on each side of the sonar, this bedform casts a shadow, and the end of that shadow is also captured by the sonar. If shadow information exists for more than one bedform on each side, then there are multiple estimates for $S /(B L)$. To get a single estimate of the asymmetry, $\alpha$, it is necessary to combine the estimates. We have chosen to use the median as our measure of central tendency because it is robust to outliers.

After computing bedform asymmetry, the height of each bedform can be estimated by solving Eq. 2.5 for $h$; however, separate equations are required for each side of the sonar when the bedforms are asymmetric as each side has a different value for $c$ (Eqs. $2.8 \& 2.9$ ): 


$$
\begin{gathered}
h_{r}=\frac{H_{i}}{\frac{B_{r} L_{r}}{S_{r}(\alpha \lambda)}+1} \\
h_{l}=\frac{H_{i}}{\frac{B_{l} L_{l}}{S_{l}((1-\alpha) \lambda)}+1}
\end{gathered}
$$

\subsection{Error correction and sensitivity analysis}

In the idealized case of theoretical triangular bedforms on a flat seabed with a known horizontal range, the estimated bedform height and asymmetry from Eqs. 2.7, 2.8, and 2.9 agree with the true prescribed values. However, a flat seabed of uniform triangular bedforms is not realistic. An empirical error correction was obtained for three realistic variations: crest sharpness, a scoured seabed, and approximating the horizontal range as the depth independent range. For each variation, a theoretical bedform field based on realistic parameters was generated, and the height and asymmetry computed. The error was obtained given this estimated parameter and the true parameter. An empirical model was then fit to the error to be applied after estimating the parameters as a correction to the variability. Each variability component was considered individually with the interaction of all variability configurations addressed in Section 2.3.4.

Additionally, a sensitivity analysis of the assumption of a uniform bedform field was performed by theoretically prescribing a distribution of bedform parameters and computing the error in estimated height and asymmetry. First, normal distributions of bedform height and wavelength were applied to otherwise uniform triangular bedforms on a flat seabed to test the sensitivity of the method to slight variations in individual bedforms. Second, a bimodal distribution of bedform parameters was considered in which smaller bedforms were superimposed on top of larger bedforms of the same aspect ratio.

For readers who seek to apply the method, proceed to Section 2.4. The below subsections detail the incorporation of variability and generation of the empirical error models.

\subsubsection{Crest sharpness}

While bedforms are approximately triangular, they typically have some curvature associated with a rounded trough and crest (Dalrymple and Rhodes, 1995; Lefebvre et al., 2016). A number of laboratory and numerical studies assume a sinusoidal stoss side and a straight lee 
Table 2.2: Range of parameters used in theoretical system geometries to obtain empirical models of the error in estimated height and asymmetry.

\begin{tabular}{cc}
\hline Parameter & Range \\
\hline$\alpha$ & {$[0: 1]$} \\
$\lambda$ & {$[0.5 \mathrm{~m}: 6 \mathrm{~m}]$} \\
$h$ & {$[0.05 \lambda: 0.2 \lambda]$} \\
$H_{i}$ & {$[0.05 \lambda: 2.5 \lambda]$} \\
$x_{\text {sonar }}$ & {$[10 \mathrm{~m}: 20 \mathrm{~m}]$} \\
\hline
\end{tabular}

side to approximate current-generated bedforms (Lefebvre et al., 2016; Smith and McLean, 1977; Nelson et al., 1993). For the generality of tidally reversing and symmetrical bedforms, we will account for this curvature by assuming both sides of the bedform are sinusoidal (Fig. $2-3)$.

A field of uniform sinusoidal bedforms results in the same relationship between bedform shape, distance from the sonar, and shadow lengths as for the field of triangular bedforms (Eq. 2.4). However, the height at which the shadow intercepts the following bedform, $y$, is defined based on the sinusoidal shape:

$$
y=\frac{h}{2} \cos \left(\frac{B \pi}{c}\right)+\frac{h}{2}
$$

Substituting this equation for $y$ into Eq. 2.4 results in the following equation for the bedform height and $c$ with respect to the measured distance from sonar and shadow length.

$$
\frac{H_{i}-h}{h}=\frac{L}{2 S}\left(1-\cos \frac{B \pi}{c}\right)
$$

Similar to the case for a field of triangular bedforms, Eq. 2.11 has two unknowns, $h$ and $c$, for each bedform. To overcome the poorly-constrained case of triangular bedforms, both sides of the sonar are considered separately, as the ratio of $B L / S$ is constant for all bedforms on each side. In the case of sinusoidal bedforms (Eq. 2.11), it is not possible to partition the unknowns $(c$ and $h)$ from the knowns $(B, L, S)$, which is necessary when considering each side of the sonar separately. Thus we assume triangular bedforms and quantify the error due to reduced crest sharpness which is common in current-generated bedforms or high flow wave-generated ripples (Nielsen, 1992). 
a)

b)
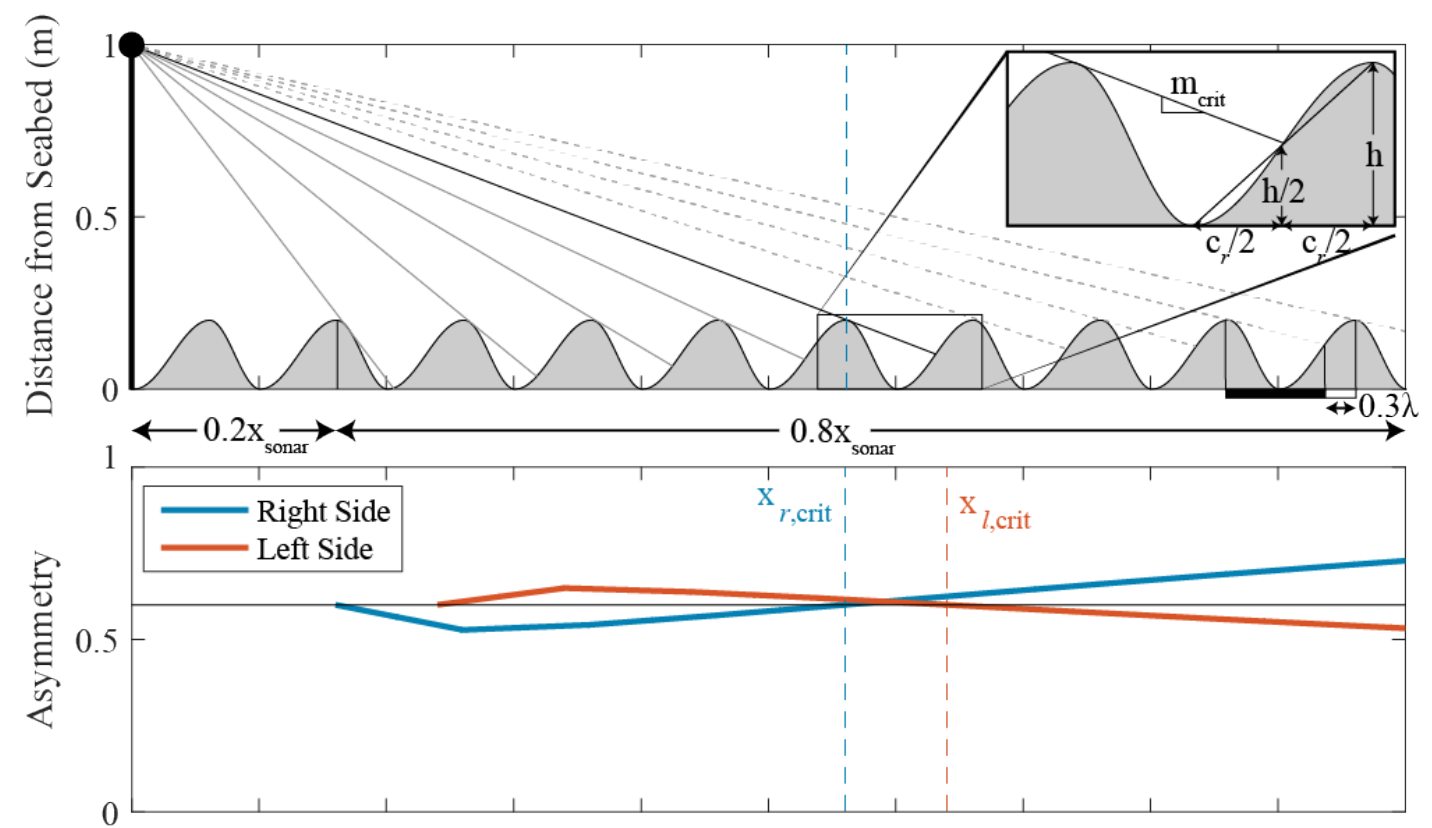

c)

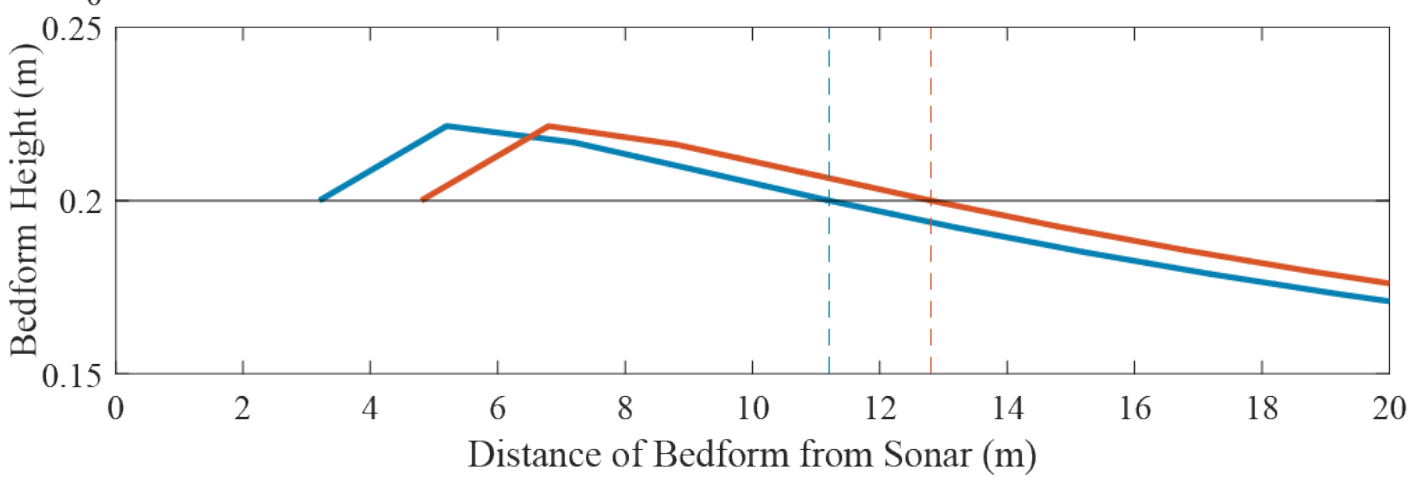

Figure 2-3: a) System geometry for the right side of the sonar, where bedforms are the composite of two sine waves. In this example, the sonar is $1 \mathrm{~m}$ above the seabed, and bedforms have a wavelength of $2 \mathrm{~m}$, height of $0.2 \mathrm{~m}$, and asymmetry of 0.6 . Ray traces from the sonar to the bedform crests are shown where the solid gray lines are rays where $m>m_{\text {crit }}$ and the dashed gray lines are rays where $m<m_{\text {crit }}$. The solid black ray is the critical ray, where asymmetry and height are accurately estimated. The annotations underneath the subplot are for reference when computing the recommended sonar height in Section 2.4.1. b) Estimated asymmetry for the left and right sides as a function of distance from the sonar. The asymmetry equals the true asymmetry of 0.6 at the critical length indicated by the vertical dashed lines. c) Estimated height assuming triangular bedforms for each side of the sonar. For distances shorter than the critical length the height is overestimated while distances larger than the critical length the height is underestimated. 
A sinusoidal bedform will result in either a larger or smaller shadow depending on the location at which the ray intercepts the subsequent bedform. At the inflection point of a sinusoidal curve, the height and location of a sinusoidal bedform is the same as that of a triangular bedform (Fig. 2-3a). The slope of the ray from the sonar to this point will be referred to as the critical slope, and is defined as:

$$
m_{c r i t}=\frac{h / 2}{\lambda-c / 2}
$$

The shadows lengths are longer for sinusoidal bedforms than triangular bedforms when the slope of a given ray, $m=\left(H_{i}-h\right) / L$, is larger than the critical slope (Eq. 2.12; and indicated in Fig. 2-3a by the solid gray lines). Thus, $c$ is underestimated by Eq. 2.5 on both sides of the sonar, and the asymmetry, $\alpha$, will be underestimated for the right side $\left(\alpha=c_{r} / \lambda\right)$ and over predicted for the left side $\left(\alpha=\left(\lambda-c_{l}\right) / \lambda\right.$; Fig. 2-3b). However, as the slope of the ray becomes smaller than the critical slope (indicated by the dashed gray lines in Fig. 2-3a), the observed shadow lengths are shorter than if the bedform was triangular, overestimating $c$ on both sides as well as overestimating $\alpha$ on the right side and underestimating $\alpha$ on the left side (Fig. 2-3b).

Sinusoidal bedforms also influence the estimated bedform height as a function of the ray slope and critical slope. If the shadow lengths are increased in which the ray slope is larger than the critical slope, then the ratio of $B L / S$ is underestimated, producing an overestimate of $h$. Likewise, if the shadow lengths are decreased which occurs when the ray slope is smaller than the critical slope, then the ratio of $B L / S$ is overestimated resulting in an underestimate of bedform height, $h$ (Fig. 2-3c).

Whether the overall estimated height and asymmetry are over- or under-predicted depends on how many bedforms have a ray slope less than or greater than the critical slope. Because a central tendency, such a mean or median, is computed for each side, the error will depend on the ray slope relative to the critical slope. The error as a function of slope can also be described in terms of length, where the length is defined as $x=\left(H_{i}-h\right) / m$. Therefore, if the average ratio of $B L / S$ is obtained from each side, the error in estimated height and asymmetry will depend on the number of bedforms that occur at a distance smaller than $x_{\text {crit }}$ as well as the number of bedforms that occur at a distance larger than $x_{\text {crit }}$. 
The error in estimated height and asymmetry from applying Eqs. 2.7, 2.8, and 2.9 (assuming triangular bedforms) was quantified on theoretical sinusoidal bedforms. The shape and size of the theoretical bedforms, along with the system geometry, were randomly generated for $10^{5}$ sets of realistic parameters of $\alpha, \lambda, h, H_{i}$, and the maximum range of the sonar, $x_{\text {sonar }}$. The range of these parameters randomly selected for each configuration are shown in Table 2.2. The difference in estimated asymmetry and true asymmetry $\left(\alpha_{\text {est }}-\alpha\right)$ for each realization is shown in Fig. $2-4 \mathrm{a}$ and the error in height $\left(\left(h_{e s t}-h\right) / h\right)$ is shown in Fig. 2-4b.

An empirical model was fit to the error using multiple linear regression with both interaction and non-linear transformation predictors. The empirical model for error in asymmetry can be represented by Eq. 2.13 and has an $R^{2}$ of 0.77 . All coefficients were significant with a p-value less than 0.001 and are given in Table 2.3. In the model, $X_{L}=x_{\text {critavg }} / x_{\text {sonar }}$ where $x_{\text {critavg }}$ is the average critical length for the right and left side. The critical length, $x_{c r i t}$, varies for each side for asymmetric bedforms (Fig. 2-3), however, their average provides a good indication of over-and-under estimation of asymmetry and height, and can be simplified such that $X_{L}=1.5\left(H_{i} \lambda h^{-1}-\lambda\right) x_{\text {sonar }}^{-1}$.

$$
\begin{array}{r}
\alpha_{e s t}-\alpha=\beta_{0} \alpha+\beta_{1} \alpha^{2}+\beta_{2} \alpha^{3}+\beta_{3} \alpha X_{L}+\beta_{4} \alpha^{2} X_{L}+ \\
\beta_{5} \alpha^{3} X_{L}+\beta_{6} \alpha X_{L}{ }^{2}+\beta_{7} \alpha^{2} X_{L}{ }^{2}+\beta_{8} \alpha^{3} X_{L}{ }^{2}
\end{array}
$$

A similar empirical model was also fit for the error in height given the non-dimensional critical length, $X_{L}$ (Eq. 2.14). The model has an $R^{2}$ of 0.90 and all coefficients (shown in Table 2.4) are significant with a p-value less than 0.001 .

$$
\frac{h_{e s t}-h}{h}=\beta_{0}+\beta_{1} X_{L}+\beta_{2} X_{L}^{2}
$$

The empirical equations for error in height and asymmetry can be used to correct for the assumption of triangular bedforms by solving Eqs. 2.13 and 2.14 for $\alpha$ and $h$, respectively, and substituting $X_{L}$ and the estimated parameters. $X_{L}$ is a function of the unknown $h$ in Eq. 2.13. Therefore, the height can first be corrected by solving for $h$ in Eq. 2.14 and this empirically corrected height used in the non-dimensional critical length, $X_{L}$, to then correct for the asymmetry using Eq. 2.13 
Table 2.3: Empirical model coefficients for quantifying the error in asymmetry given sinusoidal bedforms.

\begin{tabular}{ccc}
\hline Coefficients & Estimate & Standard Error \\
\hline$\beta_{0}$ & -0.135 & 0.001 \\
$\beta_{1}$ & 0.405 & 0.003 \\
$\beta_{2}$ & -0.269 & 0.002 \\
$\beta_{3}$ & -0.046 & 0.002 \\
$\beta_{4}$ & 0.139 & 0.007 \\
$\beta_{5}$ & -0.095 & 0.005 \\
$\beta_{6}$ & 0.076 & 0.001 \\
$\beta_{7}$ & -0.229 & 0.004 \\
$\beta_{8}$ & 0.154 & 0.003 \\
\hline
\end{tabular}

Table 2.4: Coefficients of error function in estimated height for bedforms that are sinusoidal yet assumed triangular.

\begin{tabular}{ccc}
\hline Coefficients & Estimate & Standard Error \\
\hline$\beta_{0}$ & -0.2439 & 0.0004 \\
$\beta_{1}$ & 0.3914 & 0.0009 \\
$\beta_{2}$ & -0.1088 & 0.0004 \\
\hline
\end{tabular}

\subsubsection{Scoured seabed}

Rotary sidescan sonars are usually mounted on an underwater frame in order to observe bedform dynamics. The interaction of the frame with the flow and movable seabed can result in a scour pit around the frame (Bolaños et al., 2011). If substantial scouring has occurred, the angle of the seabed relative to the sonar will be decreased, affecting the estimated asymmetry and height of the bedform. To determine these effects, the system geometry parameters $\left(\alpha, \lambda, h, H_{i}\right.$, and $\left.x_{\text {sonar }}\right)$ were randomly generated for $10^{5}$ configurations, in which the seabed slope $(\theta)$ was varied from 0 to 30 degrees to approximate the effects of a scour pit at the location of the sonar. Bedform asymmetry and height were estimated using Eqs. 2.7, 2.8, and 2.9 assuming the seabed was flat. The resulting error in asymmetry as a function of $\theta$ and $\alpha$ is shown in Fig. 2-4c with the error in height as a function of $\theta$ and aspect ratio, $h / \lambda$, shown in Fig. $2-4 d$.

An empirical model was fit to the error in asymmetry using linear regression. The model 
Table 2.5: Coefficients corresponding to the empirical model of error in estimated asymmetry where scour at the location of the sonar causes a sloped seabed.

\begin{tabular}{ccc}
\hline Coefficients & Estimate & Standard Error \\
\hline$\beta_{0}$ & $5.13 \mathrm{e}-03$ & $1.98 \mathrm{e}-04$ \\
$\beta_{1}$ & $-3.05 \mathrm{e}-03$ & $1.15 \mathrm{e}-05$ \\
$\beta_{2}$ & $-1.02 \mathrm{e}-02$ & $3.50 \mathrm{e}-04$ \\
$\beta_{3}$ & $6.09 \mathrm{e}-03$ & $2.02 \mathrm{e}-05$ \\
\hline
\end{tabular}

Table 2.6: Empirical model coefficients for error in estimated height when a scoured seabed is considered.

\begin{tabular}{ccc}
\hline Coefficients & Estimate & Standard Error \\
\hline$\beta_{0}$ & -0.068 & 0.003 \\
$\beta_{1}$ & 0.055 & 0.000 \\
\hline
\end{tabular}

is described in Eq. 2.15 with an $R^{2}$ of 0.89 and coefficients (given in Table 2.5) are significant with a p-value less than 0.001 .

$$
\alpha_{e s t}-\alpha=\beta_{0}+\beta_{1} \theta+\beta_{2} \alpha+\beta_{3} \theta \alpha
$$

A model was fit to the error in bedform height as a function of $\theta$ with an $R^{2}$ of 0.88 (Eq. 2.16). Coefficients are given in Table 2.6 and are all significant with a p-value less than 0.001 .

$$
\frac{h_{e s t}-h}{h}=\beta_{0} \frac{h}{\lambda}+\beta_{1} \frac{h}{\lambda} \theta
$$

Equations 2.15 and 2.16 can be solved for $\alpha$ and $h$ respectively to correct for the error.

\subsubsection{Estimation of horizontal range}

When the distance from the sonar and sonar-facing slope are such that all points on the slope are roughly at the same range, the horizontal range cannot be approximated as the depth independent range, and the elevation of the seabed relative to the sonar must be considered (Fig. 2-1). This can occur when the sonar is mounted at a height similar to that of the bedforms, or when a bedform has slope perpendicular to the ray slope. In these cases, 
the length of the high return may be very small relative to the actual horizontal length. This underestimation of brightness $(B)$ and overestimation of shadow length $(S)$ results in a smaller estimated value of $c$ on both sides of the sonar, producing an underestimation (overestimation) of $\alpha$ on the right (left) side (Eq. 2.7). The value of $h$ is also overestimated on both sides when considering the under-and-over estimation of $c, S$, and $B$ (Eqs. 2.8 and 2.9). This should be considered when there are large bedforms present or bedforms on a sloped seabed such that the horizontal range cannot be approximated from the slant range and height of the sonar.

Given a theoretical field of triangular bedforms, and using the depth independent range as an approximation for the horizontal range, the errors are shown in Fig. 2-4e,f as a function of bedform aspect ratio $(h / \lambda)$ for $10^{5}$ configurations. The height estimate is strongly influenced by very asymmetric bedforms such that the height estimates can become negative or extremely large. Therefore, the asymmetry is varied from 0.05 to 0.95 to generate an empirical model of the true error. Linear theory for current-generated bedforms in equilibrium predict an asymmetry of 0.67 (or equivalently 0.33 ), therefore excluding the asymmetries greater than 0.95 and smaller than 0.05 does not undermine the method or error model (Haque and Mahmood, 1985).

An empirical model described by Eq. 2.17 was fit to the error in asymmetry. The model has an $R^{2}$ of 0.78 and all coefficients are significant with a p-value less than 0.001 . The coefficients are shown in Table 2.7.

$$
\alpha_{e s t}-\alpha=\beta_{0}+\beta_{1} \frac{h}{\lambda}+\beta_{2} \alpha+\beta_{3} \frac{h}{\lambda} \alpha
$$

When estimating the height, the error can be represented by the empirical equation Eq. 2.18 with an $R^{2}$ of 0.83 . All coefficients are significant with a p-value less than 0.001 and are shown in Table 2.8 .

$$
\frac{h_{e s t}-h}{h}=\beta_{0} \frac{h}{\lambda}+\beta_{1}\left(\frac{h}{\lambda}\right)^{2}+\beta_{2}\left(\frac{h}{\lambda}\right)^{2} \frac{h}{H_{i}}+\beta_{3}\left(\frac{h}{\lambda}\right)^{2}\left(\frac{h}{H_{i}}\right)^{2}
$$

Similar to the other variations, the asymmetry and height estimates can be corrected by solving Eqs. 2.17 and 2.18 for $\alpha$ and $h$, respectively. The aspect ratio $(h / \lambda)$ can be approximated as the empirically corrected bedform height over the estimated wavelength when correcting for the asymmetry. 


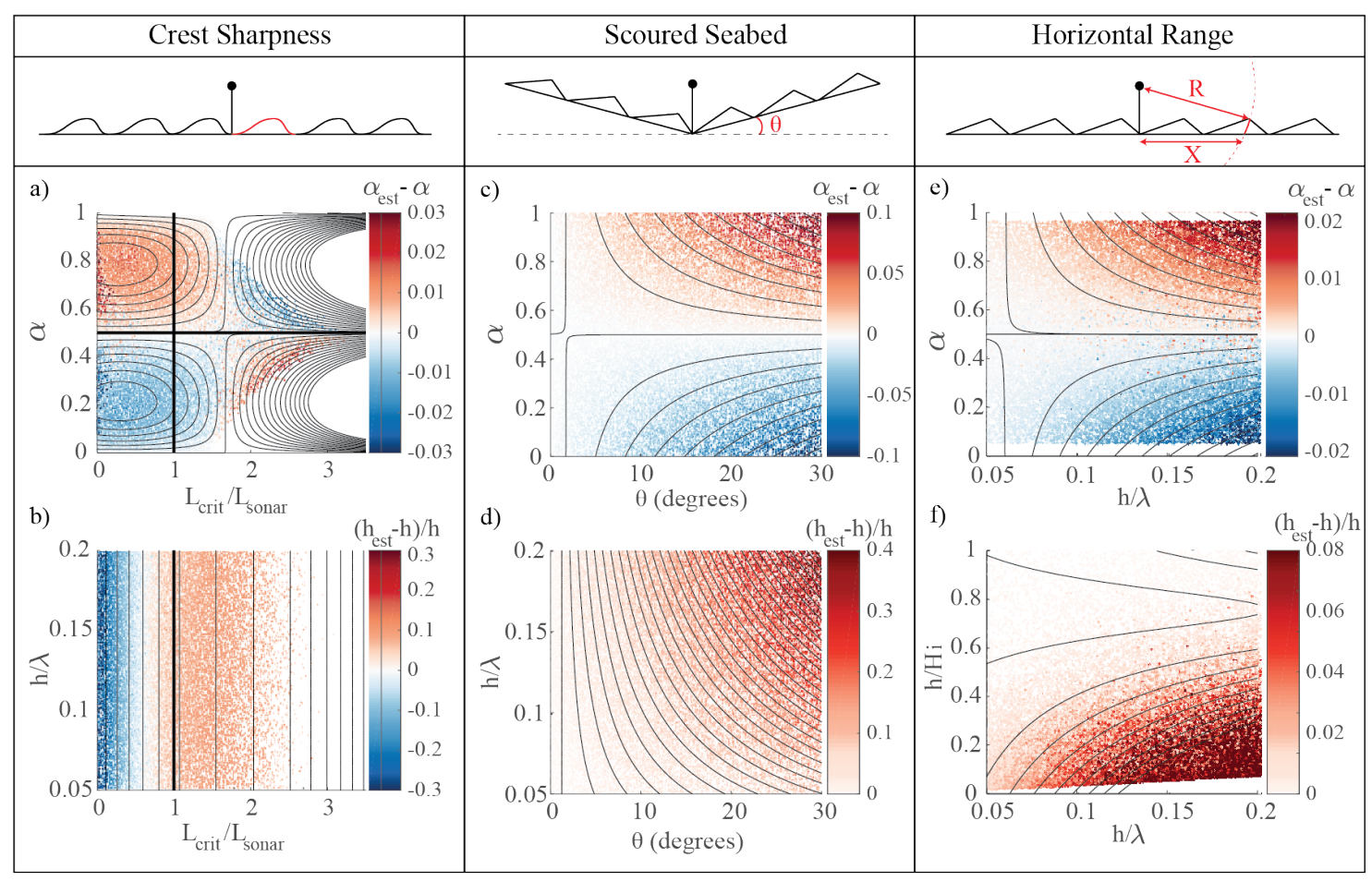

Figure 2-4: Scatter plots of error from theoretical bedforms. Contours are the empirically fitted models. The top row is the error in asymmetry while the bottom row is the error in height. a-b) Error introduced from assuming sinusoidal bedforms are triangular. c-d) Error from having a constant-sloped, scoured seabed. e-f) Error from approximating the horizontal range as the depth independent range. 
Table 2.7: Coefficients for error in estimated asymmetry by approximating the horizontal range as depth independent.

\begin{tabular}{ccc}
\hline Coefficients & Estimate & Standard Error \\
\hline$\beta_{0}$ & 0.0079 & 0.0001 \\
$\beta_{1}$ & -0.1314 & 0.0008 \\
$\beta_{2}$ & -0.0160 & 0.0002 \\
$\beta_{3}$ & 0.2646 & 0.0015 \\
\hline
\end{tabular}

Table 2.8: Empirical coefficients of the error in estimated height assuming seafloor purtubations are significantly smaller than the height of the sonar when estimating the horizontal range.

\begin{tabular}{ccc}
\hline Coefficients & Estimate & Standard Error \\
\hline$\beta_{0}$ & -0.031 & 0.005 \\
$\beta_{1}$ & 5.538 & 0.038 \\
$\beta_{2}$ & -14.196 & 0.116 \\
$\beta_{3}$ & 9.352 & 0.132 \\
\hline
\end{tabular}

\subsubsection{All seabed configurations considered}

It is possible to have a bedform configuration that contains a combination of rounded crests and troughs and a sloped seabed with unknown horizontal range. To account for this, the empirical corrections in the above equations were applied to randomly generated seabed configurations that consist of sinusoidal bedforms on a scoured seabed where the horizontal range is approximated as depth independent. The error in computed asymmetry and height versus the true parameter is shown in Fig. 2-5 for both the original estimated values and the empirically corrected values.

The error of the original asymmetry estimate has a mean of $0.00 \pm 0.77$ (standard deviation) with $95 \%$ of the data contained in the interval $[-0.06,0.06]$. The corrected asymmetry by applying the empirical model has a mean of $0.00 \pm 0.20$ with a $95 \%$ confidence interval $[-0.03,0.03]$. Similarly the error in the original estimation of aspect ratio, $h / \lambda$, has a mean of $0.01 \pm 0.23$ with a $95 \%$ confidence interval of $[-0.05,0.07]$. The error for the empirically corrected aspect ratio is $-0.01 \pm 0.22$ with $95 \%$ of the data constrained by the interval $[-0.04$, 0.02]. 
Overall, applying the empirical corrections in estimated height and asymmetry improves the estimates and better accounts for the actual bedform configuration and system geometry.

\subsubsection{Bedform parameter distributions}

The sensitivity of the method to the assumption of uniform bedforms was addressed by theoretically prescribing distributions of bedform parameters.

Sensitivity of the method to small discrepancies between individual bedforms was first considered by imposing a distribution of bedform heights and wavelengths to a theoretical bedform field. The parameters and their variation were chosen based on those observed in bathymetric data of wave-orbital ripples taken at the Martha's Vineyard Coastal Observatory (MVCO). In this data, there is a strong linear correlation, $\rho=0.8$, between ripple height and wavelength with ripple height increasing as the wavelength increases. Therefore, an aspect ratio of 0.11 , the average aspect ratio at MVCO, was chosen to remain constant for each bedform. In the field data, the ripple heights and wavelengths were normally distributed. Therefore, for the theoretical data, the wavelength was prescribed a normal distribution given the mean, $0.44 \mathrm{~m}$, and standard deviation, $0.13 \mathrm{~m}$, of the wavelengths at MVCO. The ripple height was then computed given the aspect ratio of 0.11 , which agrees well with the mean and standard deviation of the ripple height observed at MVCO. A sonar height was prescribed to be $1.15 \mathrm{~m}$ based on the ideal sonar height in Eq. 2.19. The extent of the sonar range was set to be $20 \mathrm{~m}$, which is the sonar extent at MVCO and 100 transects were considered. Finally, the asymmetry was set to 0.5 as wave-orbital ripples are symmetric.

Given these prescribed normal distributions of bedform height and wavelength in individual ripples, the resulting distribution of wavelength was also normal while the distribution of bedform height was positively skewed. The percent error in the median height was only $2.8 \%$, the percent error in median wavelength was $1.4 \%$, and the percent error in asymmetry was $0.15 \%$. Therefore, with a sufficient number of bedforms, the error from discrepancies in individual bedforms was such that the central tendency of asymmetry, height, and wavelength, agrees with the prescribed asymmetry, height, and wavelength.

The case of two scales of bedforms in which the smaller, secondary bedforms are superimposed on the larger, primary bedforms was also considered numerically. This situation can occur in nature both with tidal megaripples and wave-orbital ripples. On tidal megaripples, at the reversal of flow, incipient current ripples $\left(\lambda \approx 1000 d_{50}\right.$, or $\left.\sim 20 \mathrm{~cm}\right)$ form on top of 
a)

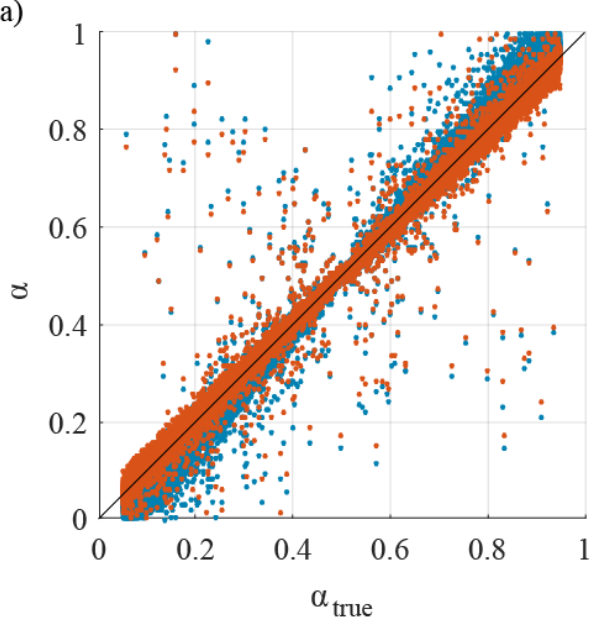

c)

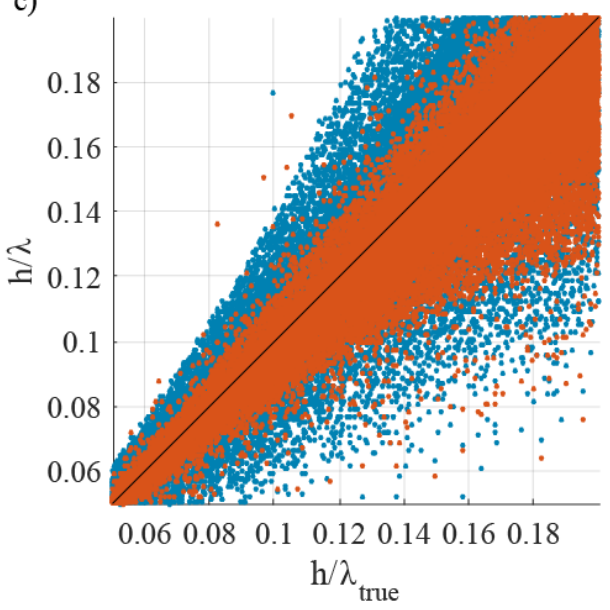

b)

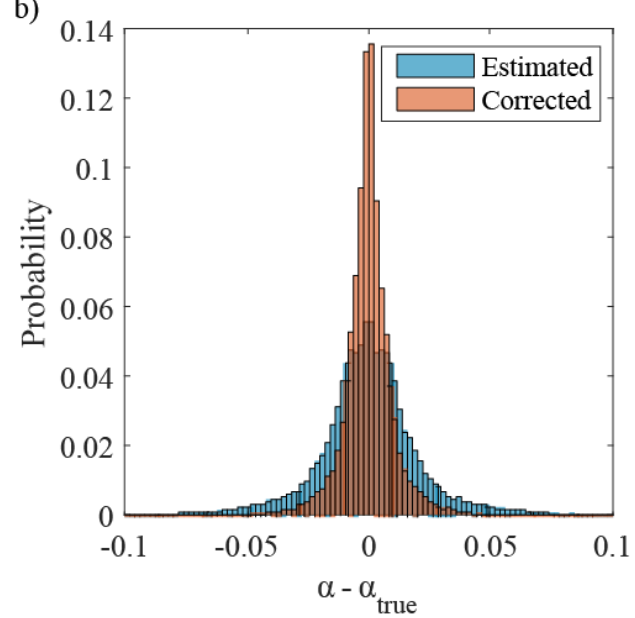

d)

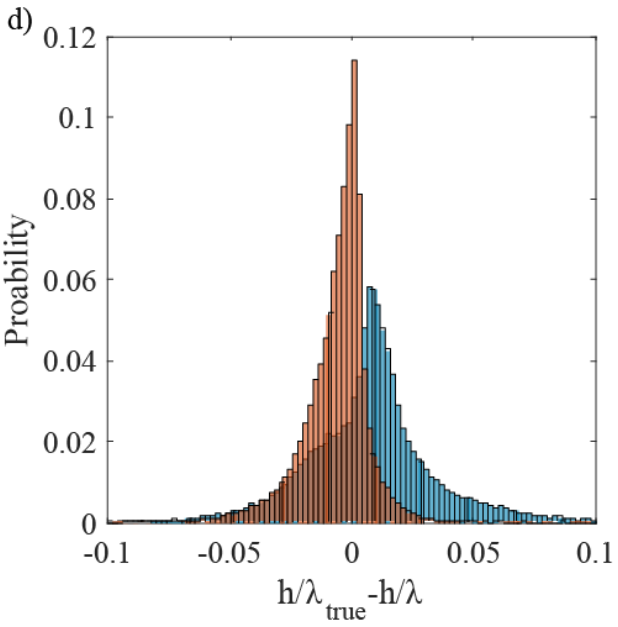

Figure 2-5: a) Estimated asymmetry versus true asymmetry for theoretical bedforms when sinusoidal bedforms on a slanted seabed with depth independent estimated horizontal range are considered together. The blue data are from assuming triangular bedforms on a flat seabed with horizontal range while the red data are empirically corrected. The black line demonstrates a perfect fit. b) Probability of the error in asymmetry for both estimated and empirically corrected asymmetry. c) Estimated $h / \lambda$ versus true $h / \lambda$ when all variations are considered. d) Probability of the error in height. 
larger megaripples (Yalin, 1964; Venditti et al., 2005; Traykovski, 2012). On wave-orbital ripples, smaller $(\sim 20 \mathrm{~cm})$ ripples can form in the troughs of meter-scale relict ripples left from previous wave events (Traykovski, 2007). When there are superimposed bedforms, the secondary bedforms cast small shadows in which otherwise would have been a bright return from the larger bedforms. If the method is directly applied with these shadow patterns, the error becomes large. It is therefore advised that the user applies a moving average filter, at least the wavelength of the smaller bedforms, to average over these smaller shadow patterns. This would result in a lower intensity in a region that otherwise should have been fully illuminated. Therefore, the threshold should be set so the filtered areas with small shadows are classified as bright.

The error of applying the method to superimposed bedforms was considered for bedforms with wavelength ratios ranging from 6 smaller bedforms superimposed on a larger bedform to 40 smaller bedforms superimposed on a larger bedform, with both bedforms having an aspect ratio of 0.1 . In all cases the height of the larger bedforms was set to $0.4 \mathrm{~m}$ with a wavelength of $4 \mathrm{~m}$. Additionally, the height of the sonar was $1.2 \mathrm{~m}$, asymmetry of 0.6 , and sonar extent of $20 \mathrm{~m}$. Although the error was not linear with respect to large bedform to small bedform wavelength ratio, the height estimates were underestimated by 10 to $15 \%$, with errors as large as $25 \%$. The wavelength estimates were all over-predicted with a percent error ranging from 2 to $2.5 \%$. Finally, the percent error in asymmetry was underestimated for all cases with an error of approximately $3 \%$. Therefore, when superimposed bedforms are present, it is recommended to filter out the shadows from the smaller bedforms to obtain estimates of the larger bedforms. Estimating the smaller bedform height and asymmetry is more difficult as they are generally superimposed on steep lee and stoss sides of the primary bedforms.

As the superimposed bedform size becomes a significant fraction of the primary bedform size (eg. 3 to 4 small bedforms per large bedform) filtering out the shadows becomes impractical and the technique produces large errors. However, as the secondary bedforms become too large to successfully filter their shadows, the bedform field becomes similar to the case of variation in bedform parameters on a flat bed. For secondary bedforms that are a factor of two smaller than the primary bedforms, which is close to the worst case scenario, the error in height is $37 \%$ and an error in asymmetry of $10 \%$. 
Table 2.9: Analytical coefficients for recommended sonar height from the seabed.

\begin{tabular}{lc}
\hline Criteria & $\gamma$ \\
\hline $80 \%$ of bedforms contain shadows & $<0.51$ \\
$30 \%$ of bedform wavelength is illuminated at the midpoint of the shadowed region & $>0.55$ \\
$x_{\text {crit }}$ occurs at the midpoint of the shadowed region & 0.4 \\
\hline
\end{tabular}

\subsection{Method}

\subsubsection{Instrument configuration}

This method relies on data collected from a low-mounted sonar such that shadows exist. To provide better statistical estimates of height and asymmetry, it is recommended that the sonar is mounted such that there is a sufficient number of bedforms with shadows and that the lengths of the shadows are not significantly large compared to the bright return. There is a tradeoff between these two criteria as a very low mounted sonar will produce a large number of bedforms with shadows; however, most of the domain will be shadows with the bright regions very small leading to errors in estimating $S /(B L)$. We recommend that at least $80 \%$ of the bedforms in the domain cast shadows and that at the midpoint of this shadowed region the brightness length is $30 \%$ of the bedform wavelength (Fig. 2-3a shown by the $0.2 x_{\text {sonar }}$ and $0.3 \lambda$ annotations). Additionally, if the bedforms are sinusoidal, the critical length, $x_{\text {crit }}$ described in Section 2.3.1 would ideally be located at the midpoint of the shadowed bedforms (Fig. 2-3a).

The ideal sonar height from the seabed, $H_{i}$, is analytically determined for the three criteria above given the system geometry and assuming symmetric triangular bedforms.

$$
H_{i}=\gamma \frac{h}{\lambda} x_{\text {sonar }}+\frac{h}{\lambda} \lambda
$$

where $\gamma$ varies for each criterion and is shown in Table 2.9. Given these values of $\gamma$, it is recommended that users set $\gamma=0.6$ as the frame on which the sonar is mounted will typically settle a few centimeters resulting in a final $\gamma=0.5$. Additionally, while $h / \lambda$ may be unknown prior to deploying the instrument, typical values are usually 0.1 to 0.15 for wave orbital ripples and 0.05 to 0.1 for current-generated megaripples which can be used as an initial approximation in Eq. 2.19 (Ashley, 1990; Nielsen, 1992). 


\subsubsection{Data analysis steps}

1. Transform the rotary sidescan sonar imagery into xy coordinates using the approximation for horizontal range given in Eq. 2.2.

2. Determine the orientation of the bedforms using either a $2 \mathrm{D}$ fast Fourier transform or variability analysis (Van Dijk and Lindenbergh, 2017; Pluymaekers et al., 2007).

3. Take transects of the backscatter intensity perpendicular to the bedform crest.

4. Remove the background attenuated echo return strength due to beam spreading and attenuation.

5. If secondary bedforms exist on primary bedforms, filter out the secondary bedform shadows.

6. Empirically identify a threshold intensity to distinguish between shadows and bright regions.

7. Compute the distance to the start of each shadow $(L)$, the length of the shadow $(S)$, the wavelength $(\lambda)$, and the length of the bright region ( $B$, from the wavelength and shadow length).

8. Calculate $S /(B L)$ for each bedform, and on each side of the sonar.

9. Plot a histogram of $S /(B L)$ for each side, and determine what central tendency best represents the distribution.

10. Use Eq. 2.7 to calculate the asymmetry, $\alpha$, assuming triangular bedforms and using the central tendency of $S /(B L)$ for each side as obtained in Step 9.

11. Estimate the height for each bedform using Eqs. 2.8 and 2.9 for each side where $\alpha$ is obtained in Step 10 and the values of $S, B, L$, and $\lambda$ exist for each bedform.

12. Plot a histogram of $h_{r}$ and $h_{l}$ and determine what central tendency best represents the distribution.

13. Apply corrections for crest sharpness, scoured seabed and horizontal range using Eqs. $2.13-2.18$, if needed. 
Table 2.10: Operating parameters of sonars used in field validation of the method

\begin{tabular}{|c|c|c|c|}
\hline Instrument & 881L Rotary Sidescan & $\begin{array}{l}\text { 881A 2-Axis } \\
\text { Pencil Beam } \\
\text { Sonar }\end{array}$ & $\begin{array}{c}\text { DT100 } \\
\text { Multibeam } \\
\text { Profiling Sonar }\end{array}$ \\
\hline Location & $\begin{array}{cc} & \text { Columbia } \\
\text { MVCO } & \text { River } \\
& \text { Mouth }\end{array}$ & MVCO & Columbia \\
\hline Elevation $(\mathrm{m})$ & 1.67 & 1.00 & 2.80 \\
\hline Frequency $(\mathrm{kHz})$ & 675 & 1100 & 675 \\
\hline Range (m) & 20 & 4 & 20 \\
\hline Range Resolution (m) & 0.04 & 0.008 & 0.04 \\
\hline Pulse Length $(\mu \mathrm{s})$ & 20 & 10 & 52 \\
\hline Step Size (deg) & 0.3 & 1.2 & $\begin{array}{c}0: 162,3 \mathrm{deg} b / \mathrm{w} \\
\text { beams }\end{array}$ \\
\hline Azimuth Step Size (deg) & $\mathrm{N} / \mathrm{A}$ & 1.6 & 3 \\
\hline Beam Width (deg) & $1.8 \times 20$ & 1.3 & $120 \times 3$ \\
\hline Averaging & 4 sequential scans & none & $\begin{array}{l}8 \text { pings in each } \\
\text { azimuth step }\end{array}$ \\
\hline
\end{tabular}

\subsection{Validation from field data}

The method is validated against wave-orbital ripples and tidally-reversing megaripples in which both a rotary sidescan sonar and bathymetric measuring instruments were deployed. The operating parameters of the different sonars are listed in Table 2.10. The bathymetric data is obtained directly below the quadpod, and the rotary sidescan sonar images up to $20 \mathrm{~m}$ away from the quadpod. While some variations in bedform geometry may occur directly under the quadpod given the interaction of the frame with the flow and an erodible seabed, the bedforms are considered to be similar, permitting the bathymetric instruments to provide ground truth for the method.

\subsubsection{Wave-orbital ripples}

Bedform height and asymmetry were estimated on wave-orbital ripples located in $8 \mathrm{~m}$ water depth approximately $1.3 \mathrm{~km}$ shore-ward from the Martha's Vineyard Coastal Observatory (MVCO) offshore node, an observatory roughly $1.5 \mathrm{~km}$ offshore of the southern coast of Martha's Vineyard. The location is dominated by waves with little-to-no influence of tidal currents. The data was collected in 2007 using a quadpod equipped with both a rotary 

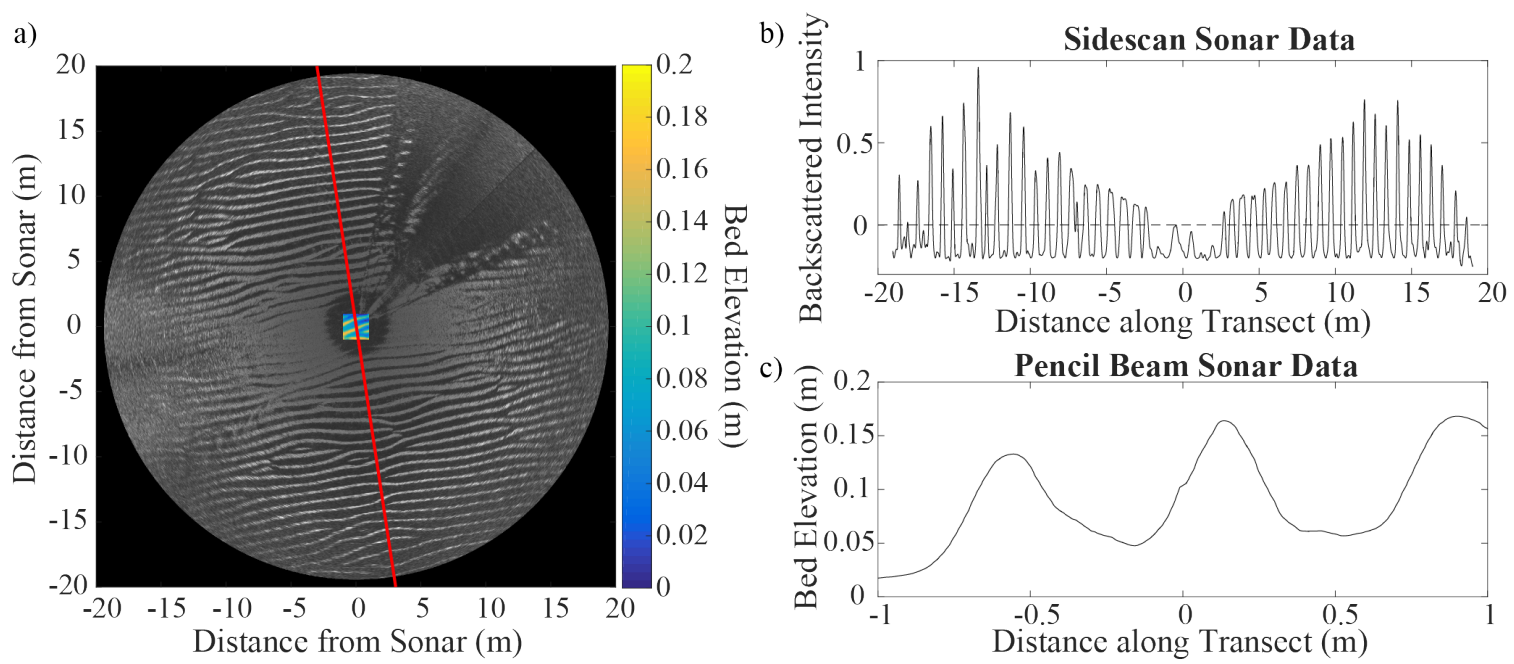

Figure 2-6: a) Rotary sidescan sonar (grayscale) and pencil beam sonar (overlaid color) data of wave-orbital ripples taken on October 5, 2007 at 17:00:00 off the southern coast of Martha's Vineyard. The red line is an arbitrary transect taken perpendicular to the ripple crests. b) Backscatter intensity of sidescan sonar data taken along the transect. The dashed line indicates the threshold used to distinguish shadow and bright regions in the method. c) Bed elevation from a transect along the pencil beam sonar data. The bed elevation is relative to the lowest elevation in the survey area.

sidescan sonar and a two axis pencil beam sonar similar to a data set collected in 2005 and documented in Traykovski (2007) which was also located at MVCO in $12 \mathrm{~m}$ water depth. The sidescan sonar, deployed $1.67 \mathrm{~m}$ from the seabed, captured the backscatter intensity over a radius of $20 \mathrm{~m}$ around the quadpod, and the pencil beam sonar obtained bathymetric data over a $2 \mathrm{~m}$ x $2 \mathrm{~m}$ region directly beneath the quadpod (Fig. 2-6a).

Ripple height and asymmetry were estimated over a 24-day period from the rotary sidescan sonar, and compared to the same parameters obtained from the pencil beam sonar (Fig. 2-7). The height, asymmetry, and wavelength for each bedform were estimated using the method described above for the rotary sidescan sonar. These parameters were computed using a zero-crossing method on the pencil beam data, in which the wavelength was defined as the distance between two troughs, the height was the averaged distance from peak to each trough, and the asymmetry was the horizontal distance from the location of the peak to the trough divided by the wavelength (Fig. 2-6c).

For each time step, the median bedform height, wavelength, aspect ratio $(h / \lambda)$, and asymmetry were computed from the bedforms on multiple parallel transects (Fig. 2-7). The median was used as the measure of central tendency because it is more robust than the mean to skewed distributions and outliers. A 95\% confidence interval for the median 
was computed for bedform height, wavelength, and aspect ratio assuming the median is binomially distributed around the estimated value (Rice, 2002). The $95 \%$ confidence interval for the bedform asymmetry was computed using a 1000-sample bootstrap method, given the interaction of terms in computing the asymmetry parameter. These $95 \%$ confidence intervals are represented by the shaded regions in Fig. 2-7.

Estimates of bedform parameters from the sidescan sonar show good agreement with the computed parameters from the pencil beam sonar (Fig. 2-7). The mean absolute difference in asymmetry between the two instruments is $0.019 \pm 0.021$ (standard deviation) with the mean absolute difference in height of $0.017 \mathrm{~m} \pm 0.016 \mathrm{~m}$ which corresponds to a mean percent error of $34.0 \% \pm 27.2 \%$.

The asymmetry $(\alpha)$ is approximately 0.5 throughout the entire time-series, which is consistent with literature for wave-orbital ripples (Bagnold, 1946; Traykovski et al., 1999). While the estimated asymmetry agrees well with the bathymetric data, the sidescan sonar data tends to overestimate ripple height and wavelength compared to the pencil beam sonar. This discrepancy could be due to the effect of the frame on the seabed and the flow, as the pencil beam sonar measures approximately three bedforms directly below the sonar, and the rotary sidescan sonar (with the shadow method) relies on bedforms $4 \mathrm{~m}$ to $20 \mathrm{~m}$ from the quadpod. The estimated wavelength and bedform height were plotted with respect to distance from the sonar to determine how these parameters vary with distance from the sonar. These plots revealed that the wavelengths linearly increased with distance from the sonar. Although the bedform height increased with distance from the sonar during some time periods, it decreased during others. To better compare the estimated parameters with that from the pencil beam sonar taken directly below the sonar, a linear regression was fit to the data to predict the bedform parameters under the frame as a function of the distance from the sonar. The estimates from the rotary sidescan sonar were then linearly extrapolated to provide an estimate of their values directly under the frame (Fig. 2-7). This extrapolated value accounts for some of the overestimation in bedform wavelength and is also able to capture the sudden decrease in wavelength around October 6th. Studies on the effect of frames on the seabed and flow have shown that in the presence of waves, there is increased turbulence near the frame (Bolaños et al., 2011; Williams et al., 2003). While the results of Bolaños et al. (2011) and Williams et al. (2003) indicate that the frame does not have as large of an effect on the flow and seabed in wave conditions as opposed to strong 
currents, it is hypothesized that this increased turbulence can result in the bedforms under the frame adjusting to a new equilibrium configuration faster than the bedforms away from the frame.

While height and bedform aspect ratio $(h / \lambda)$ estimates agree well during the waning stages of the wave events, there is noise and disagreement in the estimates at the onset and peak stages. A large part of this disagreement is due to the noise in the data from both sonars. During high wave events, suspended sediment obscures the seabed, resulting in noise in the estimates, and little confidence in their estimates. Overall, the method is able to capture the changes in bedform parameters that span multiple large wave events with some of the error being attributed to the assumption of coincident observation areas as well as noise during periods of high suspended sediment.

\subsubsection{Tidally-reversing megaripples}

The method was further tested on tidally-reversing megaripples located at the mouth of the Columbia River which discharges into the Pacific Ocean between Washington and Oregon. This location has large tidally-reversing megaripples that change asymmetry and migration direction with the tides. Traykovski (2015) deployed a quadpod equipped with a rotary sidescan sonar as well as a side-looking multibeam rotary sonar (Fig. 2-8a, b). The rotary sidescan sonar, located $1.1 \mathrm{~m}$ from the seabed, obtained an image of the seabed up to a range of $20 \mathrm{~m}$ while the multibeam rotary sonar observed the bathymetry of the seabed within a $12 \mathrm{~m}$ radius.

Bedform asymmetry and height were estimated from the multibeam sonar by detecting bedform peaks and troughs in transects perpendicular to the bedform orientation (Fig. 28c). Asymmetry was estimated by dividing $c$ by the wavelength, and bedform height was estimated by subtracting the height of the crest from the average height of the trough on each side of the crest. Again, the median was used as the measure of central tendency, and $95 \%$ confidence intervals were obtained from a binomial distribution for the height, wavelength, and aspect ratio with a 1000-sample bootstrap being used to compute the confidence interval for the asymmetry (Rice, 2002).

The asymmetry of the bedforms from the multibeam sonar was then compared to the estimated asymmetry from the rotary sidescan sonar (Fig. 2-9). There is less confidence in the estimates for the Columbia River than for MVCO as there are significantly fewer 

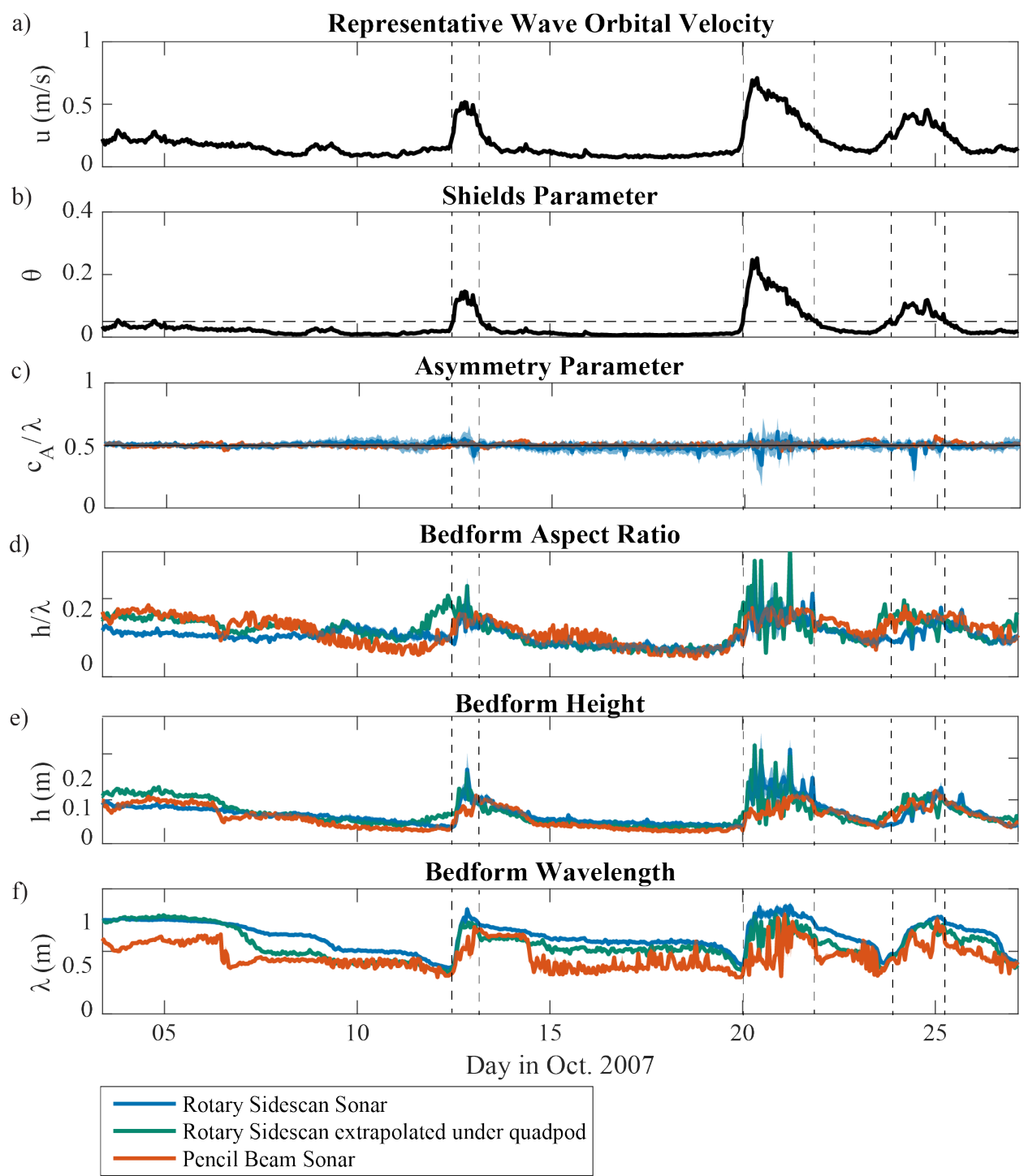

Figure 2-7: Computed wave-orbital ripple parameters from the pencil beam sonar (red) and rotary sidescan sonar (blue) over a 24 day period for bedforms located at MVCO. The shaded regions represent the $95 \%$ confidence intervals of the parameters. The green is the estimation of the bedform parameters directly below the sonar obtained from extrapolating the data from the rotary sidescan sonar. a) Representative wave orbital velocity from an Acoustic Doppler Velocimeter (ADV) located on a nearby quadpod. b) Computed Shields parameter. The dashed line at 0.05 indicates the critical Shields parameter. c) Estimated bedform asymmetry. d) Bedform aspect ratio $(h / \lambda)$ has good agreement between the estimates from the rotary sidescan sonar and pencil beam sonar. e) Bedform height which show an increase in height during large wave events. f) Bedform wavelength. The overestimation of wavelength from the rotary sidescan sonar could be due to the influence of the quadpod on the surrounding flows and seabed. 
a)

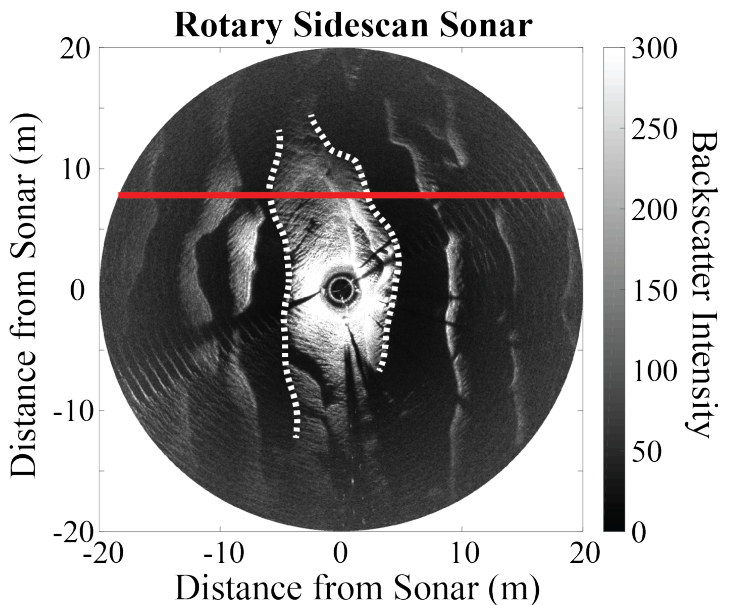

b) Multibeam Sonar

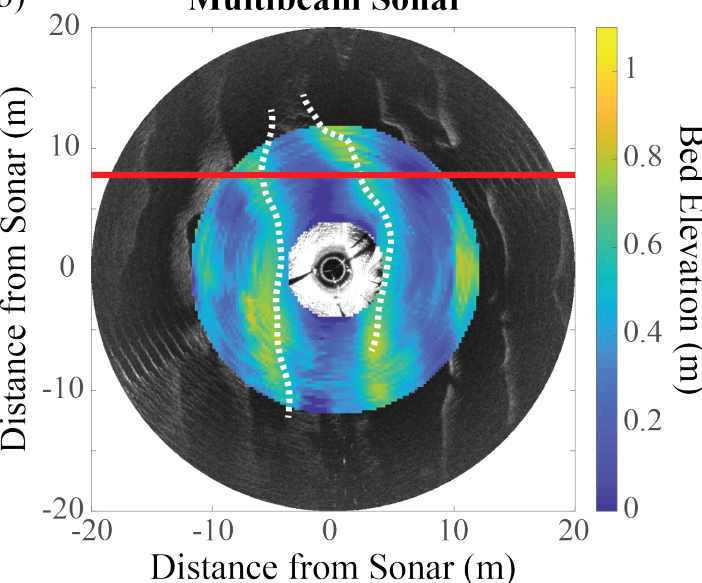

c) $\stackrel{\text { }}{\stackrel{ \pm}{E}} 1$ Rotary Sidescan Sonar

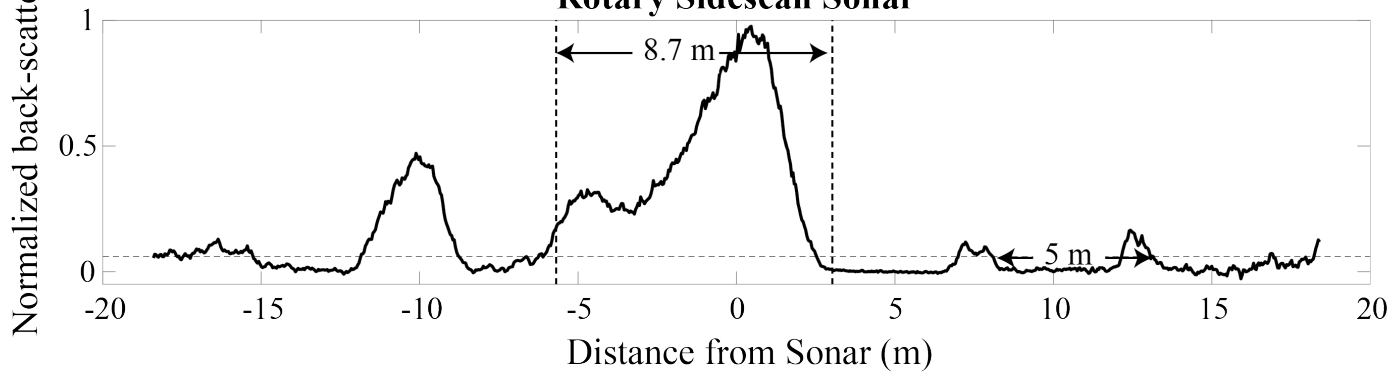

d)

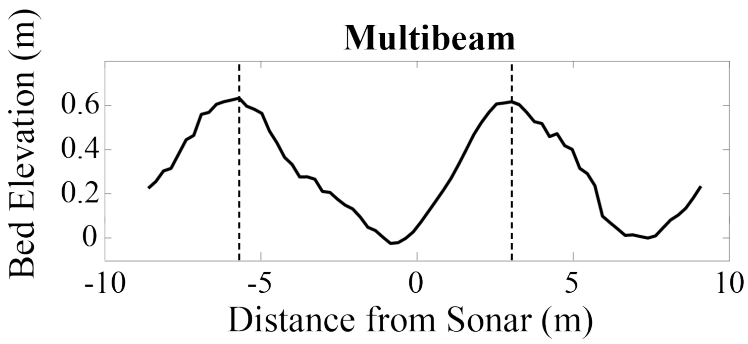

Figure 2-8: a) Rotary sidescan sonar data of megaripples taken on May 10, 2013 at 17:43:18 at the mouth of the Columbia River. The red line is an arbitrary transect taken perpendicular to the bedform crests. The white dashed lines indicate the start of a shadow region closest to the sonar. b) Multibeam data taken at the same time as the rotary sidescan sonar. The white dashed lines are superimposed at the same location on the multibeam data to show agreement in bedform detection from both instruments. c) Backscatter intensity of sidescan sonar data taken along the transect. The horizontal dashed line indicates the threshold used to distinguish shadow and bright regions in the method while the vertical dashed lines indicate the location of the crests in the multibeam data. d) Bed elevation from a transect along the multibeam sonar data. The bed elevation is relative to the lowest elevation in the survey area. 
bedforms in the domain and the bedforms are not as uniform given their two-dimensionality in planview. This two-dimensionality is in part due to the megaripples bifurcating which add to the noise in the data. The method captures the tidal reversal of the bedforms given the asymmetry, and accurately measures the bedform height; however, there are large discrepancies in wavelength and therefore aspect ratio. The almost factor of two difference in wavelength is due to the fact that the multibeam is surveying the bedforms directly under the quadpod, where the wavelengths are larger, while the method considers bedforms far from the frame where shadows are produced and the wavelengths are smaller. The wavelength of the rotary sidescan sonar was computed beneath the frame for the time period considered which shows good agreement in wavelength and aspect ratio with the multibeam sonar (Fig. $2-9 d, f)$. The difference in bedform wavelength in the presence of the frame is hypothesized to be attributed to current-frame interactions. Bolaños et al. (2011) found that underwater frames increase the horizontal velocity under the frame, resulting in a scour pit. Because the megaripple wavelengths are on the same order of size as the frame, it is believed this scour pit alters the bedform morphodynamics such that the wavelengths of bedforms under the frame are larger than those away from the frame.

While the height is accurately estimated most of the time, there is disagreement a few hours before May 11, 2013. During this time, many of the bedforms bifurcated, split and later merged back together. This results in significant changes in the estimates from both the rotary sidescan sonar and the multibeam given the area each instrument surveyed. The lack of periodicity and three-dimensionality of the bedforms at the Columbia River add noise and uncertainty to the method. Overall, the mean absolute difference in asymmetry between the two instruments is $0.11 \pm 0.10$ (standard deviation) with an absolute difference in height of $0.08 \mathrm{~m} \pm 0.07 \mathrm{~m}$ which corresponds to an absolute percent error of $16.6 \% \pm$ $14.7 \%$.

\subsection{Conclusion}

A method is outlined to estimate the height and asymmetry of bedforms from a low mounted sidescan sonar that results in the formation of shadows in the backscattered intensity data. The estimated heights and asymmetry agree moderately well with bathymetry data when applied to both wave-orbital ripples and tidally-reversing megaripples given that bathymetric 
a)

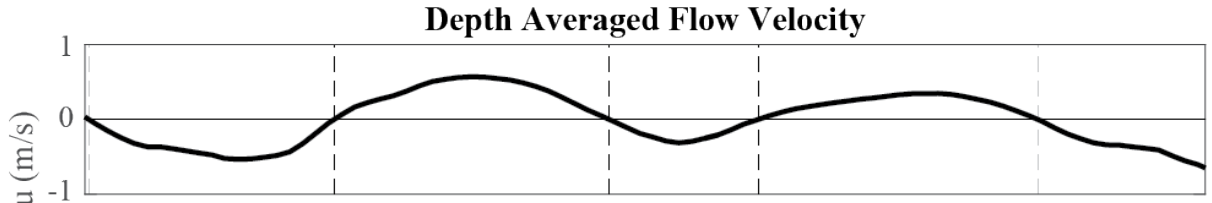

b)

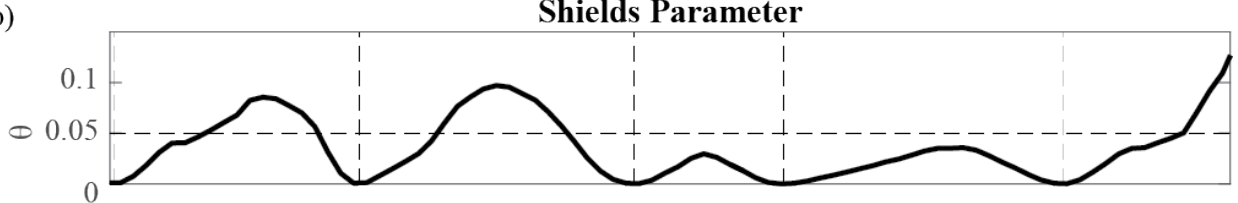

c)

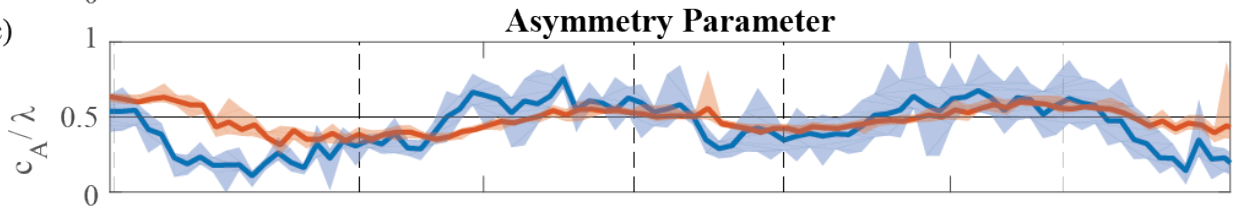

d)

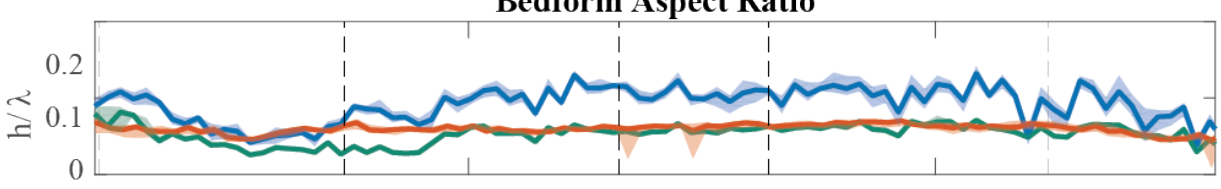

e)

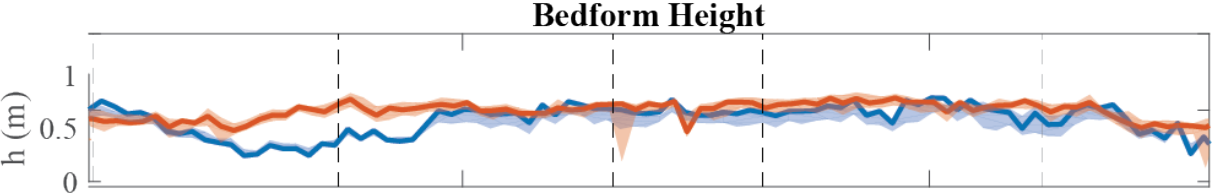

Bedform Wavelength

f)

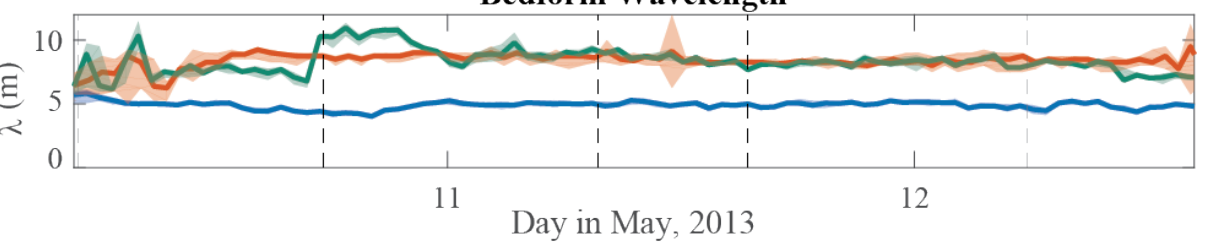

Rotary Sidescan Sonar

Rotary Sidescan under quadpod

Multibeam Sonar

Figure 2-9: Computed megaripple parameters from the multibeam sonar (red) and rotary sidescan sonar (blue) over a 2.5 day period for bedforms located at the mouth of the Columbia River. The green is the estimation of the bedform parameters directly below the quadpod. The shaded regions represent the $95 \%$ confidence intervals of the parameters. a) The depth averaged flow obtained from the same quadpod as the rotary sidescan sonar. b) Computed Shields parameter with the critical Shields parameter indicated by the dashed black line. c) Estimated bedform asymmetry. d) Bedform aspect ratio $(h / \lambda)$ which is overestimated for the rotary sidescan sonar given the underestimation of wavelength, however, when only bedform wavelength directly below the quadpod is considered there is good agreement. e) Bedform height which is in good agreement between the two instruments. f) Bedform wavelength in which the bedforms closest to the sonar have a larger wavelength than those farther from the sonar. 
measurements were taken with much smaller and sometimes different sampling areas than the sidescan sonar measurements.

While this method of estimating bedform parameters was developed based on a uniform bedform distribution, it is reasonably tolerant of small variations in bedform height and wavelength. When there are small bedforms superimposed on larger bedforms, it is recommended that the shadows formed from the smaller bedforms are filtered out in order to estimate the larger bedform parameters. This procedure was tested with idealized numerical data and shows errors of around 10 to $15 \%$ in height and $3 \%$ in asymmetry.

Although idealized cases provide unbiased estimates of asymmetry and height, some bias may exist in field data. Because the ground-truth bedforms from the field are not the same bedforms that are in the field of view of the rotary sidescan sonar, we do not have a way to test this bias in field data. We recommend studying this as future work where we can deploy a rotary sidescan sonar on a quadpod and take collocated surveys with a shipmounted multibeam sonar, or other larger sampling area techniques with high precision, to have the actual height distribution for all bedforms in consideration.

While this method is described for the deployment of a rotary sidescan sonar, it can be applied to other sidescan sonar systems, such as fixed on a frame or ship-mounted, if the geometry from the sonar to the seabed and orientation of the bedforms is known. In the case of a fixed sidescan transducer mounted on a frame, the transducer should be mounted perpendicular to the bedform crests to obtain a single transect of the shadow pattern. Users can then begin the data analysis steps as described in Section 2.4.2 at Step 4. Future work could be taken to modify the method for to ship-mounted sidescan sonars.

The addition of height and asymmetry information to the well documented planform geometry data provided by sidescan sonars has potential to increase the usefulness of such systems in studying the dynamics and properties of bedforms. The high temporal and spatial resolution of an imaging rotary sidescan sonar along with its relatively low costs make rotary sidescan sonars ideal instruments for imaging the seabed in shallow and energetic environments. Utilizing the shadows to provide estimates of bedform height and asymmetry will expand the capabilities of rotary sidescan sonars. 


\section{Chapter 3}

\section{Timescales for morphological response of multi-scale bedforms to a tidally reversing flow}

\subsection{Introduction}

The morphodynamics, or adjustment, of the seafloor in response to hydrodynamic processes has implications for coastal communities, ship navigation, and infrastructure stability. In the presence of waves and currents, an erodible seabed will not remain flat but will develop bedforms (Fredsøe and Deigaard, 1992; Venditti and Church, 2005). Unlike wave-orbital ripples which are symmetric features, the bedforms in tidal environments can be asymmetric with the steeper side of the bedform downstream of the tidal current, or for larger bedforms, downstream of the dominant flow direction. The morphological response of bedforms to an unsteady, tidally reversing flow is analyzed in this chapter with focus on the readjustment of bedform asymmetry.

Despite the societal and environmental importance, the movement of sediment is difficult to quantify given the complex feedback between the flow and a movable seabed (Dalrymple and Rhodes, 1995). Sand represented on the seabed can be transported either as bedload or suspended load (Fredsøe and Deigaard, 1992). Bedload is the movement of sand grains by rolling and sliding along the bed due to friction while suspended load is when the grains are lifted from the bed and carried by the currents (Soulsby, 1997). 
The motion of sediment occurs due to the frictional force exerted by the flow on the seabed, and is commonly expressed as a bed shear stress, $\tau_{0}$. The bed shear stress is this frictional force per unit area and is comprised of three components: skin friction $\left(\tau_{0 s}\right)$, form drag $\left(\tau_{0 f}\right)$, and sediment-transport $\left(\tau_{0 t}\right)$ (Eq. 3.1) (Soulsby, 1997). The skin friction, $\tau_{0 s}$, is produced by the roughness of individual grains. The form drag, $\tau_{0 f}$, is the drag created from the pressure field over bedforms. And $\tau_{0 t}$ is the momentum transfer to mobilized grains (Soulsby, 1997). While all three components contribute to the shear stress, only the skin friction acts directly on sand grains and contribute to their motion.

$$
\tau_{0}=\tau_{0 s}+\tau_{0 f}+\tau_{0 t}
$$

While shear stress is a force per unit area, the bed shear stress is commonly written in terms of a velocity as shown in Eq. 3.2 where $u_{*}$ is the friction or shear velocity and $\rho$ is the density of the fluid. Similar to the bed shear stress, the shear velocity can be broken down into a skin friction, form drag, and sediment transport component.

$$
\tau_{0}=\rho u_{*}^{2}
$$

The total shear velocity can be estimated given the vertical profile of the flow velocity. The velocity of the flow at the seabed must be zero if the seabed is immobile due to the viscosity, or internal friction, of the fluid. Because of this "no slip" boundary condition, a turbulent boundary layer is formed between the seabed and the free stream velocity. Given a turbulence boundary layer, the velocity profile is well established by theory and experiment to be logarithmic and is commonly stated as the "law of the wall" (Eq. 3.3) (Nielsen, 1992; Nikuradse, 1933; Williams, 1995).

$$
U(z)=\frac{u_{*}}{\kappa} \ln \left(\frac{z}{z_{0}}\right)
$$

This vertical profile in velocity is dependent on the bed stress, $\tau_{0}$, through $u_{*}$ and the texture of the seabed which is characterized by a roughness, $z_{0}$. In this velocity profile, $\kappa=$ 0.4 is the von Karman's constant and $z$ is the depth where the velocity, $U$, is considered. The bed roughness length, $z_{0}$, is approximately the height above the bed where the flow is zero and can be estimated as $z_{0}=k_{s} / 30$ for rough turbulent flow which occurs when the grain 
Reynolds number, $u_{*} d_{50} / \nu$, is greater than 70 . The variable $\nu$ is the kinematic viscosity and $k_{s}$ is the Nikuradse roughness length. For a flat seabed the Nikuradse roughness length is commonly taken as $k_{s}=2.5 d_{50}$ where $d_{50}$ is the median grain size diameter.

The amount sediment that can be transported is a function of the force needed to move a grain and the weight of the grain that is resisting this motion (Shields, 1936). The Shields parameter is a non-dimensional number shown in Eq. 3.4 that is used to estimate the initiation of sediment transport and is the ratio of the bed shear stress, $\tau_{0}$, and the weight of the sediment grain where $\rho_{s}$ is the grain density, and $\rho$ is the water density, and $g$ is gravitational acceleration (Shields, 1936). When the Shields parameter, $\theta$, is greater than the critical Shields parameter of approximately 0.05 , the transport of sediment will be initiated.

$$
\theta=\frac{\tau_{0}}{g\left(\rho_{s}-\rho\right) d_{50}}
$$

The amount of sediment that is transported as bed load, by rolling or sliding along the bed, is represented as a bed load sediment transport rate, $q_{b}$. The bedload transport rate can be estimated using the Meyer-Peter and Müeller empirical formula where $s$ is the specific gravity of the sediment, $\theta$ is the non-dimensional Shields parameter, and $\theta_{c}$ is the critical Shields parameter for threshold of motion (Eq. 3.5) (Meyer-Peter and Müller, 1948).

$$
q_{b}=8 d_{50} \sqrt{(s-1) g d_{50}}\left(\theta-\theta_{c}\right)^{\frac{3}{2}}
$$

Substituting the bed shear stress, Eq. 3.2, velocity profile, Eq. 3.3, and Shields parameter, Eq. 3.4, into the Meyer-Peter and Müeller formula results in a bedload transport equation that is proportional to $U^{3}$ for energetic conditions where $\theta>\theta_{c}$. Given this dependence on $U^{3}$, the direction that sediment is transported in tidally energetic environments will reverse directions as the flow switches direction. Depending how much sediment can be transported in a half-tidal cycle, bedforms may reverse their asymmetry and migration direction with the reversing flow. Given the time needed for bedforms to reverse asymmetry and for the Shields parameter to exceed the critical Shields parameter, changes in bedform shape and migration lag changes in flow (Dalrymple and Rhodes, 1995; Allen and Collinson, 1974; Allen, 1976b,a).

Previous studies have observed small bedforms reverse their asymmetry with the flow, 
however, limitations in spatial extent and temporal resolution throughout the tidal cycle, make these studies incomplete (Hoekstra et al., 2004). It has additionally been observed that large bedforms will remain oriented in the direction of the dominant flow, being unable to reverse their asymmetry with the tides (Bokuniewicz et al., 1976; Dalrymple and Rhodes, 1995; Lefebvre et al., 2016). This chapter analyzes the morphodynamic changes of multiple scale, superimposed bedforms using novel observational techniques with the required spatial and temporal resolution to simultaneously observe smaller bedforms superimposed on larger bedforms throughout the tidal cycle.

\subsection{Methods}

\subsubsection{Instrumentation and platforms}

Given the current state of observational techniques, it is difficult to concurrently observe the dynamics of multiple scales of bedforms on tidal timescales. Recent advances in both platforms and instrumentation are detailed below that are capable of achieving the necessary spatial and temporal resolution to observe the morphological response of superimposed bedforms to a tidally reversing flow.

\section{Autonomous jet-powered kayak}

An autonomous jet-powered kayak, referred to as a Jetyak, is a platform capable of collecting high resolution data of the seabed and flow (Fig. 3-1). The following information on the Jetyak specifications is from Kimball et al. (2014) with some aspects of the Jetyak being updated from the specifications outlined in Kimball et al. (2014). The Jetyak is jet driven with a draft of $20 \mathrm{~cm}$ and an air-breathing gasoline engine. Given these features, the Jetyak can travel up to $5.5 \mathrm{~m} / \mathrm{s}$ with 6 to 8 hours of endurance on a single gas tank allowing it to operate in strong currents and shallow environments which makes it an ideal platform for tidally energetic settings where superimposed bedforms are common. The servo that steers the Jetyak is controlled by a pixhawk 2.1 autopilot, allowing the Jetyak to be preprogrammed with Mission Planner software to operate autonomously and accurately follow track-lines in strong cross currents.

The Jetyak is equipped with instruments to measure bathymetry and flow. The data analyzed in this thesis came from two versions of the Jetyak. The first version had a 


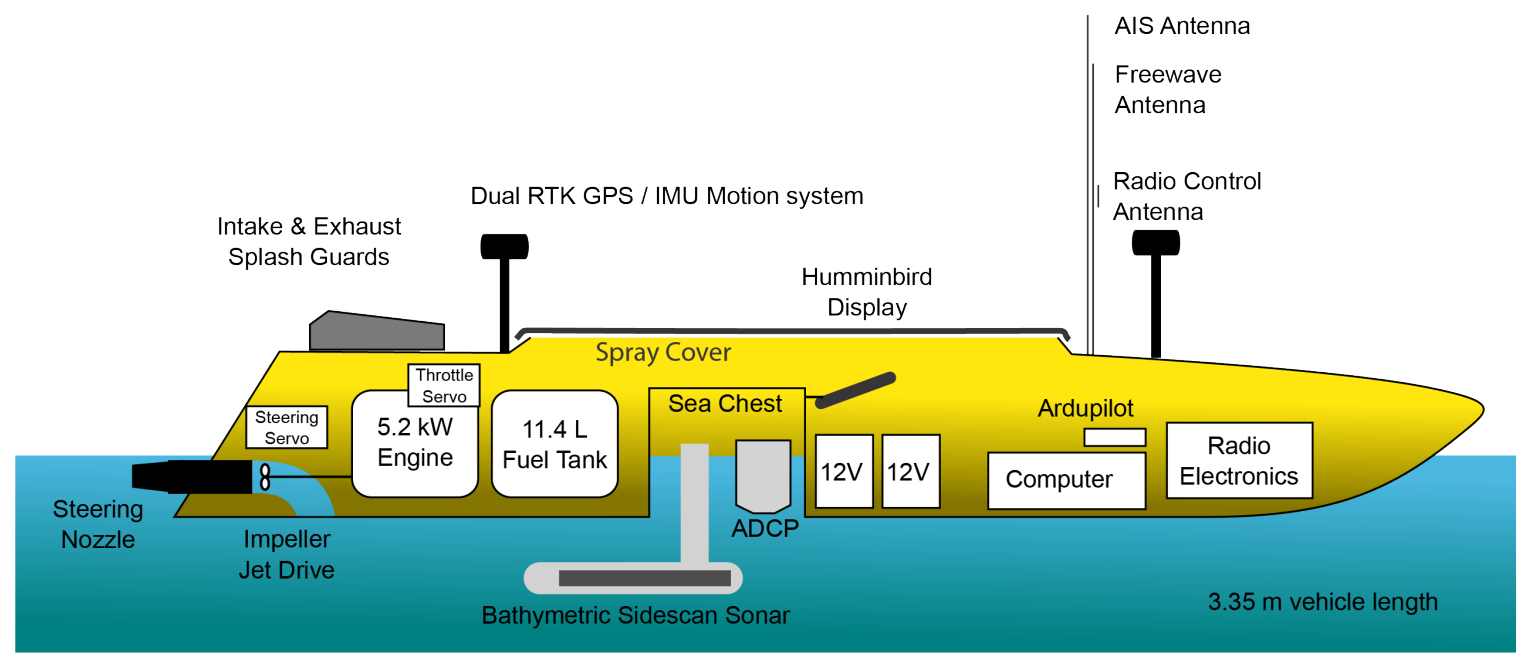

Figure 3-1: Autonomous jet-powered kayak, Jetyak, equipped with a bathymetric sidescan sonar, dual PPK GNSS antennas, and a Nortek Signature 1000 ADCP. The Jetyak is jet-driven and powered by an air-breathing gas engine. In addition to the autonomous capabilities of the Jetyak, a remote controller can be used to drive the Jetyak, communicating via radio control.

Humminbird sidescan and single-beam echosounder. With the single-beam echosounder, the Jetyak was able to obtain bathymetry along the trackline of the Jetyak. The single beam echosound was replaced by a wide swath bathymetric sonar, Ping DSP 3DSS (3D Sidescan Sonar) on the second version Jetyak. The Ping DSP 3DSS is capable of measuring bathymetry in shallow environments with a greater than $10 \mathrm{~cm}$ horizontal resolution over a swath that is 10 times the water depth. The sonar operates at $450 \mathrm{kHz}$ and uses patent pending computed angle of arrival transient imaging (CAATI) interferometry to compute the angle of the returned sonar wave from the target. The CAATI interferometry technique is able to distinguish between targets on the seafloor and in the water column that are at the same range. Due to the wide swath of the bathymetric sonar, the Jetyak heading must be accurate and precise as a slight change in heading on the Jetyak would result in substantial changes in the horizontal location of the return pings from the bathymetric sonar. A dual antenna Post Processing Kinetic (PPK) global navigation satellite system (GNSS) and NovaTel ADIS IMU was integrated on the Jetyak to improve position resolution to 2 to $4 \mathrm{~cm}$ and heading to 0.1 degrees. With the bathymetric Ping DSP 3DSS and dual PPK GNSS antennas, the Jetyak is capable of simultaneously surveying bedforms that range in wavelength from $1 \mathrm{~m}$ to $1000 \mathrm{~m}$. In addition to the bathymetric sonars, both Jetyak versions were equipped with a downward facing Acoustic Doppler Current Profiler (ADCP) 
to measure the velocity throughout the water column. A Nortek Signature 1000 ADCP with $1 \mathrm{MHz}$ frequency and broadband processing was configured to obtain measurements at a sampling rate of $4 \mathrm{~Hz}$ at $0.5 \mathrm{~m}$ bins in the vertical direction over a range of $10 \mathrm{~m}$. The ADCP also collected bottom tracking data to remove the motion of the Jetyak from the flow velocity measurements.

\section{Small unmanned aircraft system (sUAV)}

While the Jetyak equipped with the bathymetric sidescan sonar is capable of measuring the

bathymetry in shallow water, the swath width becomes small when the water depth is very shallow. This small swath width requires tight tracklines in order to survey the area which results in a long survey time. High resolution topography of intertidal environments, where areas are covered by water during high tide but above the water at low tide, can be obtained using a small unmanned aircraft system (sUAV).

This study uses a DJI Phantom 4 Professional quadcopter equipped with a 12 mega-pixel camera to take orthonormal overlapping pictures of the terrain along a preprogrammed flight path. The overlap of these photos allow for the same point to be captured from different views. Given these different views, structure-from-motion (SFM) algorithms can be used to obtain a digital elevation map. In addition to the overlapping images from the quadcopter, a number of ground control points must be deployed throughout the survey domain with their vertical and horizontal location surveyed with a high resolution GPS. Due to the lens distortion of the camera and inaccurate position information of the quadcopter, these ground control points are combined with the topographic map from the quadcopter images. For this study, the SFM computations are performed in the AGI Photoscan commercially available software. Given the flight elevation and camera quality, the elevation map has a horizontal accuracy on the order of $20 \mathrm{~cm}$. For intertidal environments the Jetyak collects bathymetry data during high tide and the quadcopter obtains topography data during low tide. These two datasets are then combined to create a high resolution digital elevation map.

\section{Seafloor frame}

Seafloor frames equipped with acoustic instruments allow for high temporal resolution data of the seafloor and flow at a given location. These underwater frames are commonly equipped with an Imagenex 881L rotary sidescan sonar which produce $40 \mathrm{~m}$ diameter images of the 


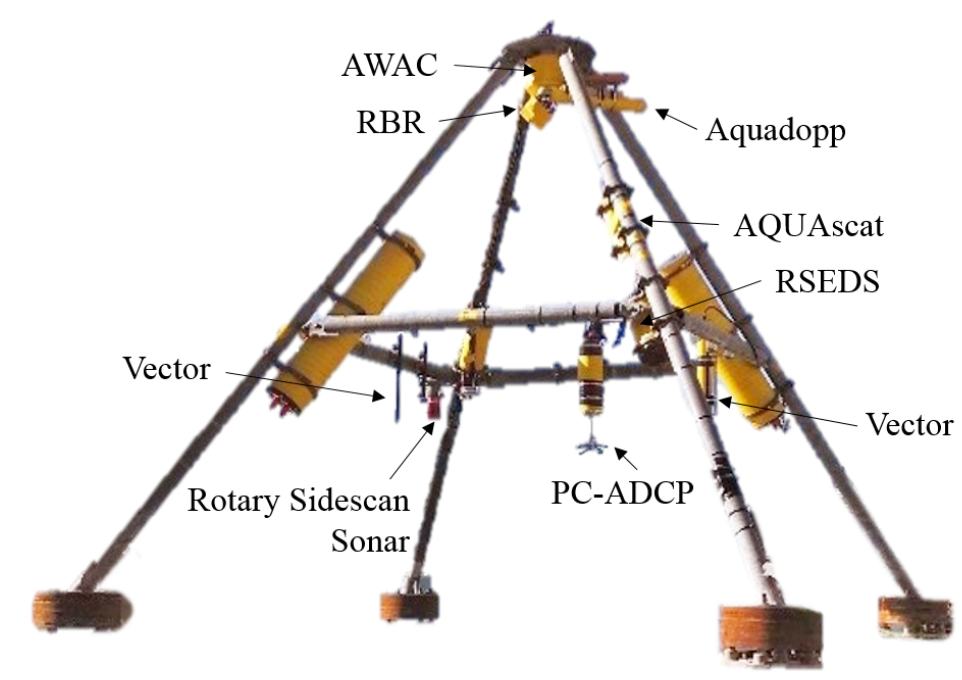

Figure 3-2: Seafloor frame, or quadpod, placed on the seabed off of the southeast corner of Martha's Vineyard. The quadpod is equipped with multiple acoustic and pressure sensors to measure the seabed and local hydrodynamics. The top of the quadpod is approximately $1.25 \mathrm{~m}$ from the seabed.

backscattered intensity of the seabed at $4 \mathrm{~cm}$ resolution every 20 minutes (Fig 3-2). The high temporal and spatial resolution of a rotary sidescan sonar allow for multiple scales of bedforms to simultaneously be observed. In addition to rotary sidescan sonars, Acoustic Backscatter Sensors (ABS) are used to measure the backscatter intensity throughout the water column at a given location. An ABS can therefore be used to obtain the local seabed elevation directly below the seafloor frame. In addition to these acoustic instruments that measure backscatter intensity, the flow velocity is commonly measured using acoustic instruments that utilize the Doppler effect. On the frames in this study, an Aquadopp current profiler measured the vertical velocity at $0.2 \mathrm{~m}$ bins over a range of $2 \mathrm{~m}$. Finally, acoustic doppler velocimeters (ADVs) are used to measure the velocity and wave properties at a single point. A number of other acoustic, optical, and pressure instruments can be mounted on a seafloor frame based on the data needs of a given study.

\subsubsection{Study sites}

Multiple scale superimposed bedforms were observed using the platforms and instruments outlined above at two locations in Massachusetts: Wasque Shoals and Nauset Inlet. Both locations are tidally energetic and have a sufficient quantity of sediment to form bedforms. 

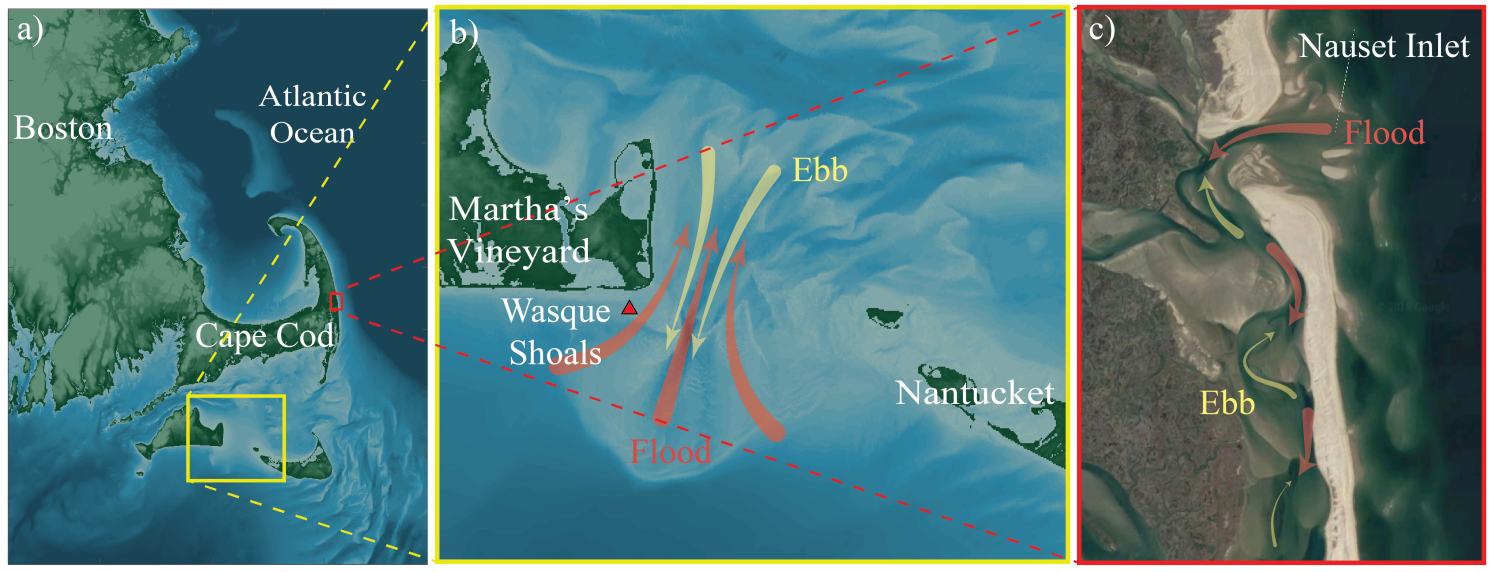

Figure 3-3: a) Digital elevation map of the east coast of Massachusetts obtained from NOAA Coastal Relief. b) Wasque Shoals is located off the southeast corner of Martha's Vineyard, indicated by the red triangle. During flood, water is funneled into the inlet between Martha's Vineyard and Nantucket. During ebb, the water leaves Nantucket Sound as a jet. This creates a flood dominated flow at Wasque Shoals. c) GoogleEarth image of Nauset Inlet. The approximate tidal flow is indicated with the arrows where the flow enters the inlet during flood, weaving its way south around the sandbars. During ebb, the flow is directed north and is weaker in velocity magnitude compared to flood.

\section{Wasque Shoals: Martha's Vineyard, MA}

Wasque Shoals is an ebb delta off the southeast corner of Martha's Vineyard, MA (Fig 3-3).

The flow in this region is tidally dominated and is funneled into the inlet between Martha's Vineyard and Nantucket during flood and shot out like a jet during ebb. This large scale flow pattern is in agreement with idealized theory for horizontal tidal exchange through an inlet (Fig. 3-3b) (Stommel and Farmer, 1952). The study site is indicated by the red triangle in Fig. 3-3b where the water depth is approximately $7 \mathrm{~m}$. Given the horizontal tidal exchange pattern, the flow is asymmetric and flood dominated at the study site as the flow during ebb is separated from the $90^{\circ}$ coastline on the southeast corner of Martha's Vineyard (Hopkins et al., 2017).

\section{Nauset Inlet: Cape Cod, MA}

Nauset Inlet is a waterway connecting the Atlantic Ocean to Nauset Harbor and is located on the Outer Cape Cod, MA (Fig. 3-3c). Nauset Inlet is a dynamic barrier beach system with very shallow, complex sand features. Inlets form in the system due to historic breaches, and once formed, migrate north given the dynamics of the system (Leatherman and Zaremba, 
1986). Inside Nauset Harbor the flow is tidally energetic and asymmetric with a stronger velocity flood tide but longer and weaker velocity ebb tide. There are large sand sheets throughout the system and the water depth is approximately $3.5 \mathrm{~m}$ deep.

\subsection{Observations}

\subsubsection{Wasque Shoals}

The bathymetry from a survey with the Jetyak is shown in Fig. 3-4 where the color is depth referenced to the North American Vertical Datum of 1988 (NAVD 88) which is within $10 \mathrm{~cm}$ of mean tidal level. A transect indicated by the red line depicts large, approximately $80 \mathrm{~m}$ wavelength, dunes that are oriented towards the north-northeast, which is in the direction of the dominant flood flow. The dunes have an asymmetry of approximately 0.8 , where bedform asymmetry is defined as the horizontal distance from bedform crest to trough on the ebb side of the bedform divided by the wavelength, $\alpha=c / \lambda$ (Jones and Traykovski, 2018). Bedform asymmetry will therefore range from 0 to 1 with symmetric bedforms having $\alpha=0.5$. The dunes maintain an asymmetry of 0.8 throughout the tidal cycle, as was observed from three surveys in 2013 and 2014 with the single-beam echosounder on the first version Jetyak.

Superimposed on these dunes are smaller megaripples with a wavelength on the order of $1 \mathrm{~m}$ (Fig. 3-4c). While the Jetyak survey produces a high resolution bathymetric map of the region that is capable of simultaneously observing bedforms that range from $1 \mathrm{~m}$ to $1000 \mathrm{~m}$, it does not capture the tidal dynamics of the system. To detect these shorter time period changes, a seafloor frame, or quadpod, shown in Fig. 3-2, was placed on the seabed at the location indicated by the red triangle in Fig. 3-4b from November 20, 2013 to January 10, 2014. This quadpod had a number of acoustic instruments to measure the flow and seabed including a rotary sidescan sonar which imaged the seabed over a $40 \mathrm{~m}$ diameter area every 20 minutes and an Aquadopp current profiler that sampled the velocity every $0.2 \mathrm{~m}$ vertically at a time interval of 10 minutes. Rotary sidescan sonars provide backscatter intensity of the seabed, however, they do not produce information on the depth. Bedform asymmetry was estimated given the shadow pattern on both sides of the sonar using the method in chapter 2 (Eq. 2.7). The depth averaged velocity and megaripple asymmetry in terms of tidal hour is shown in Fig. 3-5 where the gray shaded region is the standard deviation obtained from ensemble averaging over three tidal cycles. 


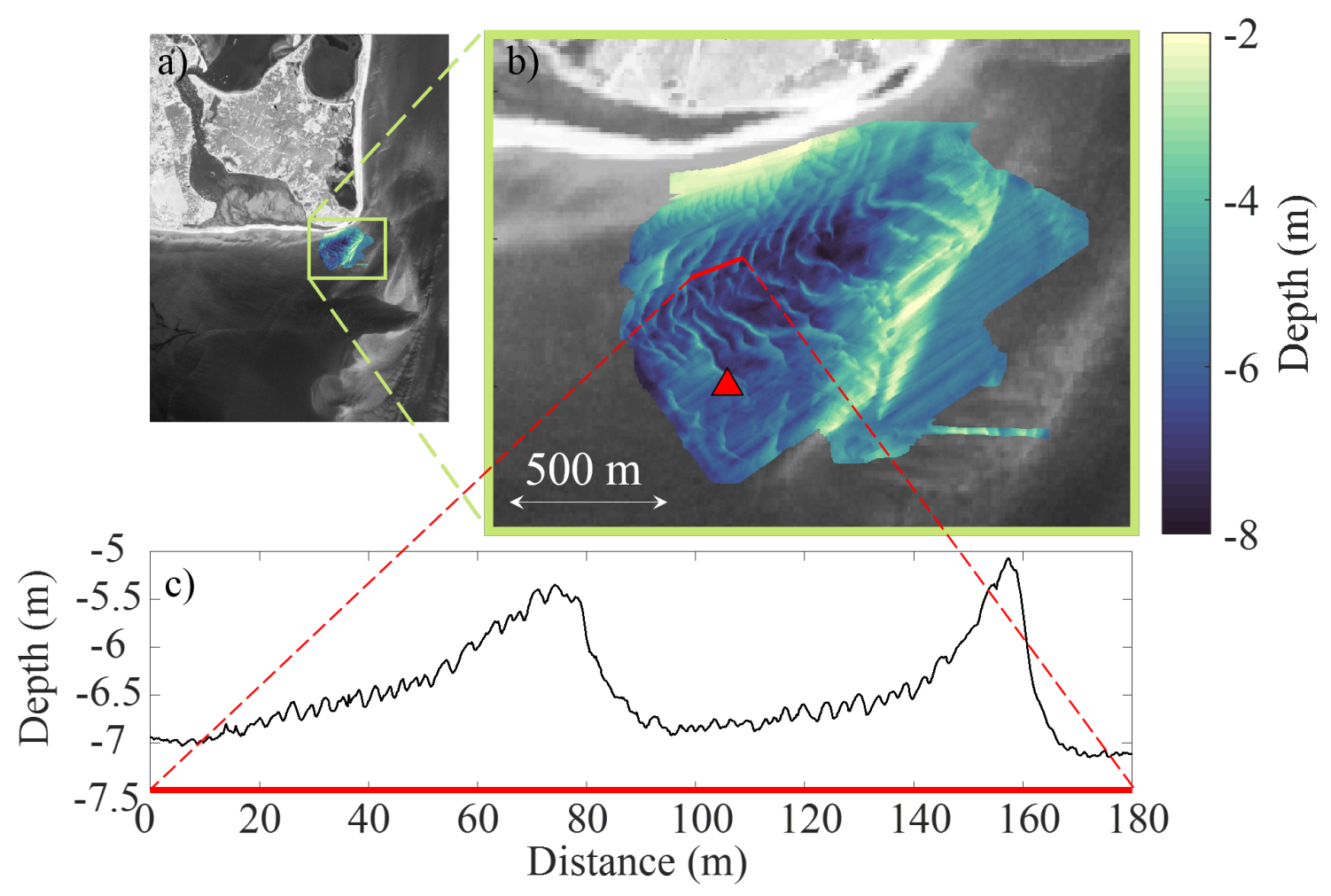

Figure 3-4: a) Greyscale image is a Landsat 8 satellite image of the corner of Martha's Vineyard taken on August 23, 2016. The colored overlay is bathymetry obtained at Wasque Shoals from the bathymetric sidescan sonar equipped on the Jetyak. b) Zoom-in of the Jetyak bathymetric survey conducted in September, 2016 referenced to the NAVD88 vertical datum. c) Transect across two dunes where the $\mathrm{x}$-axis is horizontal distance along the transect and the y-axis is depth. The transect shows flood-dominant asymmetric dunes with a wavelength of approximately $80 \mathrm{~m}$ with smaller megaripples superimposed on the dunes. 


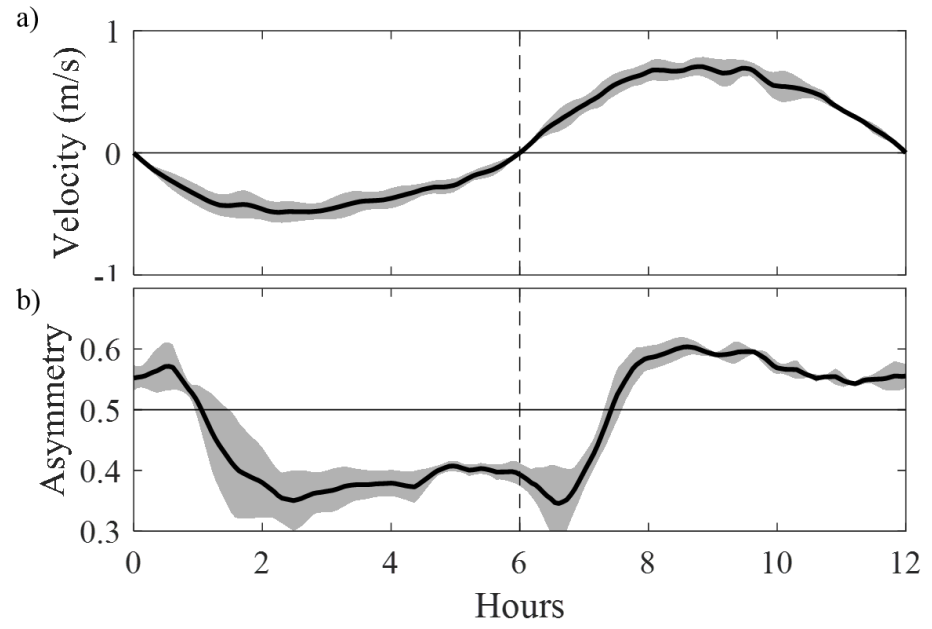

Figure 3-5: a) Depth averaged velocity from an Aquadopp mounted on the top of the quadpod over a tidal cycle. A positive flow velocity is in the direction of flood, or to the north-northeast. The black line is the ensemble averaged tidal velocity between November 28, 2013 and December 1, 2014 while the gray line is the standard deviation. b) Megaripple asymmetry estimated from the shadow pattern of the rotary sidescan sonar. An asymmetry of 0.5 represents a symmetric bedform. The vertical black dashed line is the zero-crossing in velocity.

These data show that megaripple asymmetry is approximately 0.6 during flood and 0.35 during ebb, therefore resulting in slightly more asymmetric megaripples during ebb. Two timescales to represent the lag time in bedform morphology with the flow will be considered in this chapter: (1) the time between slack tide and when the bedforms are symmetric, henceforth referred to as the "phase lag", and (2) the time it takes for the bedforms to change their asymmetry from being oriented in one direction to being orientated in the other direction, referred to as the "morphological lag".

During both flood and ebb the megaripple asymmetry lags the flow with an approximate phase lag of 1.5 hours. Additionally, there is a morphological lag of roughly 2 hours for a bedform to fully reverse asymmetry. While the dunes remain oriented in the direction of flood, the dominant flow direction, the smaller, approximately $1 \mathrm{~m}$ wavelength, megaripples superimposed on top of the dunes reverse their asymmetry with the tides.

\subsubsection{Nauset Inlet}

The lag time of superimposed bedform asymmetry has also been observed at Nauset Inlet (Fig. 3-3c). Using a quadcopter and the Jetyak equipped with a wide-swath bathymetric 


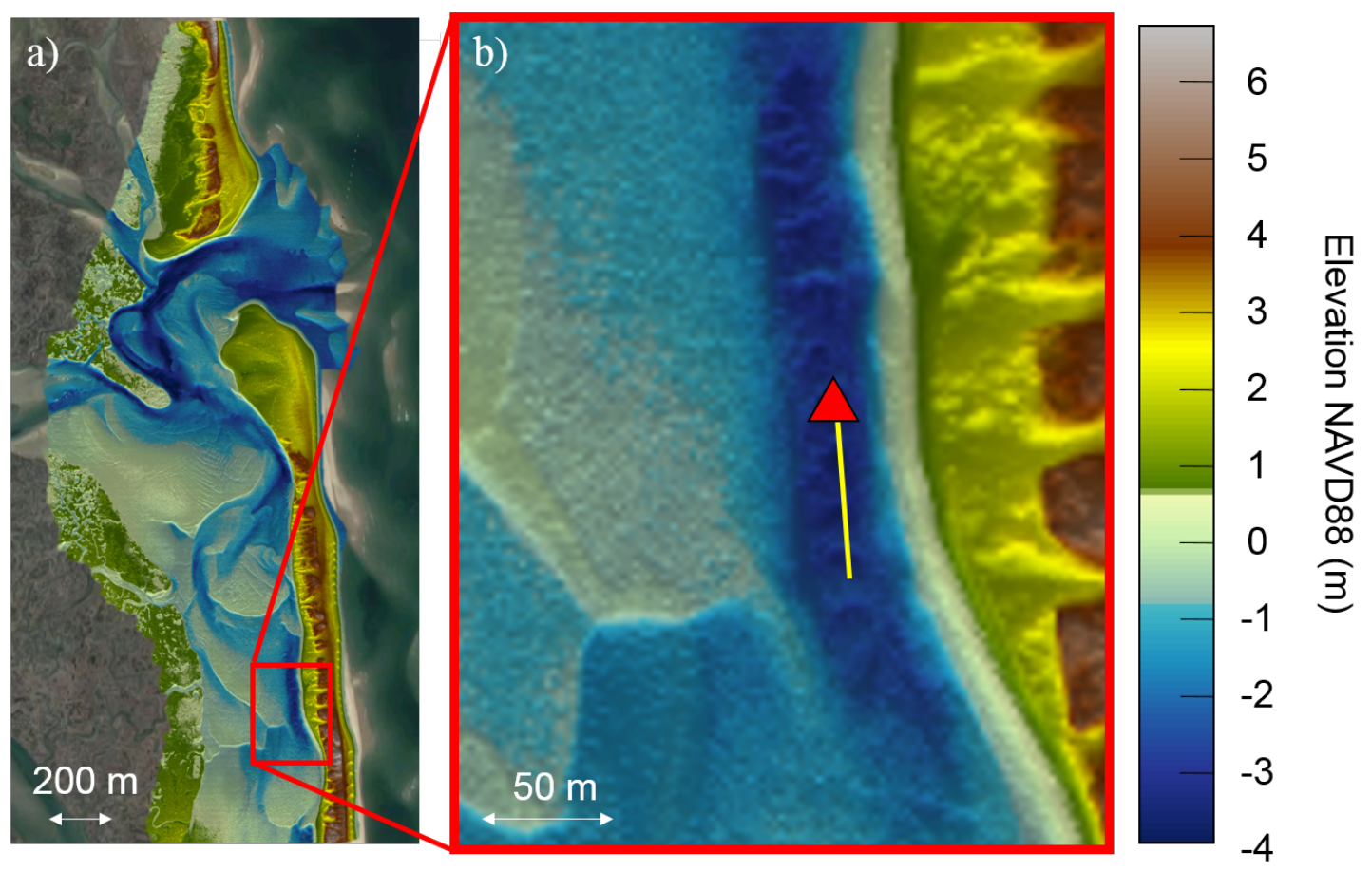

Figure 3-6: a) Google-Earth image of Nauset Inlet with a digital elevation map taken from the quadcopter and Jetyak on November 2, 2017 superimposed in color. The elevation is with respect to the NAVD88 datum. b) Zoom-in of the channel where a tripod, indicated by a red triangle, was located which was equipped with an ADV. The yellow line indicates a transect considered near the tripod.

sonar, a high resolution bathymetric and topographic map of the inlet system was obtained (Fig. 3-6). The quadcopter was flown during low-tide and took multiple overlapping orthonormal photos which were used in structure-from-motion algorithms to construct a digital elevation model. The Jetyak obtained bathymetric information during high-tide. While it takes roughly a day to collect the data needed to create the combined bathymetric and topographic map, the Jetyak would transverse a given area approximately four to five times throughout the bathymetric survey. Therefore, the tidal dynamics of the system can begin to be resolved by considering the individual Jetyak transects. This study considers digital elevation maps obtained from surveys conducted on October 17, 2017 when the flow transitioned from flood to ebb, November 2, 2017 during ebb, and a week later on November 9, 2017, when the flow transitioned from ebb to flood.

In addition to the digital elevation maps a number of in-situ instruments were deployed in the system including a tripod with Acoustic Doppler Velocimeters (ADVs) to measure the flow velocity. This tripod was located in a $3.5 \mathrm{~m}$ deep channel as indicated by the red 


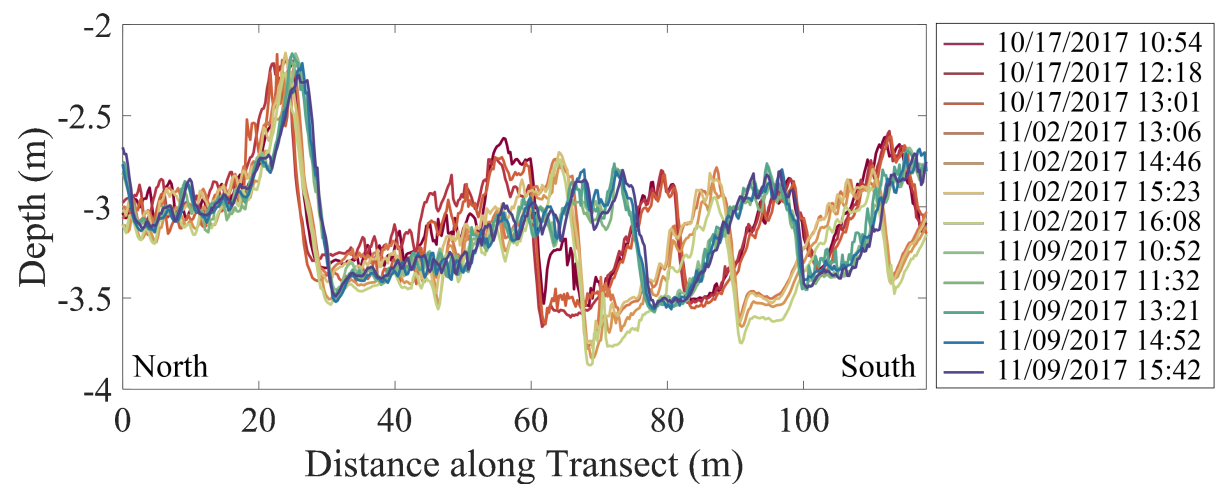

Figure 3-7: Bathymetry from the Jetyak of a transect near the tripod. The different colors are the times the Jetyak was near the tripod with the red-colors taken from a survey on October 17, 2017 where the flow went from flood to ebb, the yellow-colors taken on November 2, 2017 during ebb and the blue-colors taken on November 9, 2017 where the flow went from ebb to flood. The depth is taken with respect to the NAVD88 datum.

triangle in Fig. 3-6b. The tripod was deployed from October 26, 2017 to November 26, 2017 and therefore provided flow information during the two November quadcopter and Jetyak surveys. Tidal predictions outside of Nauset Harbor were used to estimate the time the Jetyak was near the tripod during the October 17, 2017 survey given the tidal phase shift from outside Nauset Harbor to the tripod.

A transect of the seabed near the tripod, indicated by the yellow line in Fig. 3-6b, is shown in Fig. 3-7. The transect is taken with distance from the tripod and the different colors represent the different times the Jetyak was located near the tripod. The red-colors are from the survey taken on October 17, 2017 where the flow went from flood to ebb, the yellow-colors were taken from the November 2, 2017 survey during ebb, and the blue-colors are from the survey taken on November 9, 2017 where the flow transitioned from ebb to flood. The transect in Fig. 3-7 shows approximately $30 \mathrm{~m}$ wavelength dunes with a height of roughly $0.8 \mathrm{~m}$. These dunes migrate and remain oriented towards the south, or in the direction of flood, throughout all surveys with an asymmetry of roughly 0.9 .

A short transect along the top of a given dune reveals megaripples with a wavelength on the order of $3 \mathrm{~m}$ and ripple height of approximately $0.1 \mathrm{~m}$ (Fig. 3-8b-d). During the October $17^{\text {th }}$ survey, the megaripples begin to slightly reorient their asymmetry towards the north, or to the left in the figure, in addition to migrating towards the north (Fig. 3-8b). As the ebb flow begins to peak, the megaripples realign their asymmetry from being oriented towards the south to towards the north during the November $2^{\text {nd }}$ survey (Fig. 3-8c). On 

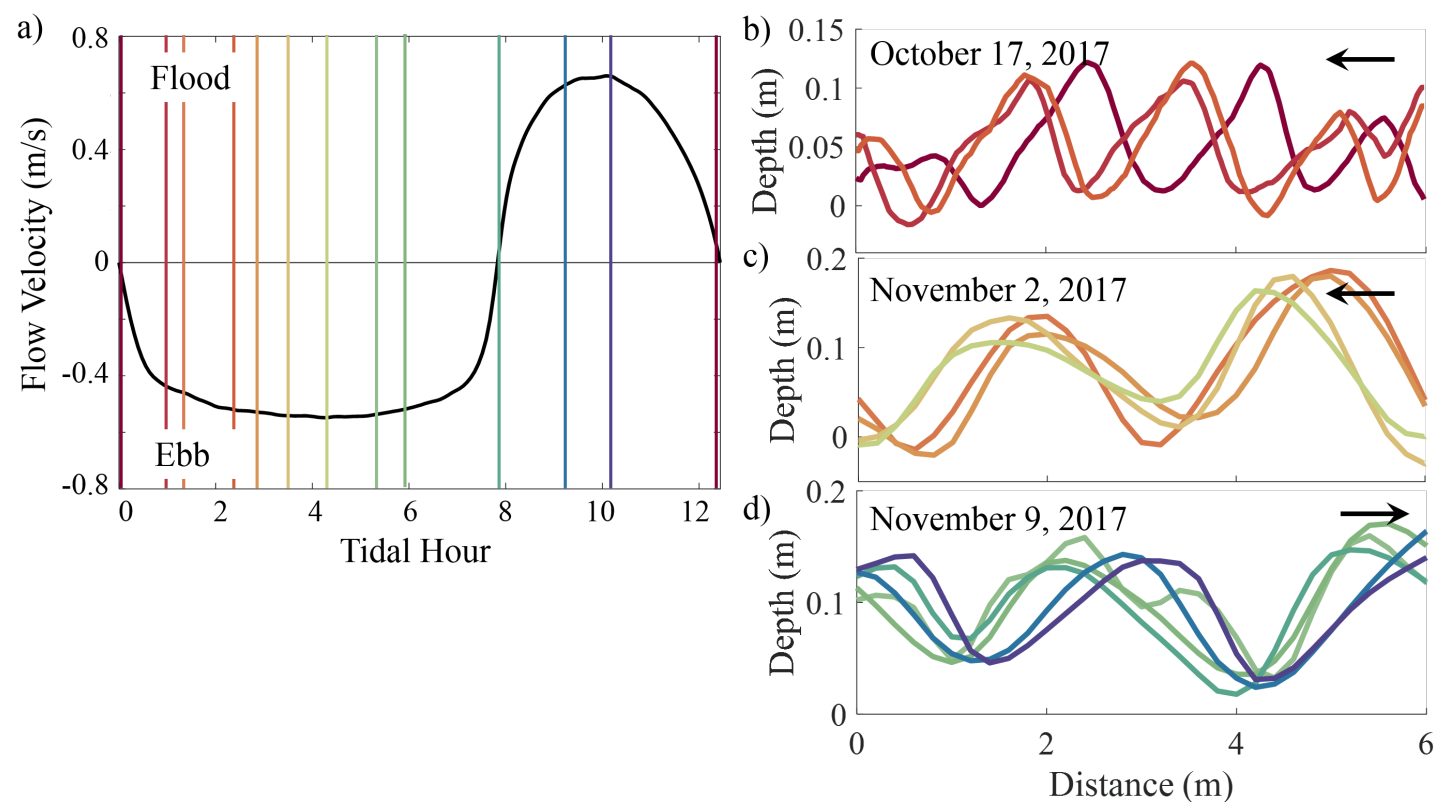

Figure 3-8: a) Flow velocity at the tripod in Fig. 3-6b. Positive values are during flood where the flow is going towards the south, and negative values are during ebb as the flow goes to the north. The colored lines are the times the Jetyak was near the tripod. b) Bathymetry obtained from the Jetyak relative to NAVD88 for October 17, 2017 survey where the flow transitioned from flood to ebb. c) Bathymetry of megaripples from November 2, 2017 during ebb. d) Bathymetry from November 9, 2017 survey as the flow went from ebb to flood.

November $9^{\text {th }}$, the opposite reversal is observed as the megaripples asymmetry realigns from being oriented towards the north to towards the south as the flow reverses from ebb to flood (Fig. 3-8d).

The megaripple asymmetry was directly computed from the bathymetry each time the Jetyak was near the tripod by dividing the distance from the bedform crest to the northern trough by the wavelength. This asymmetry along with the tidal flow obtained from an ADV approximately $1 \mathrm{~m}$ from the seabed in terms of tidal hour is shown in Fig. 3-9. The symbols in the megaripple asymmetry plot are the mean and the vertical lines are the standard deviation where the bathymetry of approximately 40 megaripples were considered. From this plot, it is apparent that the megaripple asymmetry reversal lags the flow reversal with a phase lag of approximately 2.5 hours during ebb and 1 hour during flood. This asymmetric lag is most likely due to the asymmetric flow at this location. Unlike the megaripples at Wasque Shoals, the megaripples take a longer time to reverse asymmetry with a morphological lag time of approximately 4 to 5 hours during ebb and approximately 3 to 4 hours during flood. 
a)
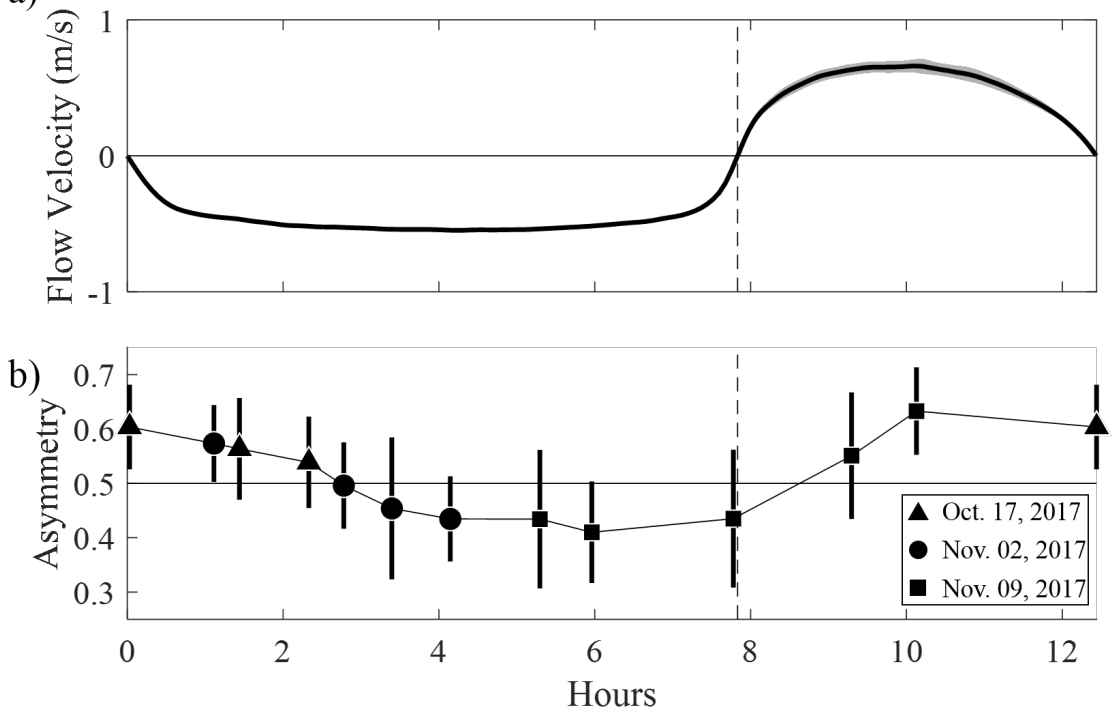

Figure 3-9: a) Average flow velocity over 34 tidal cycles at the tripod taken between November 1, 2017 and November 18, 2017. Positive values are during flood where the flow is going towards the south, and negative values are during ebb as the flow goes to the north. b) Megaripple asymmetry given multiple transects of megaripples near the tripod. The symbols represent the average asymmetry while the vertical lines are the standard deviation. The vertical black dashed line represents slack tide between ebb and flood.

\subsection{Morphological lag time theory}

In a current driven flow, bedforms are asymmetrical in cross-section with a steeper slope on the downstream, or lee, side of the bedform (Soulsby, 1997). When a current reverses direction, the bedform asymmetry may re-equilibrate with the flow depending on the amount of sediment that can be transported in a half-tidal cycle and the size of the bedform. Bokuniewicz et al. (1976) relates the time it takes for a bedform to reach a new equilibrium, or the morphological lag time, with the volume of sediment that needs to be moved divided by the bedload transport rate. Assuming a triangular bedform, this equation simplifies to Eq. 3.6 where $q_{b}$ is the bedload sediment transport rate, which can be estimated by the Meyer-Peter and Müeller empirical equation (Eq. 3.5), $\lambda$ is the bedform wavelength, $h$ is the bedform height, and $\delta=\alpha_{2}-\alpha_{1}$ is the change in asymmetry (Fig. 3-10).

$$
T_{r}=\frac{A}{q_{b}}=\frac{\lambda \delta h}{2 q_{b}(1+\delta)}
$$

Substituting Eqs. 3.2 - 3.5 into Eq. 3.6 results in an equation for the morphological lag time that is inversely proportional to $U^{3}$ and proportional to $\lambda^{2}$ when assuming a constant 


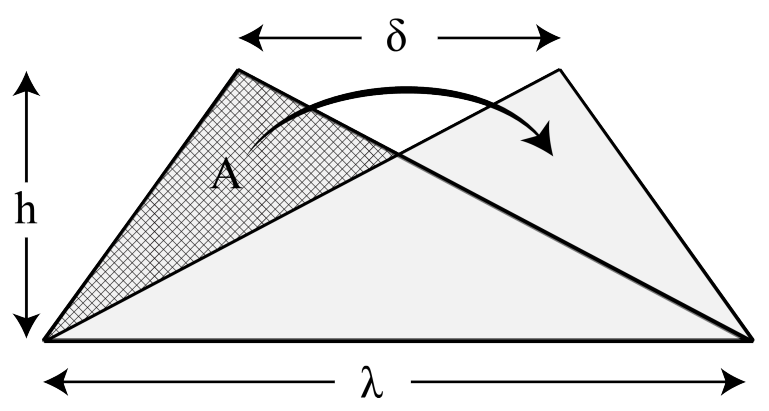

Figure 3-10: Geometric representation of sediment transport needed to change bedform asymmetry which is used in computing the morphological lag time. $A$ is the area of sediment that must be moved, $\delta$ is the change is asymmetry, $h$ is the bedform height, and $\lambda$ is the bedform wavelength.

bedform aspect ratio $h / \lambda$. Therefore, large bedforms will not be greatly impacted by shortperiod variations in the flow as the amount of sediment that can be transported in that given time is substantially smaller than the scale of the bedform (Bokuniewicz et al., 1976). In these cases, the larger bedforms will remain facing the direction of the dominant flow and can therefore be used as an indication of the net circulation pattern (Bokuniewicz et al., 1976; Dalrymple and Rhodes, 1995). Smaller bedforms, however, will equilibrate with the flow and can reach a lee slope near the angle of repose of around 30 degrees (Dalrymple and Rhodes, 1995).

The morphological lag time was estimated with respect to bedform wavelength using the simple geometric model in Eq. 3.6 and the Meyer-Peter and Müeller empirical formula for the bedload transport rate (Fig. 3-11). A flow velocity of $0.6 \pm 0.1 \mathrm{~m} / \mathrm{s}$ was considered which is approximately the flow observed at both Wasque Shoals and Nauset Inlet along with two aspect ratios of $h / \lambda=0.1$ and 0.04 . These aspect ratios are consistent with the bedform parameters observed from the bathymetric sidescan sonar at Nauset Inlet $(h / \lambda=0.04)$ and from applying the method in chapter 2 to the rotary sidescan sonar data at Wasque Shoals $(h / \lambda=0.1)$. Finally, a change in asymmetry, $\delta=0.1$ was considered.

The plot of morphological response time versus bedform wavelength depicts a longer response time for slower flows (Fig. 3-11). Additionally, the smaller the aspect ratio, the shorter the response time for a given wavelength. This is intuitive as less sediment would need to be moved for short bedforms compared to tall bedforms.

The morphological response time for $\delta=0.1$ was estimated from the observations at both Wasque Shoals and Nauset Inlet during flood and ebb and compared with the geometric 


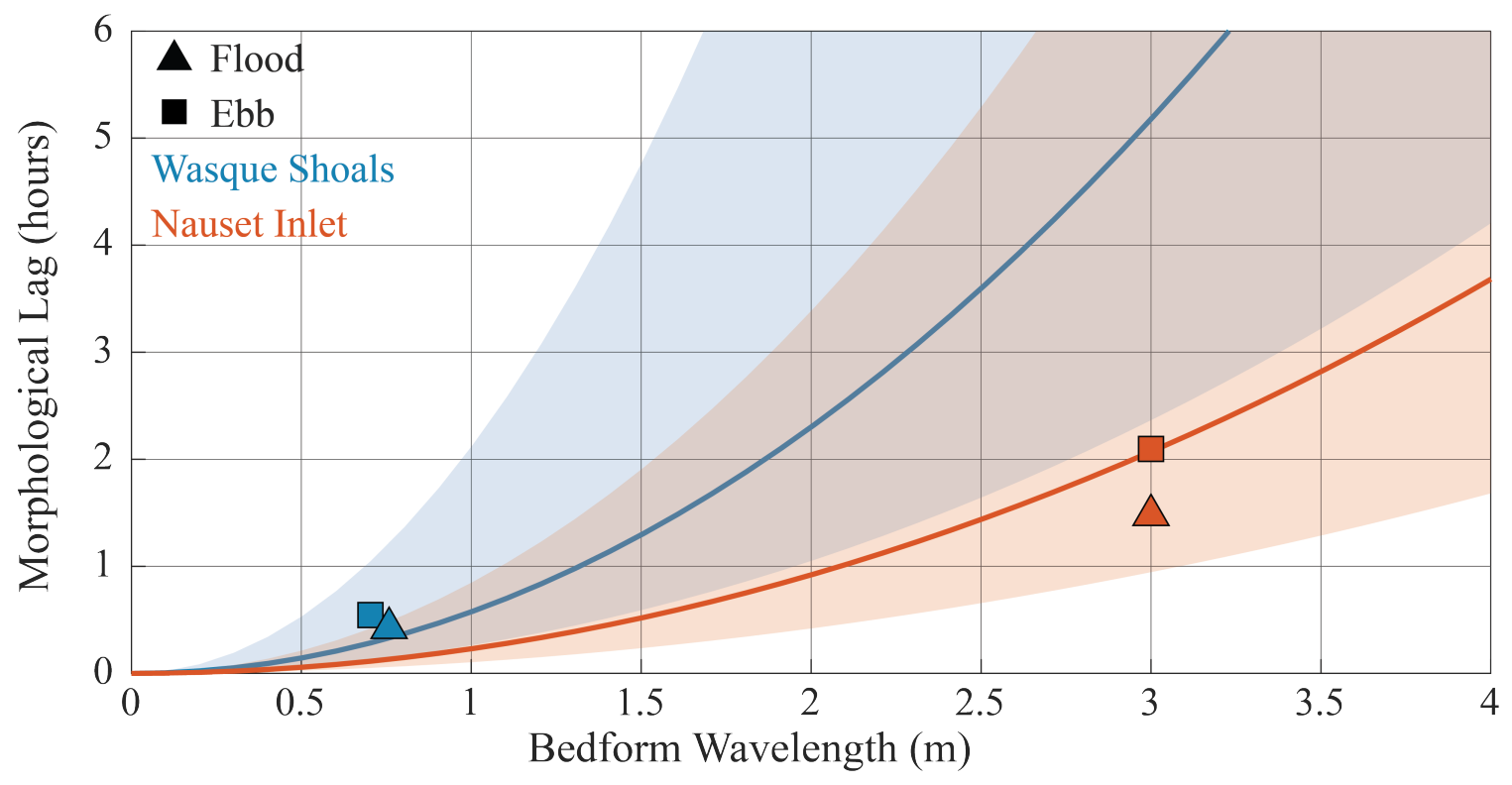

Figure 3-11: Morphological lag time versus bedform wavelength for a change in bedform asymmetry of $\delta=0.1$ from $\alpha=0.45$ to $\alpha=0.55$. The solid line with shading is the estimated morphological lag time from a simple geometric model, Eq. 3.6, using the Meyer-Peter and Müeller empirical formula for bedload transport rate. The shaded regions represents a velocity range from 0.5 to $0.7 \mathrm{~m} / \mathrm{s}$ with the solid line the morphological lag time given a flow velocity of $0.6 \mathrm{~m} / \mathrm{s}$. The blue line is the estimated morphological lag time for a bedform aspect ratio of 0.1 , the aspect ratio observed at Wasque Shoals, while the red line is the estimated lag time for a bedform aspect ratio of 0.04 , the megaripple aspect ratio at Nauset Inlet. The morphological lag time was directly computed from the asymmetry data for flood, indicated by a triangle, and ebb, indicated by a square, at both Wasque Shoals and Nauset Inlet for a change in asymmetry between 0.45 and 0.55 .

model. These response times are plotted on Fig. 3-11, indicated by the squares and triangles, given a bedform wavelength of approximately $0.7 \mathrm{~m}$ at Wasque and $3 \mathrm{~m}$ at Nauset. The response time is very similar between flood and ebb at Wasque Shoals, whereas the ebb response time is substantially larger than the flood response time at Nauset Inlet. This difference is most likely due to the higher velocities during flood compared to ebb at Nauset Inlet which is in agreement with the geometric model (Eq. 3.6).

\subsection{Conclusion}

With new observational techniques, the morphodynamics of multiple scale superimposed bedforms were observed. These platforms and instruments, along with utilizing the method described in chapter 2, were able to capture the response timescale of megaripple asymmetry 
and the dunes on which they are superimposed in the presence of a reversing flow. The morphological lag time due to changes in bedform asymmetry is in agreement with a simple theory for the lag time based on the volume of sediment that needs to be transported and the bedload transport rate.

The observations show that in tidal flows on the order of $0.6 \mathrm{~m} / \mathrm{s}$, smaller megaripples with a wavelength of $1 \mathrm{~m}$ will reverse their orientation while the larger dunes $(30 \mathrm{~m}<\lambda)$ on which they are superimposed will remain oriented in the direction of the dominant flow. The smaller megaripples at Wasque Shoals with $\lambda=1 \mathrm{~m}$ reverse their asymmetry with a morphological lag time of approximately 2 hours. This is faster than the megaripples, $\lambda=$ $3 \mathrm{~m}$, at Nauset Inlet which have a morphological lag time of approximately 4 hours. This is in agreement with morphological lag time theory as larger bedforms require more sediment to be transported in a half tidal cycle in order to reverse their asymmetry (Eq. 3.6).

At Wasque Shoals the megaripple asymmetry lags the flow with a phase lag of approximately 1.5 hours while at Nauset Inlet the megaripple asymmetry lags the flow by approximately 2.5 hours as the flow begins to ebb and 1 hour as the flow begins to flood. This time from slack tide to when the megaripples are symmetric may therefore be more dependent on tidal current velocity than the bedform geometry.

Overall, this novel dataset provides information on the response of bedform morphology to a non-steady reversing flow. Larger bedforms maintain oriented in the direction of the dominant flow and are therefore orientated against the flow for half the tidal cycle and with the flow for the other half of the tidal cycle. The smaller megaripples superimposed on the dunes, however, reverse their orientation, slightly lagging the tidally reversing flow. This response time of bedforms to a tidally reversing flow may have implications for the seabed roughness felt by the flow as flow separation around bedforms increases seabed roughness (Fredsøe and Deigaard, 1992; Lefebvre et al., 2013). Accurately estimating the roughness of the seabed in the presence of bedforms is crucial to hydrodynamic numerical modeling efforts where bedforms may not be fully resolved but rather the roughness due to the bedforms is parameterized (Williams, 1995). The roughness due to bedforms is commonly parameterized using an empirical equation dependent on bedform height and wavelength but not asymmetry (Grant and Madsen, 1982). Given that both megaripple and dune asymmetry were fully observed throughout the tidal cycle, these novel observations can be used in a numerical model to address the possible effect of bedform asymmetry on 
form drag.

The effect of bedform asymmetry on the seabed roughness can further be explored given pressure measurements from seafloor frames and sea-surface elevation from the Jetyak. A drag coefficient which quantifies bed roughness can be determined by balancing friction, advection, and pressure in the momentum equation. These quantities have been obtained from field campaigns at both Wasque Shoals and Nauset Inlet and can be used in combination with the above numerical modeling to further address the effect of superimposed asymmetric bedforms on the surrounding hydrodynamics. 


\section{Chapter 4}

\section{Interaction of superimposed}

\section{megaripples and dunes in a tidally energetic environment}

\subsection{Introduction}

Superimposed bedforms, where smaller bedforms exist on top of larger bedforms, are ubiquitous to nearshore, tidally energetic environments. Bedforms tend to scale with some combination of water depth, grain size, and flow velocity (Dalrymple and Rhodes, 1995). Therefore, the simultaneous existence of multiple scales of bedforms in a given location has given rise to several different theories for the existence of superimposed bedforms in an effort to understand this contradiction to the bedform scaling theories.

Two prior explanations exist for the simultaneous existence of multiple scales of bedforms; equilibrium superposition and disequilibrium superposition. In disequilibrium superposition, large bedforms are hypothesized to be formed from large flood events or strong flows while smaller bedforms form during calmer periods. The different scaling hierarchies therefore act independently, only existing together due to the large response time of the dunes (Dalrymple and Rhodes, 1995). In Allen and Collinson (1974) it was concluded that only the smallest scale bedform is expected to be active at a given time from field work in a river where disequilibrium superposition was assumed to be the explanation for superimposed bedforms. In equilibrium superposition, the boundary layer of the dunes cause the formation of the 
smaller bedforms (Dalrymple and Rhodes, 1995). A numerical study of dune generation observed smaller bedforms forming on the stoss side of large dunes due to a slight deflection on the dune stoss slope which is in agreement with equilibrium superposition (Doré et al., 2016). In both equilibrium and disequilibrium superposition, however, the smaller bedforms do not influence the larger scale features.

While these theories on the existence of superimposed bedforms suggest that the multiple scales simply coexist, more recent studies have hypothesized that the different scales of bedforms interact although this interaction is still poorly understood (Doré et al., 2016). Off (1963) believed there should be a relation between sand waves and tidal current ridges, however, due to a lack of accurate surveys, this relation could not be quantified. Further work on tidal ridges similarly hypothesized that offshore tidal ridges are made from the accretion of cross-beds formed by dunes (Lobo et al., 2010; Reynaud and Dalrymple, 2012). More recently, Lefebvre et al. (2013) suggested that smaller bedforms may be influencing the dunes on which they reside. Laboratory studies of superimposed bedforms in unidirectional flows concluded that the sediment transport of the smaller features may influence the sediment transport of the larger bedforms, however, this hypothesis was not validated (Venditti et al., 2005). Finally, numerical modeling studies on nonlinear bed development in a unidirectional flow show smaller bedforms migrating faster and eventually merging with the larger bedforms in the domain (Doré et al., 2016). When there were superimposed bedforms on dunes, this study found that the superimposed bedforms eventually promoted the decaying of the dune crest (Doré et al., 2016). While these past studies hypothesize the interaction of the different scales of bedforms that make up a superimposed bedforms, they lack the field data needed to quantify and validate this hypothesis.

Using novel observational techniques, the migration rate of multiple scales of bedforms can be simultaneously observed, providing insight into the interaction of different scales of bedforms. The migration rate of bedforms in a uniform flow and energetic conditions where the Shields parameter, $\theta$, is greater than the critical Shields parameter is proportional to $U^{3}$ and inversely proportional to bedform height, $h$ (Simons et al., 1965; Fredsøe and Deigaard, 1992). For a given flow velocity, $U$, larger bedforms will therefore migrate at a slower rate than smaller bedforms. As a result of the differential migration rate from bedform migration theory, the smaller megaripples superimposed on the dunes will consequently migrate faster than the dunes on which they reside (Dalrymple and Rhodes, 1995; Dalrymple, 1984; Rubin, 
1987).

In tidally energetic environments where the flow reverses direction, there may be enough sediment transport for the smaller bedforms to reverse their asymmetry and migration direction; however, the larger bedforms may not be able to reverse their migration direction (Bokuniewicz et al., 1976). This results in a complex migration pattern where the larger bedforms are slowly migrating in the direction of the dominant flow, while the smaller bedforms superimposed on them are migrating back and forth with the tides.

In addition to the tidally reversing flow, the presence of the larger bedforms may also impact the smaller bedform migration. In nearshore environments, the large height of bedforms relative to the water depth may significantly influence the surrounding flow and subsequent smaller bedform migration. The Bernoulli equation, which conserves energy, predicts flow acceleration over bedform crests given the smaller water depth. These larger velocities over the dune crests may influence the migration rate of the smaller bedforms as bedform migration is roughly proportional to $U^{3}$ (Simons et al., 1965; Fredsøe and Deigaard, 1992). Additionally, when bedforms have a steep lee face, the flow may separate forming a wake. This wake may result in the net migration of smaller features in the opposite direction of the free stream flow (Winter et al., 2008). Therefore, the presence of a larger bedform may impact the migration rate of smaller superimposed bedforms.

Using the novel observational techniques outlined in section 3.2.1, the migration of multiple scales of superimposed bedforms were observed. Given the high spatial and temporal resolution of these new techniques, a spatial variation in migration rate of the megaripples as a function of distance along the dunes was observed. Based on size dependent bedform migration rate scaling, a new conceptual model on the interaction of multiple scales of bedforms in a tidally energetic environment is presented. This conceptual model suggests that smaller bedform migration serves as an intermediate step between grain-scale transport processes and larger scale bedform migration.

\subsection{Observations}

Data was obtained from Wasque Shoals, located off the southeast corner of Martha's Vineyard, MA, using the field observational platforms and instruments outlined in chapter 3 (Section 3.2.1, Fig. 3-3b). The flow at Wasque Shoals is tidally energetic and flood domi- 
nant with the seabed consisting of approximately $80 \mathrm{~m}$ wavelength dunes with roughly $1 \mathrm{~m}$ wavelength megaripples superimposed on them (Fig. 3-4).

\subsubsection{Dunes}

Three bathymetric surveys were obtained from a single-beam echosounder equipped on the Jetyak taken over a nine month period on October 16, 2013, January 10, 2014, and January 10, 2014. The survey covered a $400 \mathrm{~m} \times 800 \mathrm{~m}$ area with tracklines spaced roughly $30 \mathrm{~m}$ apart. An interpolation scheme was utilized to obtain bathymetry information between the tracklines that first computed intermediate tracklines and then applied an Over-determined Laplacian Partial Differentiation Equation solver (ODETLAP) (Li et al., 2014). These surveys reveal dunes migrating to the northeast, in the direction of flood, averaging 50 $\mathrm{cm} /$ day while also rotating counterclockwise (Fig. 4-1b). The "Y" shaped dune in Fig. 4-1b ended up burying the quadpod on January 10, 2014, and is the dune that is referenced in the data from the quadpod.

In all three surveys, the large dunes remain oriented towards the direction of flood with the steep slope of the dune facing the northeast throughout the tidal cycle. Because the flow reverses direction, the lee and stoss side of the dune also switch throughout the tidal cycle. To distinguish between the two dune sides, the steep face will be defined as the dominant lee face and the shallower dune slope as the dominant stoss face. The dunes have approximately a $7.5^{\circ}$ dominant lee slope and $2^{\circ}$ dominant stoss slope. These dune slopes are consistent with those observed with the high resolution bathymetric sonar Jetyak survey taken in September, 2016 (Fig. 3-4).

In addition to the single-beam echosounder, the Jetyak was also equipped with an Acoustic Doppler Current Profiler (ADCP) to measure the flow velocity at $0.5 \mathrm{~m}$ bins throughout the water column over a range of $10 \mathrm{~m}$. The data from the ADCP show flow acceleration over the dune crests along with a wake on the dominant lee face during flood but not during ebb. Data depicting the wake during flood is shown in Fig. 4-1c from a survey taken with the Jetyak on July 18, 2014.

\subsubsection{Megaripples}

An instrumented sea-floor frame was deployed on November 20, 2013 and collected data until it was buried by a dune on January 10, 2014. The quadpod had a rotary sidescan 


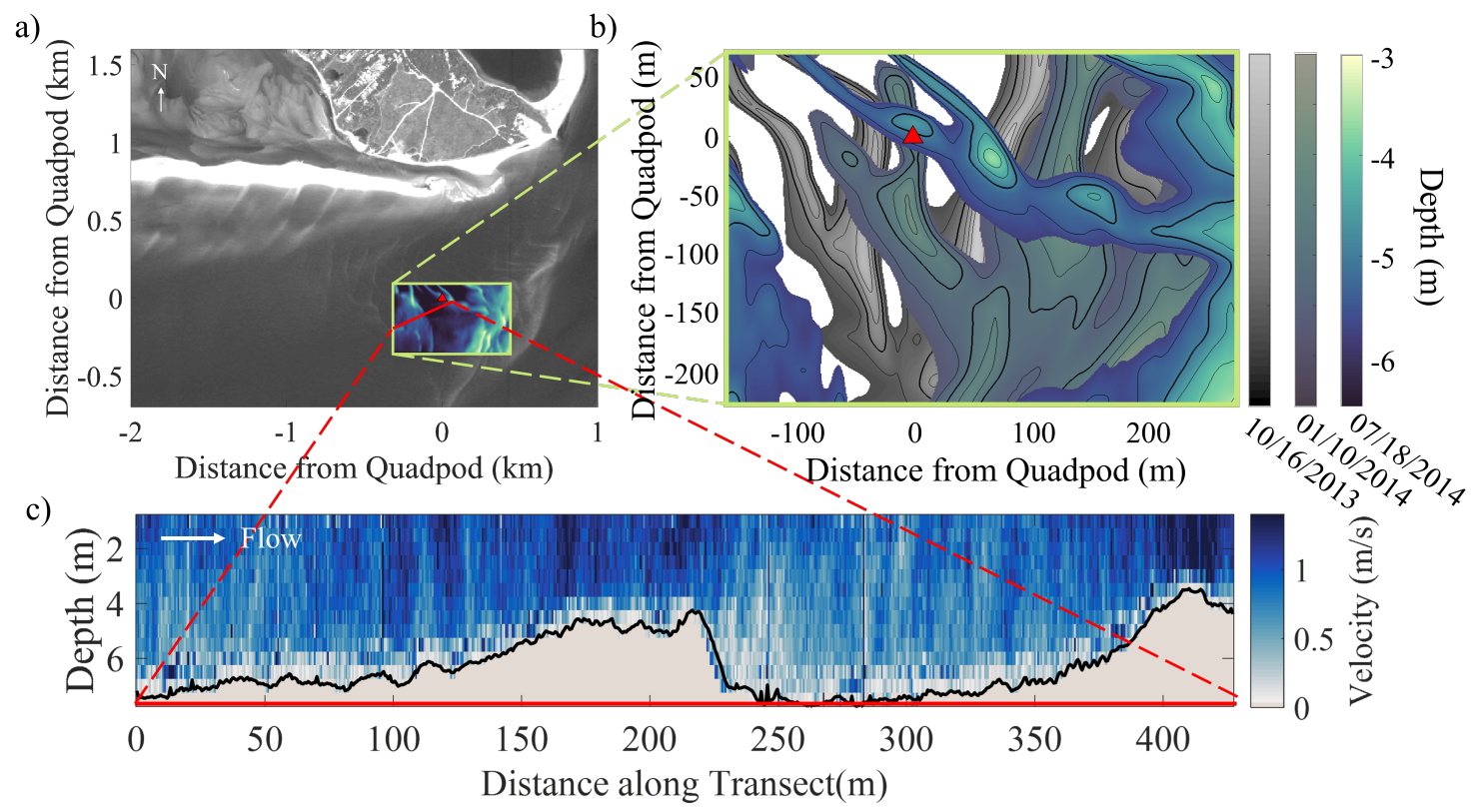

Figure 4-1: a) The gray-scale image is a Pléiades satellite image taken on July 22, 2014 of the corner of Martha's Vineyard and Wasque Shoals and obtained from Airbus Defence and Space (www.intelligence-airbusds.com/pleiades/). The color is bathymetry from a Jetyak survey with a single-beam echosounder taken on July 18, 2014. b) Bathymetry from three Jetyak surveys over a nine month period. The bedform bathymetry was contoured to a maximum depth of $5.5 \mathrm{~m}$ from the mean tidal elevation. The surface below $5.5 \mathrm{~m}$, not shown, is relatively flat with a maximum depth around $6.5 \mathrm{~m}$. The dunes are primarily migrating northeast at a rate of $50 \mathrm{~cm} /$ day and also rotating slightly in response to flood tide dominated currents and waves from the southwest. The triangle depicts the location of the quadpod that was buried by the ' $\mathrm{Y}$ ' shaped dune on January 10, 2014. Up is north. c) Transect of flow throughout the water column obtained from the ADCP on the Jetyak during flood. The flow is going from left to right and a wake is present behind the dominant lee face of the dune. 

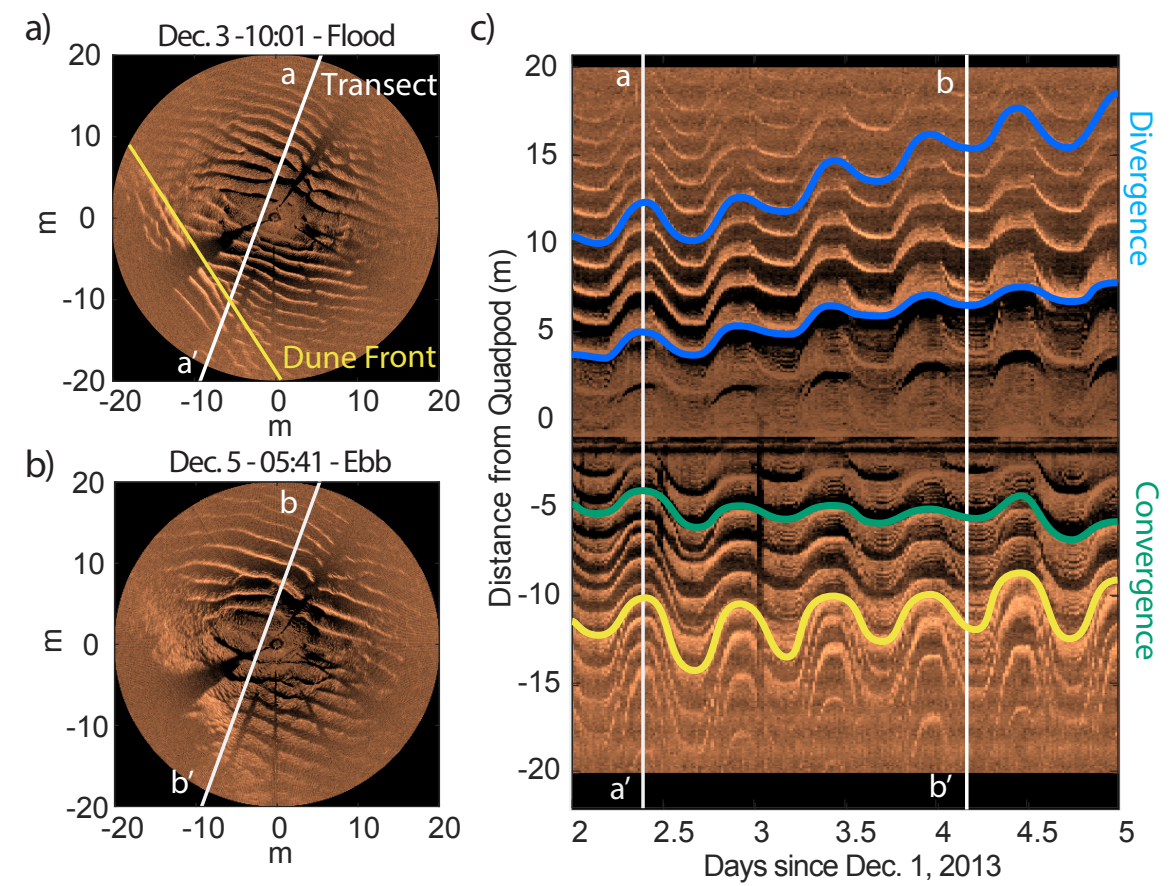

Figure 4-2: a) Rotary sidescan sonar imagery during peak flood on December 3, 2013 at 10:01. b) Sonar imagery during peak ebb on December 5, 2013 at 05:41. c) Time-stack of the intensity along a transect perpendicular to the megaripple crests and relative to distance from the quadpod. The blue tracked megaripples depict the divergence of megaripples while the green tracked megaripple converges into the dune front which is tracked in yellow.

sonar, ABS, and Aquadopp current profiler (Fig. 3-2). Imagery from the rotary sidescan sonar depict $1 \mathrm{~m}$ wavelength megaripples superimposed on the "Y" shaped dune (Fig. 42a,b). These megaripples migrate and change asymmetry with the tides as indicated by the length and position of their shadows and explored in detail in chapters 2 and 3 . The megaripple wavelength and planview orientation were computed from edge detection and spectral analysis techniques, resulting in wavelengths ranging from 0.5 to $3 \mathrm{~m}$ and oriented approximately $20^{\circ}$ clockwise from north.

To depict the migration of the megaripples, timeseries of backscatter intensity profiles along transects perpendicular to the megaripple crests are shown in Fig. 4-2c. This timeseries depicts the tidal migration of the megaripples giving the sinusoidal signal of the megaripple crests with a period of approximately 12.4 hours. In addition to the megaripples migrating back and forth with the tides, there is also a net component of the megaripple migration that is dependent on the location of the megaripples on the dune. This can be visually seen by tracking individual megaripples in the timeseries of Fig. 4-2c. In this fig- 
ure, the dune front, or lower edge of the dominant lee face, is defined as the location where the megaripple planview orientation changes and the backscatter intensity is large which is indicative of a surface facing the sonar. In the trough of the dune, to the northeast of the dune front, the megaripples move in the net direction of flood and diverge, which is demonstrated by the two megaripples tracked in blue (Fig. 4-2c). Close to the dune front, the megaripples migrate in the net direction of ebb, which is indicated by the green tracked megaripple (Fig. 4-2c). These megaripples also converge with the dune front (yellow line) which is slowly migrating in the direction of flood.

To quantify this spatial variation in megaripple migration and to average over several megaripples, the following procedure was used. The migration rate of the megaripples was computed from the backscatter intensity obtained from the rotary sidescan sonar over a 16 day period from November 27, 2013 to December 15, 2013 when there were no large wave events. Seven transects approximately $2 \mathrm{~m}$ apart were taken perpendicular to the megaripple crests and stacked in time, similar to Fig. 4-2c. Megaripple crests were then identified based on the peak in backscatter intensity with the megaripple migration rate computed from the change in megaripple crest location between timesteps. These megaripple migration rates were binned at $1 \mathrm{~m}$ with respect to the dune front where the dune front was defined for each tidal cycle by the location along the transect where the megaripples changed orientation (Fig. 4-2a). The megaripple migration rate averaged over seven transects is shown in Fig. 4-3b which depicts the tidal signal in the megaripple migration rate. Integrating the megaripple migration rate (Fig. 4-3b) with respect to distance from the dune front results in the megaripple convergence (Fig. 4-3c).

While the data of megaripple migration rate and convergence have a strong tidal signal (Fig. 4-3b,c), the net megaripple excursion and convergence can be calculated by integrating each horizontal bin in time. Fig. 4-4a depicts the net cumulative megaripple excursion at four locations along the dune, $-4 \mathrm{~m}, 0 \mathrm{~m}, 8 \mathrm{~m}$, and $25 \mathrm{~m}$, over the time period from November 27, 2013 to December 15, 2013. The megaripple excursion at $-4 \mathrm{~m}$ and $25 \mathrm{~m}$ with respect to the dune front have a positive excursion indicating a net migration in the direction of flood. While the bins at the dune front and $8 \mathrm{~m}$ from the dune front have a net negative, or ebb, migration. The net megaripple excursion for each bin along the dune is shown in Fig. 4-4b which shows a positive net megaripple migration everywhere expect between the dune front and approximately $12 \mathrm{~m}$ from the dune front. The net convergence was similarly temporally 


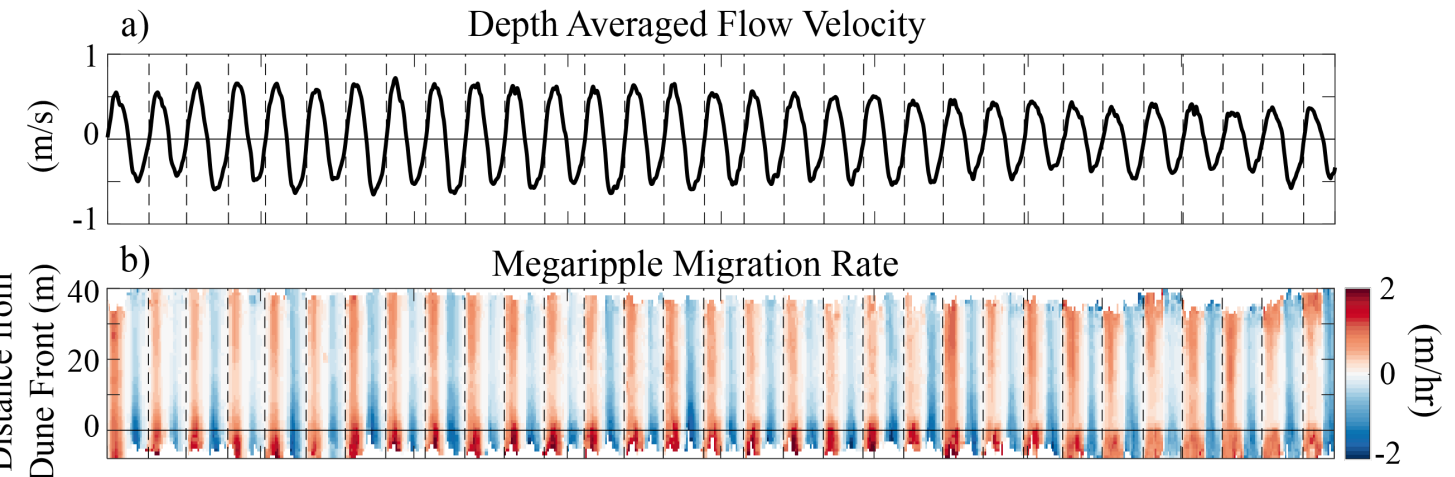

c)

Megaripple Convergence

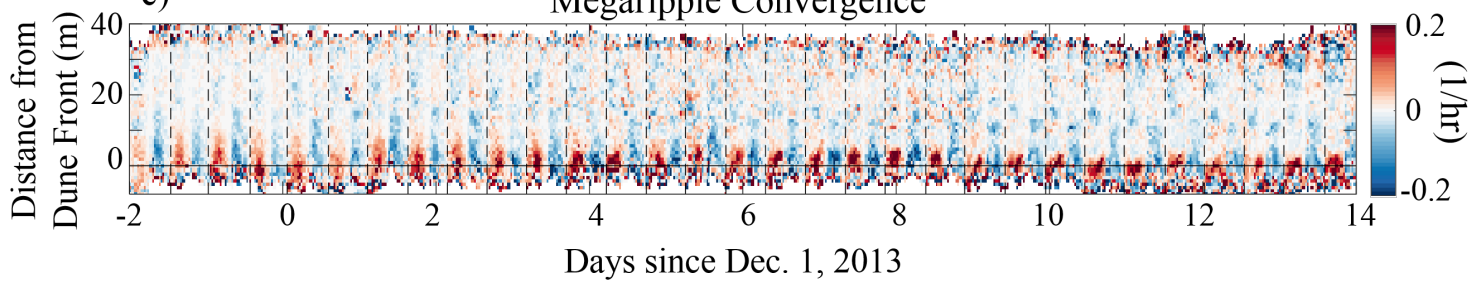

Figure 4-3: a) Depth averaged velocity from the Aquadopp mounted on the seafloor frame. The black vertical dashed lines represent the upward zero crossing used to define a tidal cycle. Positive numbers indicate flood where the flow is going towards the north-northeast. b) Megaripple migration rate with respect to distance from the dune front averaged over seven transects perpendicular to the bedform crests and binned at $1 \mathrm{~m}$. Positive values indicate megaripple migrating in the direction of flood. c) Megaripple convergence with respect to distance from the dune front for a 16 day period. 

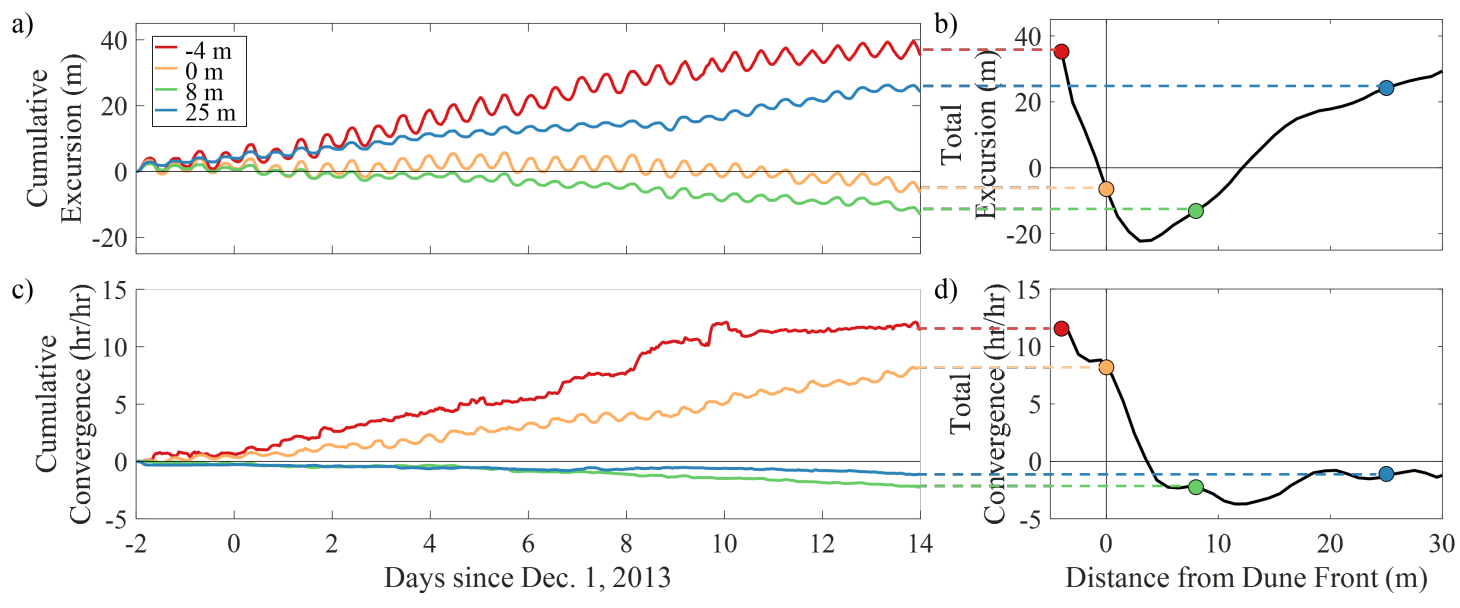

Figure 4-4: a) Megaripple cumulative excursion over a 16 day period at four locations, $-4 \mathrm{~m}$, $0 \mathrm{~m}, 8 \mathrm{~m}$, and $25 \mathrm{~m}$, from the dune front. Positive excursion indicates megaripple migration in the direction of flood, or towards the north-northeast, whereas negative excursion indicates migration in the direction of ebb. b) Total megaripple excursion after 16 days. c) Megaripple cumulative convergence for the same four locations as in (a). d) Total megaripple convergence.

integrated with the cumulative convergence at $-4 \mathrm{~m}, 0 \mathrm{~m}, 8 \mathrm{~m}$, and $25 \mathrm{~m}$ from the dune front shown in Fig. 4-4c and the total megaripple convergence between $-5 \mathrm{~m}$ and $30 \mathrm{~m}$ from the dune front shown in Fig. 4-4d. This convergence pattern results in megaripple convergence along the dominant lee face of the dune (roughly $4 \mathrm{~m}$ from the dune front) and divergence in between $4 \mathrm{~m}$ and $30 \mathrm{~m}$ from the dune front.

A tidally average megaripple migration rate and convergence can be computed by integrating the megaripple migration rate and convergence (Fig. 4-3b,c) for each horizontal bin over a tidal cycle with a tidal cycle defined by the upward zero crossing in the depth averaged velocity (Fig. 4-3a). This results in a similar pattern in migration and convergence as shown in Fig. 4-4b,d with convergence of megaripples at the dune front and divergence away from the dune front (Fig. 4-5a,b).

\subsection{Principles of bedform migration}

In the presence of a current, bedforms migrate in the direction of the flow as sediment moves up the stoss side of the bedform, reaches the crest, and is then deposited on the downstream face (Simons et al., 1965). The change in seabed elevation at a given location, $\eta(x)$, due to the convergence of sediment flux from bedform migration can be determined from the 
conservation of sediment mass and is commonly referred to as the one-dimensional Exner equation (Exner, 1920).

$$
\frac{\partial \eta}{\partial t}=\frac{1}{(1-n)} \frac{\partial q_{b}}{\partial x}
$$

where $n$ is the sediment porosity and is approximately equal to $0.3, q_{b}$ is the bedload sediment transport rate, $x$ is distance in a parallel direction to the flow, and $t$ is time. For a given position on the bedform, $\zeta$ (for example the location of the bedform crest), the location, $x$, of that position at a later time can be determined by the transformation in Eq. 4.2 given a constant bedform migration rate, $a$ (Simons et al., 1965).

$$
\zeta=x-a t
$$

Using the transformation in Eq. 4.2, the change in seabed elevation can be expressed in terms of bedform migration and bedform slope.

$$
\frac{\partial \eta}{\partial t}=\frac{\partial \eta}{\partial \zeta} \frac{\partial \zeta}{\partial t}=-\frac{\partial \eta}{\partial \zeta} a
$$

Eq. 4.3 is also known as the kinetic equation and assumes the uniform migration of bedforms, a, with no sediment bypassing (Engel and Lau, 1981; Berg, 1987; Ten Brinke et al., 1999; Hoekstra et al., 2004).

While the bedload transport rate, $q_{b}$, is commonly estimated from empirical equations such as the Meyer-Peter and Müeller empirical formula (Eq. 3.5), the bedload transport rate associated with bedform migration can also be estimated from the Exner equation, Eq. 4.1. The partial derivative of $q_{b}$ with respect to $x$ in Eq. 4.1 can be replaced as follows given the partial derivative of $\zeta$ with respect to $x$ in Eq. 4.2.

$$
\frac{\partial q_{b}}{\partial x}=\frac{\partial q_{b}}{\partial \zeta} \frac{\partial \zeta}{\partial x}=\frac{\partial q_{b}}{\partial \zeta}
$$

Substituting Eq. 4.3 and Eq. 4.4 into Eq. 4.1 results in the following differential equation with respect to distance along the bedform $\zeta$.

$$
\frac{\partial q_{b}}{\partial \zeta}=-\frac{\partial \eta}{\partial \zeta} a(1-n)
$$


Integrating Eq. 4.5 across a bedform with respect to $\zeta$ produces the average bedload sediment transport rate over the whole bedform $\left[q_{b}\right]=-[\eta] a(1-n)+c$. Where the square

brackets, $[y]=\frac{1}{\zeta} \int_{x}^{x+\zeta} y d \zeta$, indicate a spatial average of a given variable, $y$, over a bedform and $c$ is a constant of integration. For triangular bedforms, $[\eta]=0.5 h$ where $h$ is the height of a bedform. Additionally, at the threshold of motion, $c=0$ as $q_{b}=0$. As long as the seabed is covered by bedforms and there is no bypassing of sediment from one bedform to the next, $c$ will remain 0 and the equation for bedload transport averaged over a bedform can be simplified as shown in Eq. 4.6 (Simons et al., 1965).

$$
\left[q_{b}\right]=-\frac{h}{2} a(1-n)
$$

For energetic conditions where the Shields parameter, $\theta$, defined in Eq. 3.4, is greater than the critical Shields parameter, the bedload transport rate, $q_{b}$ is proportional to $U^{3}$ where $U$ is the free stream flow velocity. Therefore, the bedform migration rate, $a$, is proportional to $U^{3}$ and inversely proportional to bedform height, $h$ (Eq. 4.6). For a given flow velocity, $U$, larger bedforms will therefore migrate at a slower rate than smaller bedforms. As a result of the differential migration rate from bedform migration theory, the smaller megaripples superimposed on the dunes will consequently migrate on top of the slower moving dunes (Dalrymple and Rhodes, 1995; Dalrymple, 1984; Rubin, 1987).

\subsection{Megaripple and dune interaction conceptual model}

The observations of the megaripple convergence with respect to the dune front motivated the development of a conceptual model relating the interaction of the two features. From conservation of mass assuming no sediment bypassing and the fact that megaripples consist of sediment, the convergence of megaripples will result in an accumulation of sediment and subsequent increase in seabed elevation while the divergence of megaripples will result in a decrease in seabed elevation. Because the convergence zone extends slightly past the dune front, the dune is expected to slowly migrate in the direction of flood as sediment is accumulated in front of the dune, thereby creating a two-way interaction between the bedform scales.

The megaripple convergence pattern can be attributed to the asymmetric, flood-dominated tide and flood-oriented dune as depicted in Fig. 4-5c-e. The flood-dominated tide results 


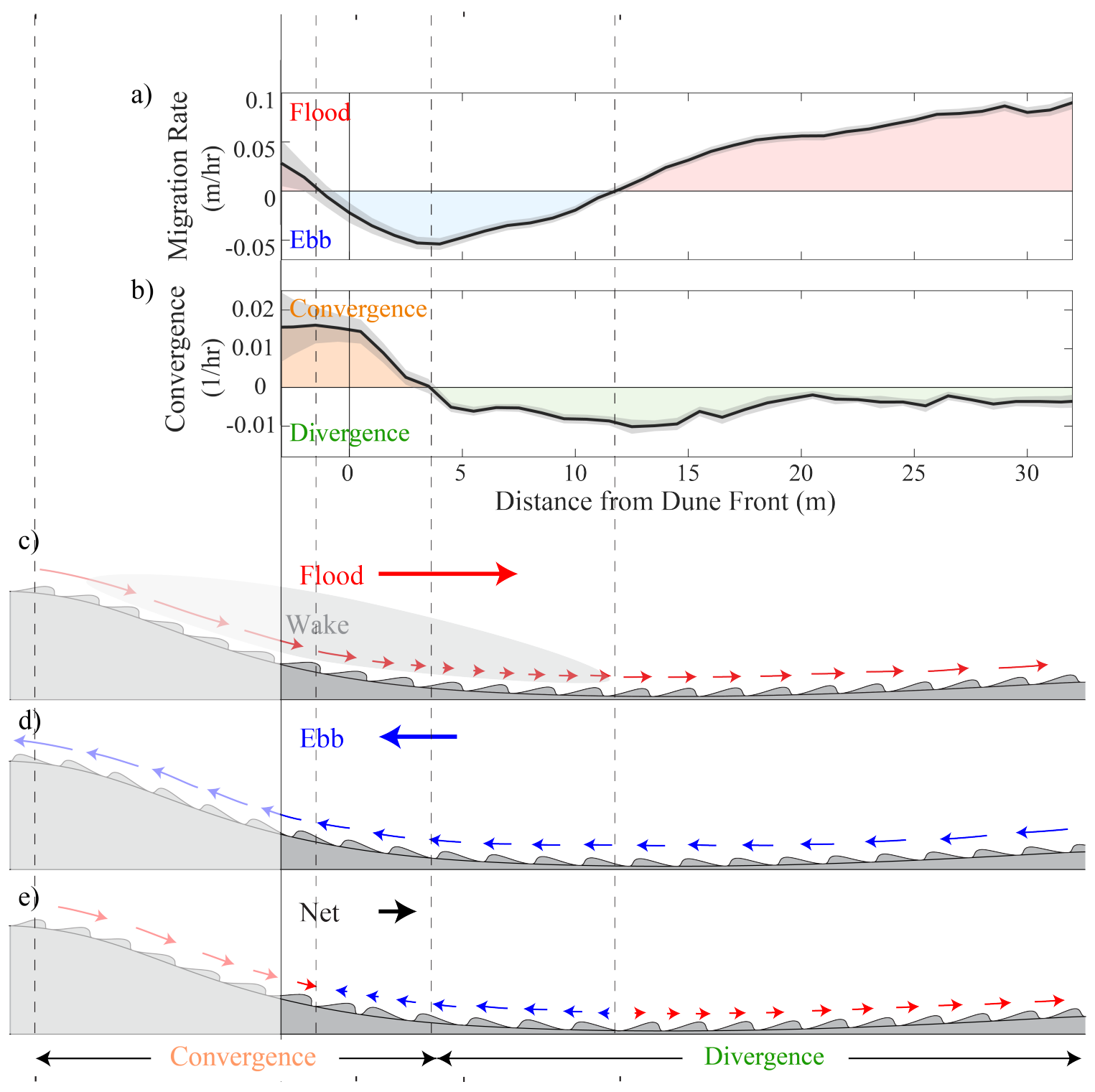

Figure 4-5: a) Net tidally averaged megaripple velocity over a 16 day period in a coordinate system relative to distance from the dune front. The gray shaded region is the standard error of the number of bins included in the average from both different tidal periods and different transects. b) Tidally averaged convergence obtained from differentiating the megaripple migration rate. c-e) Schematic of the superposition of megaripples on the dune and their migration and asymmetry during flood (c) and ebb (d) tides. The faded region on the left was not directly observed due to the limited field of view of the rotary sonar system. 
in the majority of the megaripples having a net migration in the direction of flood. However, because the dune also remains flood oriented, it is in temporal disequilibrium with the flow during ebb. This results in the presence of a wake during flood but no wake during ebb (Kwoll et al., 2014). While measurements were only obtained on part of the dominant lee-face due to the location of the frame relative to the dune, theory suggests that there would be a strong convergence of megaripples on the dominant lee-side due to gravity acting on the megaripples migrating down the steep dune face during flood. Downstream of the dominant lee face, the megaripple migration slows due to the weaker near-bed velocity from the presence of the wake. Outside of the wake where the flow reattaches, the megaripple migration begins to accelerate. On ebb, the effect of gravity reduces the megaripple migration rate up the dominate dune lee-side. Combining the megaripple migration rate during flood and ebb results in a net migration with a convergence pattern on the lee face of the dune and divergence in the trough (Fig. 4-5e). This pattern results in the accumulation of sediment on the lee face of the dune and erosion of sediment near the trough. These locations of sediment erosion and deposition result in the net migration of the dune in the dominate flow direction.

To quantitatively test this conceptual model that the megaripples are driving dune migration with observations, both the change in seabed elevation and the dune migration rate were predicted from megaripple convergence and compared to direct measurements of these quantities from other instruments.

\subsubsection{Change in seabed elevation}

The change in seabed elevation over time was directly observed from an Acoustic Backscatter Sensor (ABS) located on a tripod (Fig. 3-2). The ABS measures backscatter intensity where the depth of the seabed was determined from the high intensity that results from the large reflection of the seabed. Fig. 4-6c depicts the depth of the seabed from the ABS from November 27, 2013 until December 19, 2013. During most of this time period the seabed elevation deceases slightly with time, however, there are two instances where there is a rapid increase in seabed elevation. During these periods, there are large wave events along with flood tidal flows. Therefore, while the sudden increases in seabed elevation can be attributed to large wave events, the seabed elevation slowly decreases with time when the waves are small. The change in seabed elevation estimated using linear regression is -0.66 

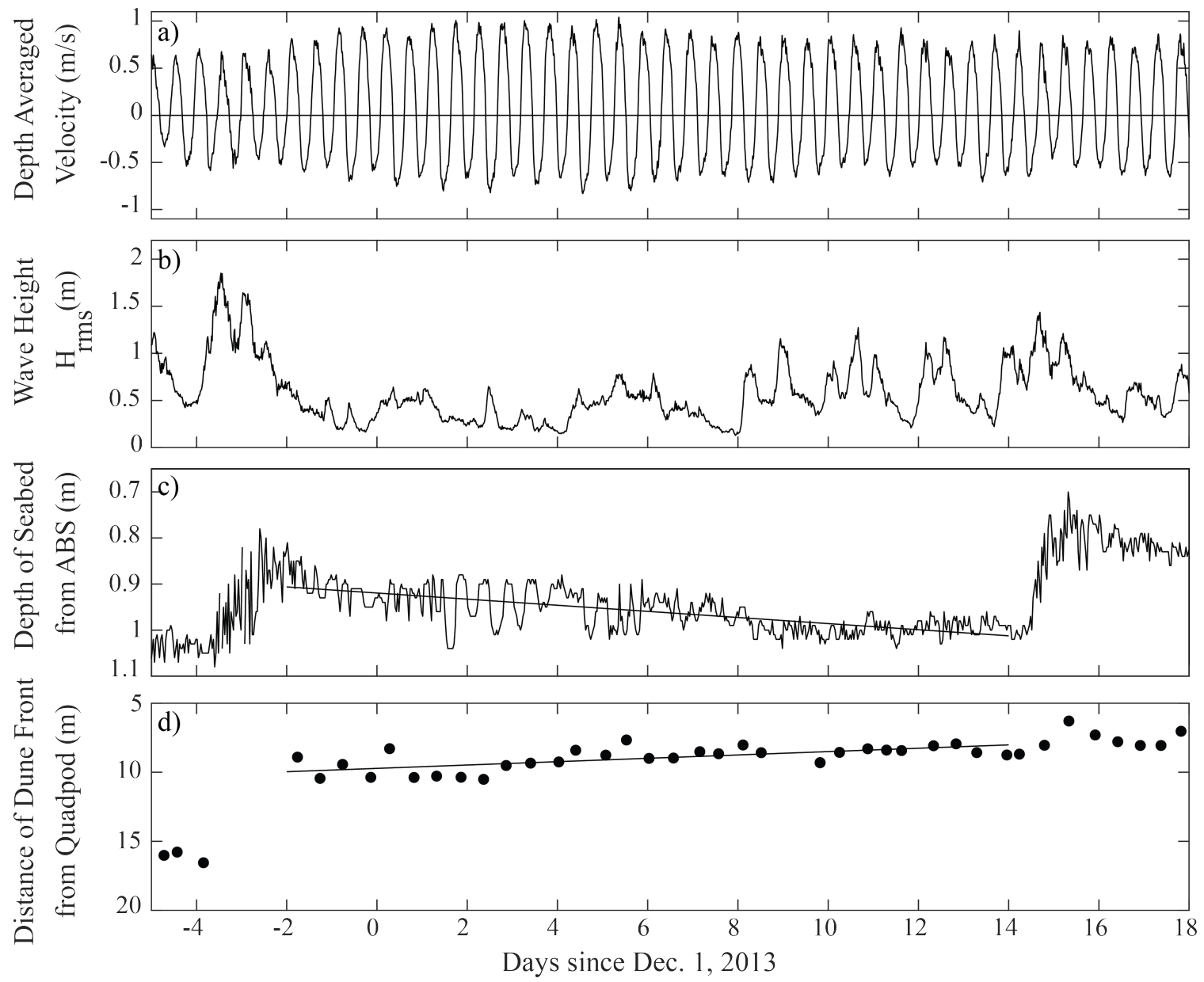

Figure 4-6: a) Depth averaged flow velocity from the Aquadopp current profiler located at the quadpod. b) RMS wave height computed from ADVs on the quadpod. c) Depth of the seabed measured from the ABS with a linear fit during 16 days when there were no large wave events. d) The distance of the dune front from the quadpod where the ABS was located with a linear fit over 16 days with no large wave events. 
$\pm 0.06 \mathrm{~cm} /$ day $(95 \%$ confidence interval) over a 16 day period when there were no large wave events (Fig. 4-6). This 16 day period was also chosen as it is the period used for the megaripple migration rate (Fig. 4-3b). The decrease in seabed elevation at the quadpod is expected as the quadpod is located on the dominant stoss side of a subsequent dune. Therefore, as the trough of the "Y" shape dune migrates towards the quadpod, the quadpod observes a decrease in seabed elevation.

In addition to the direct measurement of seabed elevation with time, the change in seabed elevation can also be estimated given the conservation of mass through the one-dimensional Exner equation (Eq. 4.1) and the average bedload transport rate over a megaripple (Eq. 4.6). Substituting Eq. 4.6 into Eq. 4.1 results in the following equation for change in seabed elevation where $h$ is the height of the megaripples and $a_{m}$ is the migration rate of the megaripples.

$$
\frac{\partial \eta}{\partial t}=-\frac{h}{2} \frac{\partial a_{m}}{\partial x}
$$

To consider the net effect of megaripple migration, Eq. 4.7 was tidally averaged as shown in Eq. 4.8 where the overbar represents a temporal average over a tidal cycle.

$$
\overline{\frac{\partial \eta}{\partial t}}=-\frac{h}{2} \frac{1}{T} \int_{0}^{T} \frac{\partial a_{m}}{\partial x} d t
$$

$T=12.42 \mathrm{hr}$ is the length of a tidal cycle and $h$ is the megaripple height. A megaripple height of $0.1 \mathrm{~m}$ was approximated given a megaripple aspect ratio, $h / \lambda$, of 0.1 obtained from applying the method outlined in chapter 2 to the rotary sidescan sonar data. The tidally average megaripple convergence on the right hand side of Eq. $4.8, \frac{1}{T} \int_{0}^{T}-\frac{\partial a}{\partial x} d t$, can be estimated from megaripple migration rates as shown in Fig. 4-5b. Because the megaripple convergence varies spatially with location on the dune, the convergence at the location of the quadpod is considered as this is where the change in seabed elevation from the ABS is estimated. During the 16 day time period where the change in seabed elevation was directly estimated from the ABS and the megaripple convergence was computed, the dune front was approximately $8 \mathrm{~m}$ from the quadpod (Fig. 4-6d). The net convergence of the megaripples $8 \mathrm{~m}$ from the dune front is $-0.0059 \pm 0.0021 / \mathrm{hr}$ (95\% confidence interval) (Fig. 4-5b). Multiplying this by $h / 2$ based on a triangular bedform assumption results in a change in seabed height estimated from Eq. 4.8 of $-0.71 \pm 0.25 \mathrm{~cm} /$ day ( $95 \%$ confidence interval). 
Table 4.1: Estimate of the change in seabed elevation with time obtained from directly from the ABS and indirectly from megaripple convergence.

\begin{tabular}{ccc}
\hline Estimate Method & $\partial \eta / \partial t(\mathrm{~cm} /$ day $)$ & $95 \%$ CI \\
\hline Direct & -0.66 & 0.06 \\
\hline Predicted & -0.71 & 0.25 \\
\hline
\end{tabular}

The estimated change in seabed elevation due to the convergence of megaripples $(-0.71$ $\pm 0.25 \mathrm{~cm} /$ day) has overlapping error bounds with the seabed elevation change computed directly from the ABS $(-0.66 \pm 0.06 \mathrm{~cm} /$ day $)$ with a percent difference in the mean of $7.3 \%$ (Table 4.1). This suggests that megaripple convergence can directly force dune scale elevation changes.

\subsubsection{Dune migration}

The theory that megaripples serve as an intermediate step in dune migration can be further quantitatively examined from the dune migration rate. The migration of the dune over a period with little wave energy can be directly estimated given the distance of the dune front to the quadpod. A dune migration rate of $12 \pm 3.6 \mathrm{~cm} /$ day $(95 \%$ confidence interval) is estimated from a linear regression of the distance of the dune front from the quadpod (Fig. $4-6 d)$.

The dune migration rate can also be estimated from the convergence of the megaripples given the kinetic equation that assumes the dune moves at a constant velocity without changing shape and there is no sediment bypassing (Eq. 4.3). Tidally averaging Eq. 4.3 results in the following equation for the tidally averaged dune migration rate, $a_{d}$.

$$
\overline{a_{d}}=-\frac{\overline{\frac{\partial \eta}{\partial t}}}{\frac{\partial \eta}{\partial \zeta}}=-\frac{\frac{h}{2} \frac{1}{T} \int_{0}^{T} \frac{\partial a_{m}}{\partial x} d t}{\frac{\partial \eta}{\partial \zeta}}
$$

Because the dune migrates a very small distance over a tidal cycle compared to the bedform size, the tidally averaged dune slope, $\overline{\partial \eta / \partial \zeta}$ can be assumed to be constant. The dune front is defined based on the high backscatter intensity from the seabed, and the change in megaripple orientation which is hypothesized to be due to the steep dominant lee face of the dune. From the Jetyak survey with an echosounder taken on October 16, 2013, the 
Table 4.2: Estimate of the change in seabed elevation with time obtained from directly from the ABS and indirectly from megaripple convergence.

\begin{tabular}{ccc}
\hline Estimate Method & $\overline{a_{d}}(\mathrm{~cm} /$ day $)$ & $95 \%$ CI \\
\hline Direct & 12 & 3.6 \\
\hline Predicted & 13.8 & 5.5 \\
\hline
\end{tabular}

slope at the dune front is estimated to be $\partial \eta / \partial \zeta=-0.13$ with a maximum dominant lee face slope of -0.18 and slope at the transition from a gradual slope to steep slope of -0.07 . The average change in bed elevation from megaripple convergence can be estimated from the tidally averaged Exner equation, Eq. 4.8. In section 4.4.1, the change in bed elevation due to megaripple convergence at the quadpod ( $8 \mathrm{~m}$ from the dune front) was approximately $-0.71 \mathrm{~cm} /$ day while the average change in bed elevation at the dune front is predicted to be $1.8 \pm 0.7 \mathrm{~cm} /$ day $(95 \%$ confidence interval) based on a convergence of $0.015 \pm 0.0061 / \mathrm{hr}$. This results in a dune migration rate of $13.8 \pm 5.5 \mathrm{~cm} /$ day (Eq. 4.9 ).

The average migration rate obtained from assuming megaripple convergence is within the $95 \%$ confidence interval of the dune migration rate obtained directly from the observations with a percent different in the mean of $13.9 \%$ (Table 4.2). In addition to the analysis showing dune scale elevation changes can be predicted from megaripple convergence, section 4.4.1, this analysis suggests that megaripple convergence may be driving dune migration.

\subsection{Conclusion}

This study proposes a conceptual model that suggests megaripple convergence acts as an intermediate step between grain-scale movement and dune migration. Past work on bedform dynamics attributes the migration of bedforms to individual sediment grains moving up the stoss side of a bedform, reaching the crest, and avalanching into the trough (Simons et al., 1965; Engelund and Fredsøe, 1982; Nielsen, 1992). While this process is believed to still drive the smaller megaripple migration, the conceptual model presented in this chapter proposes that when multiple scale bedforms are superimposed, the migration of the larger scale bedforms is dependent on the smaller superimposed bedforms.

Furthermore, this conceptual model challenges two prior explanations for the existence 
of superimposed bedforms; equilibrium superposition and disequilibrium superposition. Disequilibrium superposition suggests that only one scale of bedform can be active at a given time and the different scales are formed from different processes such as a large flood. In this case, different scales of bedforms coexist but do not interact. In equilibrium superposition, the smaller scales are formed from the boundary layer of the larger bedforms. In this case, the larger bedforms influence the smaller features, however, the smaller bedforms do not influence the larger features.

The conceptual model presented from this work is based on tidally dominated flows with minimal wave energy. Large wave events, however, are substantial to dune dynamics as the average dune migration rate over a nine month period obtained from Jetyak surveys is approximately $50 \mathrm{~cm} /$ day, roughly five times as large as the dune migration rate estimated from megaripple convergence. During storms, large amounts of sediment is suspended and the dune migrates far as indicated by the large change in both seabed elevation from the ABS and the distance of the dune front from the quadpod. We speculate that the direction of the waves, the timing of large wave events relative to tidal phase, and the intensity of the wave event can all contribute to the migration of the dunes and alteration of the seafloor bathymetry. Understanding the large wave events and the subsequent suspended sediment is crucial in the overall migration and morphodynamics of the larger dunes in environments with episodic large waves such as Wasque Shoals. However, in environments with smaller waves and tidally dominated bedform migration processes, this new conceptual model may account for the migration of larger scale superimposed bedforms. 


\section{Chapter 5}

\section{Concluding Remarks}

Sub-aqueous bedforms have a large impact on coastal communities, ecosystems, and environments through their effect on the surrounding flow and subsequent sediment transport. This thesis utilizes novel observational platforms and instruments to understand the morphological evolution of multiple scales of bedforms in the presence of a tidally reversing flow

In chapter 2, a method is outlined to expand the capabilities of a common oceanographic instrument, a sidescan sonar. This method estimates bedform height and asymmetry from acoustic "shadows" accounting for the periodic structure of bedforms and natural variability in bedform and seafloor configuration. The method is validated for wave orbital ripples and tidally reversing megaripples where a low-mounted rotary sidescan was deployed along with a bathymetric measuring instrument. The method was able to capture the changes in the bedform field due to both large wave events and a tidally reversing flow.

The method presented in chapter 2 was applied to data of megaripples at Wasque Shoals, a tidally energetic environment off of Martha's Vineyard where megaripples were superimposed on dunes. The time scale response of the bedforms to a tidally reversing flow were explored in chapter 3 where the dataset at Wasque revealed that smaller megaripples, on the order of $1 \mathrm{~m}$ wavelength, reverse their asymmetry and migration direction with the flow while the larger dunes on which they reside, wavelength on the order of $80 \mathrm{~m}$, remain oriented in the direction of the net tidal flow. This time scale response of bedforms to a tidally reversing flow were further explored with data collected at Nauset Inlet on the Outer Cape Cod using a quadcopter and autonomous jet-powered kayak. At both study sites, 
the time scales for lag in megaripple asymmetry agrees with a simple geometric model for morphological lag time given an empirical model for bedload transport.

Finally, in chapter 4 the interaction of superimposed bedforms in a tidally energetic environment was analyzed. Data from Wasque Shoals was considered which revealed the differential migration rate of megaripples as a function of their location on the dune. This differential migration rate results in a convergence and divergence pattern that is proposed to drive the larger dune migration. This interaction of the megaripples with the dunes on which they are superimposed challenges explanations for the existence of superimposed bedforms.

Overall, this thesis presents measurements of the dynamics of multiple scales of bedforms throughout a tidal cycle. The findings suggest that smaller bedforms migrate and change their asymmetry faster than larger bedforms. When there are smaller bedforms superimposed on larger dunes, this difference in migration rate and asymmetry lead to the interaction of the two scales of features with the smaller bedforms driving larger dune migration. 


\section{Bibliography}

Allen, J.

1976a. Computational models for dune time-lag: general ideas, difficulties, and early results. Sedimentary Geology, 15(1):1-53.

Allen, J.

1976b. Time-lag of dunes in unsteady flows: an analysis of nasner's data from the r. weser, germany. Sedimentary Geology, 15(4):309-321.

Allen, J. and J. Collinson

1974. The superimposition and classification of dunes formed by unidirectional aqueous flows. Sedimentary Geology, 12:169-178.

Amos, C. and E. King

1984. Bedforms of the canadian eastern seaboard: a comparison with global occurrences. Marine Geology, 57(1-4):167-208.

Ashley, G. M.

1990. Classification of large-scale subaqueous bedforms; a new look at an old problem. Journal of Sedimentary Research, 60(1):160-172.

Bagnold, R. A.

1946. Motion of waves in shallow water. interaction between waves and sand bottoms. Proceedings of the Royal Society of London A: Mathematical, Physical and Engineering Sciences, 187(1008):1-18.

Berg, J. H.

1987. Bedform migration and bed-load transport in some rivers and tidal environments. Sedimentology, 34(4):681-698.

Berne, S., P. Castaing, E. Le Drezen, and G. Lericolais

1993. Morphology, internal structure, and reversal of asymmetry of large subtidal dunes in the entrance to gironde estuary (france). Journal of Sedimentary Research, 63(5).

Blondel, $\mathrm{P}$.

2009. The Handbook of Sidescan Sonar. Berlin: Springer-Verlag.

Bokuniewicz, H., R. Gordon, and K. Kastens

1976. Form and migration of sand waves in a large estuary, long island sound. Marine Geology, 24:185-199. 
Bolaños, R., L. O. Amoudry, and K. Doyle

2011. Effects of instrumented bottom tripods on process measurements. Journal of Atmospheric and Oceanic Technology, 28(6):827-837.

Boothroyd, J. C. and D. K. Hubbard

1975. Genesis of bedforms in mesotidal estuaries. In Geology and Engineering, Pp. 217234. Elsevier.

Bouma, A. H., M. L. Rappeport, R. C. Orlando, and M. A. Hampton

1980. Identification of bedforms in lower Cook Inlet, Alaska. Sedimentary Geology, 26:157 -177 .

Chew, A. L., P. B. Tong, and C. S. Chia

2007. Automatic detection and classification of man-made targets in side scan sonar images. In 2007 Symposium on Underwater Technology and Workshop on Scientific Use of Submarine Cables and Related Technologies, Pp. 126-132.

Clifton, H. E. and J. R. Dingler

1984. Wave-formed structures and paleoenvironmental reconstruction. Marine Geology, 60:165-198.

Coiras, E., Y. Petillot, and D. M. Lane

2007. Multiresolution 3-d reconstruction from side-scan sonar images. IEEE Transactions on Image Processing IEEE Trans. on Image Process., 16(2):382-390.

Dalrymple, R. W.

1984. Morphology and internal structure of sandwaves in the bay of fundy. Sedimentology, $31(3): 365-382$.

Dalrymple, R. W. and R. N. Rhodes

1995. Estuarine dunes and bars. Geomorphology and Sedimentology of Estuaries. Developments in Sedimentology, 53:359-422.

Doherty, M. F., J. G. Landowski, P. F. Maynard, G. T. Uber, D. W. Fries, and F. H. Maltz 1989. Side scan sonar object classification algorithms. In Proceedings of the 6th International Symposium on Unmanned Untethered Submersible Technology,, Pp. 417-424.

Doré, A., P. Bonneton, V. Marieu, and T. Garlan

2016. Numerical modeling of subaqueous sand dune morphodynamics. Journal of Geophysical Research: Earth Surface, 121(3):565-587.

Engel, P. and Y. L. Lau

1981. Bed load discharge coefficient. Journal of the Hydraulics Division, 107(11):14451454.

Engelund, F. and J. Fredsøe

1982. Sediment ripples and dunes. Annual Review of Fluid Mechanics, 14:13-37.

Exner, F.

1920. Zur physik der dünen. Akad. Wiss. Wien Math. Naturwiss. Klasse. 
Falques, A., D. Calvete, H. D. Swart, and N. Dodd

1998. Morphodynamics of shoreface-connected ridges. Coastal Engineering, Pp. 28512864 .

Fredsøe, J. and R. Deigaard

1992. Mechanics of coastal sediment transport, volume Advanced Series on Ocean Engineering - 3. World Scientific.

Grant, W. D. and O. S. Madsen

1982. Movable bed roughness in unsteady oscillatory flow. Journal of Geophysical Research: Oceans, 87(C1):469-481.

Green, M. O.

1986. Side-scan sonar mosaic of a sand ridge field: southern Mid-Atlantic Bight. GeoMarine Letters, 6:35-40.

Haque, M. I. and K. Mahmood

1985. Geometry of ripples and dunes. Journal of Hydraulic Engineering, 111:48-63.

Hay, A. and D. Wilson

1994. Rotary sidescan images of nearshore bedform evolution during a storm. Marine Geology, 119:57-65.

Hoekstra, P., P. Bell, P. van Santen, N. Roode, F. Levoy, and R. Whitehouse 2004. Bedform migration and bedload transport on an intertidal shoal. Continental Shelf Research, 24:1249-1269.

Hopkins, J., S. Elgar, and B. Raubenheimer

2017. Flow separation effects on shoreline sediment transport. Coastal Engineering, 125:23 $-27$.

Hume, T., M. Green, and K. Bryan

2000. Scanning the seabed for ripples. National Institute of Water and Atmospheric Research, 8:19-22.

Irish, J., J. Lynch, P. Traykovski, A. Newhall, and K. Prada

1998. A self-contained sector-scanning sonar for bottom roughness observations as part of sediment transport studies. Journal of Atmospheric and Oceanic Technology, 16:18301999 .

Johnson, D. W.

1916. Contributions to the study of ripple marks. The Journal of Geology, Pp. 809-819.

Jones, K. R. and P. Traykovski

2018. A method to estimate bedform height and asymmetry from a low-mounted sidescan sonar. Journal of Atmospheric and Oceanic Technology.

Kennedy, J. F.

1969. The formation of sediment ripples, dunes, and antidunes. Annual Review of Fluid Mechanics, Pp. 147-168. 
Kimball, P., J. Bailey, S. Das, R. Geyer, T. Harrison, C. Kunz, K. Manganini, K. Mankoff, K. Samuelson, T. Sayre-McCord, F. Straneo, P. Traykovski, and H. Singh

2014. The WHOI jetyak: An autonomous surface vehicle for oceanographic research in shallow or dangerous waters. In Autonomous Underwater Vehicles (AUV), 2014 IEEE/OES, Pp. 1-7.

Klein, M.

2002. Side Scan Sonar.

Knaapen, M., C. V. V. Henegouw, and Y. Hu

2005. Quantifying bedform migration using multi-beam sonar. Geo-marine letters.

Kwoll, E., M. Becker, and C. Winter

2014. With or against the tide: The influence of bed form asymmetry on the formation of macroturbulence and suspended sediment patterns. Water Resources Research, Pp. 78007815 .

la Beche, H. D.

1851. The Geological Observer. Phiadelphia, Carey \& Lea.

Langhorne, D.

1973. A sandwave field in the outer thames estuary, great britain. Marine Geology, 14(2):129 - 143 .

Leatherman, S. P. and R. E. Zaremba

1986. Dynamics of a northern barrier beach: Nauset spit, cape cod, massachusetts. GSA Bulletin, 97(1):116.

Lefebvre, A., V. B. Ernstsen, and C. Winter 2013. Estimation of roughness lengths and flow separation over compound bedforms in a natural-tidal inlet. Continental Shelf Research, 61:98-111.

Lefebvre, A., A. J. Paarlberg, and C. Winter 2016. Characterising natural bedform morphology and its influence on flow. Geo-Marine Letters, 36(5):379-393.

Li, W., W. R. Franklin, S. V. Magalhães, and M. V. Andrade 2014. Restricted bathymetric tracklines interpolation.

Lobo, F., A. Maldonado, and R. Noormets

2010. Large-scale sediment bodies and superimposed bedforms on the continental shelf close to the strait of gibraltar: interplay of complex oceanographic conditions and physiographic constraints. Earth Surface Processes and Landforms, 35(6):663-679.

Lonsdale, P., W. R. Normark, and W. Newman

1972. Sedimentation and erosion on Horizon Guyot. Geological Society of America Bulletin - GEOL SOC AMER BULL, 83.

Meyer-Peter, E. and R. Müller

1948. Formulas for bed-load transport. In IAHSR 2nd meeting, Stockholm, appendix 2. IAHR. 
Nelson, J. M., S. R. McLean, and S. R. Wolfe

1993. Mean flow and turbulence fields over two-dimensional bed forms. Water Resources Research, 29(12):3935-3953.

Nielsen, P.

1992. Coastal Bottom Boundary Layers and Sediment Transport. World Scientific.

Nikuradse, J.

1933. Str $\{\ddot{0}\}$ mungsgestze in rauhen rohren.

Nishimura, C. E.

1997. Fundamentals of acoustic backscatter imagery. Technical report, Naval Research Laboratory Washington DC Marine Physics Branch NRL/FR/7420-97-9848.

Off, T.

1963. Rhythmic linear sand bodies caused by tidal currents. AAPG bulletin, 47(2):324341.

Pluymaekers, S., R. Lindenbergh, D. Simons, and J. de Ronde

2007. A deformation analysis of a dynamic estuary using two-weekly MBES surveying. In OCEANS 2007 - Europe, Pp. 1-6.

Pretious, E. and T. Blench

1951. Final report on special observations of bed movement in the lower fraser river at ladner reach during 1950. National Research Council of Canada.

Reed, S., Y. Petillot, and J. Bell

2003. An automatic approach to the detection and extraction of mine features in sidescan sonar. IEEE Journal of Oceanic Engineering, 28(1):90-105.

Reynaud, J.-Y. and R. W. Dalrymple

2012. Shallow-marine tidal deposits. In Principles of Tidal Sedimentology, Pp. 335-369. Springer.

Rice, J.

2002. Mathematical Statistics and Data Analysis. Duxbury Press.

Rubin, D., D. McCulloch, and H. Hill 1983. Sea-floor-mounted rotating side-scan sonar for making time-lapse sonographs. Continental Shelf Research, 1(3):295 - 301.

Rubin, D. M.

1987. Cross-bedding, bedforms and paleocurrents. Society of Economic Paleontologists and Mineralogists, Oklahoma (EUA).

Shields, A.

1936. Application of similarity principles and turbulence research to bed-load movement.

Siau

1841. De l'action des vagues e grandes profondeurs. Comptes rendus de l'academie des sciences, Pp. 207-231. 
Simons, D., E. Richardson, and C. N. Jr.

1965. Bedload equation for ripples and dunes. Sediment Transport in Alluvial Channels.

Smith, J. D. and S. R. McLean

1977. Spatially averaged flow over a wavy surface. Journal of Geophysical Research, 82(12):1735-1746.

Soulsby, R.

1997. Dynamics of marine sands: a manual for practical applications. Thomas Telford.

Stommel, H. and H. G. Farmer

1952. On the nature of estuarine circulation. P. 54.

Tang, D., K. L. Williams, and E. I. Thorsos

2009. Utilizing high-frequency acoustic backscatter to estimate bottom sand ripple parameters. IEEE Journal of Oceanic Engineering, 34(4):431-443.

Ten Brinke, W., A. Wilbers, and C. Wesseling

1999. Dune growth, decay and migration rates during a large-magnitude flood at a sand and mixed sand-gravel bed in the dutch rhine river system. Fluvial sedimentology VI, Pp. $15-32$.

Traykovski, $\mathrm{P}$. 2007. Observations of wave orbital scale ripples and a nonequilibrium time-dependent model. Journal of Geophysical Research: Oceans, 112(C6). C06026.

Traykovski, P. 2012. SW (new) channel rotary sidescan imagery of bedforms in New River Inlet, NC.

Traykovski, P. 2015. Observations of the geometry and migration of tidally reversing dunes. In Coastal Sediments 2015: The Processings of the Coastal Sediments 2015.

Traykovski, P., A. E. Hay, J. D. Irish, and J. F. Lynch

1999. Geometry, migration, and evolution of wave orbital ripples at leo-15. Journal of Geophysical Research: Oceans, 104(C1):1505-1524.

Van Dijk, T. A. G. P. and R. C. Lindenbergh 2017. Atlas of Bedforms in the Western Mediterranean, Methods for Analysing Bedform Geometry and Dynamics.

Venditti, J. G., M. Church, and S. J. Bennett 2005. Morphodynamics of small-scale superimposed sand waves over migrating dune bed forms. Water Resources Research, 41(10). W10423.

Venditti, J. G. and M. A. Church

2005. Bed form initiation from a flat sand bed. Journal of Geophysical Research, 110.

Williams, J., P. Bell, L. Coates, N. Metje, and R. Selwyn

2003. Interactions between a benthic tripod and waves on a sandy bed. Continental Shelf Research, 23(3):355 - 375. 


\section{Williams, J. J.}

1995. Drag and sediment dispersion over sand waves. Estuarine, Coastal and Shelf Science, 41(6):659-687.

Winter, C., G.Vittori, V. Ernstsen, and J. Bartholdy

2008. On the superimposition of bedforms in a tidal channel. Marine and River Dune Dynamics, Pp. 337-344.

Yalin, M.

1964. Geometrical properties of sand waves. J. Hydraul. Eng., 90:105-119. 